Alma Mater Studiorum - Università di Bologna DEPARTMENT OF ECONOMICS

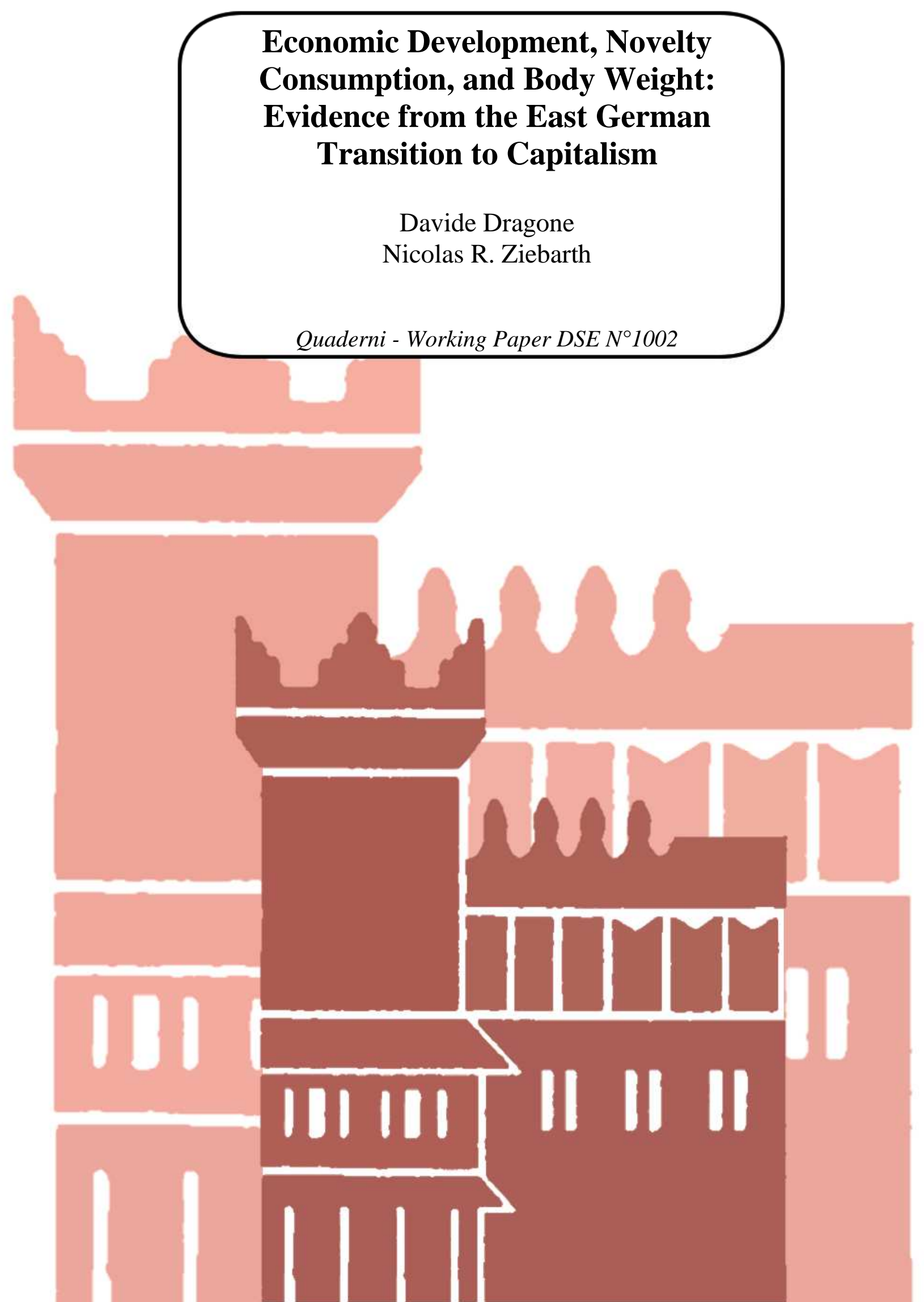




\title{
Economic Development, Novelty Consumption, and Body Weight: Evidence from the East German Transition to Capitalism $\ddagger$
}

\author{
Davide Dragone \\ University of Bologna*
}

\author{
Nicolas R. Ziebarth \\ Cornell University, DIW Berlin \& IZA Bonn ${ }^{\dagger}$
}

April 10, 2015

\begin{abstract}
This paper develops a conceptual framework that can explain why economic development goes along with increases in body weight and obesity rates. We first introduce the concept of novelty consumption, which refers to an increase in food availability due to trade or innovation. Then we study how novel food products alter the optimal consumption bundle and welfare, and possibly lead to changes in body weight. We test our model employing the German reunification as a fast motion natural experiment of economic development. Our data elicit detailed information on East Germans' food consumption, body mass, and diet-related health. After the fall of the Wall, East Germans permanently changed their diet by consuming novel western food products. A significant population share permanently gained weight. This is consistent with our theoretical framework where past affects current consumption, and where novel goods determine consumption changes over time with ambiguous effects on dietrelated health.
\end{abstract}

Keywords: economic development, food consumption, habit formation, learning, novel goods, obesity, nutrition-related health, German reunification

JEL classification: D11, D12, I12, I15, L66, O10, O33, Q18, R22

\footnotetext{
$\ddagger_{W}$ would like to thank John Cawley, Charles Courtemache, Gabriella Conti, Monica Deza, Pilar Garcia-Gomez, Therese Bago d'Uva, David Frisvold, Anne Gielen, Martin Karlsson, Christoph Moser, Stefan Pichler, Darjusch Tafreschi, Eddy van Doorslaer, and conference participants at the 2014 ASHEcon conference in LA as well as seminar participants at the KOF Swiss Economic Institute at ETH Zurich, participants at the Applied Economics seminar of the Erasmus School of Economics in Rotterdam, and the The Institute on Health Economics, Health Behaviors and Disparities at Cornell University. In particular we thank Frank Sloan and Katharina Walliczek for excellent discussions of this work. We take responsibility for all remaining errors in and shortcomings of the article. We would also like to thank Peter Eibich and Aline Paßlack for excellent research assistance and Philip Susser for excellence in editing this paper. The research reported in this paper is not the result of a for-pay consulting relationship. Our employers do not have a financial interest in the topic of the paper that might constitute a conflict of interest.

*University of Bologna, Department of Economics, Office 52, Piazza Scaravilli 2, 40126, Bologna, Italy, phone: (+39)(0)51-209-8880, e-mail: davide.dragone@unibo.it

${ }^{\dagger}$ Corresponding author: Cornell University, Department of Policy Analysis and Management (PAM), 106 Martha Van Rensselaer Hall, Ithaca, NY 14850, USA, phone: +1-(607)255-1180, fax: +1-(607)255-4071, e-mail: nrz2@cornell.edu
} 


\title{
1 Introduction
}

\begin{abstract}
"Even though the GDR [...] was for the most part self-sufficient concerning production of food and consumer goods, the choice of items available to the average consumer was limited. It is a well-known fact that some of the first items East Germans bought during their excursions to West Berlin in November 1989 were bananas and other exotic fruits, which had not been available to them in the GDR" (Ganter, 2008, p.81).
\end{abstract}

Over the last decades obesity rates have been rapidly increasing in all industrialized countries (Sassi, 2010; World Health Organization, 2015; see Figure 1). The health risks associated with this trend are significant: obese people are more likely to suffer from diseases such as high blood cholesterol and hypertension (Surwit et al., 1988; Appel et al., 1997; National Heart, Lung, and Blood Institute, 1998; Mohn et al., 2005; Buettner et al., 2007), and body fat releases hormones such as resistin and leptin that cause type II diabetes and cardiovascular diseases (Trayhurn and Beattie, 2001; Kahn et al., 2009). Obesity implies higher health care costs (Cawley and Meyerhoefer, 2012) and a reduced life expectancy (Fontaine et al., 2003), as well as indirect non-health related outcomes, such as lower labor market productivity (Cawley, 2004; Cawley et al., 2007) and lower social outcomes (Puhl and Heuer, 2009).

An explanation proposed in the literature suggests that economic growth has been playing a crucial role in determining this trend. To empirically test this hypothesis, the ideal experiment would require exogenous variation in economic development at a specific point in time. However, such an ideal scenario is typically not available because economic development involves multiple factors which asynchronously change over long time horizons. A notable exception is the German reunification which joined East and West Germany on November 9, 1989, and that, under assumptions that are commonly accepted in the literature, allows interpreting the overall post-reunification transition from socialism to capitalism as a fast motion experiment of economic development. In this paper we exploit this unique natural experiment to test a theory that can shed light on the relationship between growth, innovation, food consumption and obesity.

The first part of the paper formally develops a dynamic model of novelty consumption that captures two main features of our setup: availability and novelty. These are typical features of markets where, due to technological innovation or removal of trade barriers, consumption goods are made available to consumers for the first time. We formalize the availability of novelty goods as a negative price shock making them suddenly affordable, and we capture the effect of novelty in consumption by allowing consumers' preferences and health to depend on current consumption choices as well as on past consumption experiences. The latter assumption is common in the literature on intertemporal consumer problems. It illustrates demand elasticities for novelty consumption both at the time of the reunification and along the transition to the equilibrium, depending on whether the novel good features learning in consumption or habit formation.

In our context, novel goods became available in the course of the unexpected German reunification which, basically overnight, introduced a large variety of consumption goods that East Germans could not buy previously-either because of trade barriers or because of extremely high prices of western goods on the East German black market. Novelty refers to the fact that East Germans had virtually no previous consumption experience with these goods that had suddenly become available. Two subcategories of Novel food are (i) newly developed and engineered 
food, such as processed food, and (ii) exotic high quality food (formerly luxury goods) such as exotic fruits, for which relative prices have fallen and which consumers can now afford thanks to economic development. In addition to Novel Food, the choice set of Germans also consisted of common Familiar Food, such as meat and potatoes.

Our model shows that the demand for novel goods unambiguously increases when they become available and affordable to the general population. If the novel good features habit formation, consumption subsequently decreases over time until it reaches its long-run equilibrium. That is: Consumption first overshoots and then it adjusts to a lower equilibrium level. In contrast, when a novel good features learning, the initial increase in consumption will be followed by further subsequent increases. Note that demand for common familiar goods does not necessarily fall after the introduction of novel goods into the market. We show that when a familiar good features learning in consumption, consumption will change monotonically over time, while it will overshoot and change non-monotonically in case of habit formation, even under the coexistence with novel goods.

Finally, we show that, although individual intertemporal consumption is optimized because it maximizes the agent's objective function, it may not necessarily optimize body weight or dietrelated health. This is because people maximize their individual preference-dependent utility; the pleasure of eating can be in contrast with the corresponding health consequences. Hence, depending on the consumers' preferences and the amount of healthy and unhealthy food consumed, consumers may gain or lose weight, and possibly find themselves in a worse health state than before novel goods became available.

In the second part of the paper, we demonstrate how individual food consumption choices, body mass, and nutrition-related health changed in the course of the reunification. In other words, we estimate the short- and long-run effects of a sharp exogenous economic development shock on food consumption and diet-related health. In doing this, we identify two groups of consumers that both changed their diet: those who gained weight and those who lost weight. This empirical exercise exploits three detailed representative cross-sectional datasets: (i) the German National Health Survey East-West 1991, (ii) the German National Health Interview and Examination Survey 1998, and (iii) the German Microcensus 2005. The first two surveys include a battery of current and retrospective information on food consumption, nutrition and body weight changes. They also include several objective health measures that are directly related to nutritional choices, including weight and height, hypertension and blood cholesterol levels. We focus on the following food types: (a) meat and (nonprocessed) potatoes, which represent Familiar Food, and (b) exotic fruits and convenience food, which represent Novel Food. Note that both food categories, familiar and Novel Food, contain what one would commonly label as 'healthy' or 'unhealthy' food, although the boundaries are blurry and certainly also depend on the quantities consumed.

Our empirical findings show that, shortly after a plenitude of novel western products became available in the GDR, a significant share of East Germans changed their eating habits. The consumption of potatoes fell, while the consumption of novel healthy food (such as exotic fruits) and novel unhealthy food (such as convenience food) increased. A significant share of East Germans gained weight - in absolute terms and relative to West Germans—and exhibited diet-related medical conditions such as elevated cholesterol levels. These differences cannot be attributed to less physical activity and calorie output among East Germans, nor are they the result of a lower 
awareness about medical conditions, or a worse health care access. Interestingly, the changes in eating habits and body weight are persistent and still detectable one decade after the reunification. Even in 2005, we find that the positively selected group of East Germans who migrated to West Germany have significantly higher BMIs than native West Germans.

Our contribution to the literature is both theoretical and empirical. Our theoretical approach builds on, and contributes to, the literature on habit formation (see, e.g, Abel, 1990; Overland et al., 2000; Carroll, 2000), taste formation and learning in consumption (Stigler and Becker, 1977), rational addiction (Becker and Murphy, 1988), and health formation (Grossman, 1972). Our model encompasses and generalizes the above mentioned contributions because no a priori assumption is made concerning the way past consumption affects current preferences. Yet, based on estimated empirical East-West consumption differences, we are able to infer how past consumption affects preferences for current consumption, which is in general an unobservable property of the utility function. In particular, we show that preferences featuring habit formation are revealed by consumption patterns that overreact to exogenous shocks and produce overshooting when the shock occurs. On the contrary, learning in consumption implies undershooting and monotonic paths of consumption over time.

By stressing that availability and novelty can produce long-lasting demand responses for consumption goods, health and obesity, our model also contributes to the literature on the role of economic development and technological change as driving forces behind the obesity epidemic (Philipson and Posner, 1999; Cutler et al., 2003; Lakdawalla et al., 2005; Lakdawalla and Philipson, 2009). Cutler et al. (2003) suggest that the reduction in the time cost of food preparation that results from technological innovation is a main reason for the rise in obesity rates. This theory is consistent with their finding that married women-the group that benefited most from the reduction in food preparation costs-gained most weight between the 70s and the 90s. From a different, but complementary perspective, Philipson and Posner (1999); Lakdawalla et al. (2005) and Lakdawalla and Philipson (2009) develop an elegant, consistent theory which links technological change and increases in body weight to rising incomes and decreasing food prices in general. Cutler et al. (2003), however, argue that the rise in the overall US Food Consumer Price Index was only $3 \%$ below the corresponding index for non-food between 1970 and 1999. Maybe in contrast to the public perception, at least average real food prices have been surprisingly constant over time. To be specific, average food price inflation was 5.2\% between 1960 and 1983 and has been $3.0 \%$ since then (Congressional Research Service, 2013). ${ }^{1}$ This paper builds upon and specifies Philipson and Posner (1999); Lakdawalla et al. (2005) and Lakdawalla and Philipson (2009)'s main idea in the sense that we allow the prices for specific products to decline sharply, thereby conceptualizing and introducing the central role of Novel Food products.

By specifying the concept of novelty consumption, we provide a possible explanation for the puzzling evidence that obesity rates continues to rise even though real food prices have been very stable since the 1990s (Ruhm, 2012). A theory proposed by Strulik (2014) builds on the idea that being obese is more acceptable the higher the population obesity rates, which would create social multiplier effects fostering the obesity epidemic even after the initial triggers have become less relevant. Our model proposes a different perspective which is based on the impact of past

\footnotetext{
${ }^{1}$ The analogous numbers for the general inflation rates were 5.3 and $2.9 \%$, i.e., almost identical and also almost perfectly correlated.
} 
consumption experiences on current consumption choices, and on the availability of novel food products.

Although we focus on the case of the German reunification in our empirical part, we argue that the impact of novelty consumption on changes in diet, body weight, and diet-related health is generalizable and pervasive in developed industrialized economies. The business model of the international food industry largely depends on employing food engineering technology and mass marketing strategies to design and introduce new (novel) food products into the market (Dodgson et al., 2014). ${ }^{2}$ Simultaneously, international trade and technological innovation (Acemoglu et al., 2011 , 2014) have made products that were previously not available nor affordable to the massessuch as exotic fruit and fresh exotic fishery products like salmon, oysters, or caviar-more and more common in groceries chains around the corner. ${ }^{3}$

The increased availability of new products is also witnessed by the incredibly large variety of products on sale in modern supermarkets. In 1946, the average supermarket carried 2,500 products, in 1975 it carried about 9,000 products, and today it carries almost 44,000 products (Congressional Research Service, 2013; Food Marketing Institute, 2014a,b). ${ }^{4}$ While a significant number of food items sold at supermarkets are certainly substitutes, the fact that the average supermarket carries four times more products than in the 1970s, and seventeen times more than in 1946, underlines the idea that novelty consumption is a characterizing feature of economic growth.

To assess the impact of economic development on dietary choice and body mass, our empirical approach is complementary to, but still different from, the ones used in studies that use microdata to identify and carve out the causal impact of single specific factors on obesity, such as increased availability of (fast food) restaurants (Currie et al., 2010; Anderson and Matsa, 2011), consumption of soda (Fletcher et al., 2010), increases in portion sizes (Jeitschko and Pecchenino, 2006), decreases in gas prices (Courtemanche, 2011), increase in cigarette taxes (Courtemanche, 2009), decreases in food prices (Grossman et al., 2014; Courtemanche et al., 2015; Dubois et al., 2014), or changes in physical activity (Cawley et al., 2013; Sarma et al., 2014). ${ }^{5}$ The contributions cited above can be interpreted as case studies that focus on a sophisticated causal identification of one single, specific factor. They are all econometrically 'clean', but typically find that the estimated effects are modest or sometimes ambiguous. Consequently there remains an odd divergence between the strong

\footnotetext{
${ }^{2}$ Between 1980 and 2012 in the US, the number of food chemistry patents has tripled from 668 to 2134 (World Intellectual Property Organization (WIPO), 2014). Focusing on specific ingredients for functional food and patents in the field of food and agriculture, probiotic patents increased from 4 to 61 between 1999 and 2009 (Bornkessel et al., 2014), and phytosterol ("plant sterols") patents increased from 35 to 180 in the same time period worldwide (Curran et al., 2010).

${ }^{3}$ Before commercial salmon farming was established in the 1970s, (wild) salmon was very expensive, a delicacy that would cost around \$5 per quarter pound (in nominal terms in the US), and that was only available in specialized delicatessen stores (Fishman, 2006; Henson, 2008). Today, ALDI supermarkets sell pink salmon fillets for $\$ 4.84$ per pound (as on November 14, 2014 in the ALDI store in Ithaca, NY) while household income has increased by a factor 3.5. Whether Atlantic salmon raised under aquaculture conditions is of lower quality is controversial (US Food and Drug Administration, 2014). As another example, in 1978 a pineapple cost $\$ 0.29$ in Illinois and an average US household had to spent $4.5 \%$ of its daily income to buy a pineapple. Today, ALDI sells them for $\$ 1.29$ each, and the relative price has decreased to $1.3 \%$ of the daily income (assuming that taxes and deductions add up to $30 \%$ of the gross wage (United States Census Bureau, 1980, 2014).

${ }^{4}$ Walmarkt, the world's largest company, stands representative for the success of supermarket chains offering more and more food products under one roof. On their web page, Walmarkt posts ingredients for 20,000 different food products offered in more than 3,000 stores all over the US (Blatt, 2014).

5 There exists yet another literature strand that identifies the impact of (adverse) early childhood conditions on health, and particularly obesity, later in life. These empirical reduced-form papers exploit exposure to World World II (Kesternich et al., 2014, 2015), famines in the 20 ${ }^{\text {th }}$ century (Lindeboom et al., 2010; van den Berg et al., 2015), or recessions (van den Berg et al., 2006; Scholte et al., 2014).
} 
increases in obesity rates observed at the macro population level and the modest roles that have been identified and attributed to single push factors by clean reduced-form papers that typically focus on short time horizons.

One may hypothesize that this rather unsatisfactory state of the research is due to the very nature of economic development, which involves slow, long-term changes in multiple factors that are hard to identify by conventional reduced-form methods that focus on short-time horizons and sharp exogenous variations in single impact factors. This paper addresses this issue by deliberately exploiting the fact that the German reunification affected multiple factors overnight. Admittedly, the downside of this 'big picture' approach is that one cannot trace changes in outcomes variables back to single specific factors. The main advantage, however, is that this approach essentially simulates an experiment on economic development which forms in a short time horizon (several months) an entire set of economic and technological changes which usually occur at different paces and over very long time horizons (see, e.g., Acemoglu and Johnson, 2007; Acemoglu, 2010).

The next section provides background information on the German reunification and the food choices available to consumers before and after the reunification. Section 3 presents the model of novelty consumption and Section 4 shows the empirical results. 5 discusses and concludes.

\section{Germany's Reunification and Food Availability Under Socialism}

\subsection{Division and Reunification of Germany}

After World War II (WWII), Germany's boundaries changed substantially from its pre-war borders. At the Potsdam Conference in summer 1945, the allies divided Germany into four military occupation zones: American, British, French, and Soviet zones. The division was based on the idea of allocating territory proportional to the size of the nations' army and according to military considerations (Mee, 1977). In 1949, the capitalist and democratic Federal Republic of Germany (FRG) was founded, comprising of the French, British, and American military occupation zones. In the Soviet zone the German Democratic Republic (GDR) - a totalitarian Stalin-oriented communist state—was forged in 1949. ${ }^{6}$ Between 1950 and 1961, about 3.6 million refugees migrated from the GDR to the FRG (Bethlehem, 1999).

To stop the mass exodus, on August 13, 1961, the communist GDR regime started erecting a 155 kilometers (96 miles) long cement and 3.6 meter (12 feet) high "Berlin Wall" around West Berlin. Outside of Berlin and around the rest of the GDR territory, a physically different, but technically very similar 1,393 kilometer (866 miles) long "Inner German Border" was erected (see Figure A1 in the Appendix). This border ran from the Baltic Sea to Czechoslovakia and represented the boundary of the "Iron Curtain." Henceforth, we loosely refer to the whole Inner German border as the "Wall."

For 28 years, from 1961 to 1989, the Wall served as border between the FRG and the GDR. It largely prevented East-West migration, although around 5,000 GDR citizens attempted to escape over the Berlin Wall alone; between 100 and 400 lost their lives at this attempt (Hertle, 2009). After mass demonstrations by the GDR residents, the communist regime decided to allow East-

\footnotetext{
${ }^{6}$ Henceforth, we use the terms GDR and East Germany, and the terms as FRG and West Germany interchangeably.
} 
West migration on November 9, 1989. The fall of the Wall was completely unanticipated and unexpected. On October 3, 1990, Germany officially reunited and became one state again.

\subsection{Food Availability and Prices in the GDR and After the Reunification}

\footnotetext{
"Bananas and exotic fruits have a special symbolic meaning in the relationship between the FRG and the GDR. [...] Initially, the banana [...] [was] symbolic for the shortages and lack of consumer goods in the East. [...] The banana can also be reminiscent of the run on certain goods shortly after fall of the Berlin wall (p. 144, Patent, 2013)."
}

The quotes above nicely illustrate some of the facts concerning food choices around the time of the German reunification. First of all, note that the GDR was the richest and most prosperous economy of the Union of Soviet Socialist Republics (USSR). In 1990, it was the $21^{\text {st }}$ biggest economy in the world. Its Gross Domestic Product (GDP) per capita was \$9,679 (West Germany: \$15,300; US: \$21,082) (CIA World Factbook, 1990; Classora Knowledge Base, 2014). However, although the population of the GDR did not suffer from malnutrition or hunger, food was only produced within the GDR or imported from other socialist countries, mostly the USSR. This led to a restricted food availability in the GDR. ${ }^{7}$ The GDR state food policy heavily subsidized basic food such as potatoes, milk or butter. Consequently, the state-determined prices were relatively low and comparable with those in the FRG (where basic food was also subsidized).

Table B1 in the Appendix shows consumption per capita as well as prices for selected basic food categories in the GDR in 1989 and in the FRG in 1988. First, we see that GDR residents consumed slightly more than $5 \mathrm{~kg}$ (12lbs) meat per month and per person, whereas the consumption in the FRG was very similar but slightly below $5 \mathrm{~kg}$. Although absolute prices for meat were slightly higher in West Germany ( $€ 6.63$ vs. $€ 5.19$ per $\mathrm{kg}$ )—since net household income was about 50\% higher in the West-relative meat prices were lower in West Germany. For a kilogram of meat, West Germans had to spend $0.5 \%$ of their monthly income in 1989; this value slightly decreased to $0.4 \%$ in 1998 due to rising incomes. ${ }^{8}$

Second, Table B1 illustrates that potato consumption was three times higher in the GDR as compared to the FRG in 1989 (9.7 kg vs. $3.03 \mathrm{~kg}$ per month and person). One reason lies certainly in the limited availability of food substitutes, another potentially in differences in prices. Relative to disposable household income, potato prices were only half as high in the GDR (0.02\% vs. 0.04\%). However, given the extremely low prices of potatoes, their demand elasticity is very low. Hsieh et al. (2009) use US Nielsen Scanner data and show that the own price elasticity for the most popular potato consumed at home, the Russell potato, is -0.1 and not statistically different from zero. It is very plausible to assume that differences in the availability of substitute food, not price differences, account for the three times higher potato consumption in the East prior to the reunification. In contrast to potato consumption, egg consumption was slightly higher in West as compared to East Germany. According to the official data sources, sugar consumption was 32\% higher in the West (1.18 vs. $1.56 \mathrm{~kg}$ per person/month).

\footnotetext{
${ }^{7}$ Official state rationing on food was abolished in the 1960s in the GDR (Bochniak, 2009).

${ }^{8}$ Note that this table likely contains measurement errors due to limited data availability and comparability. Particularly the comparison of net household incomes per person is based on several assumptions. For the GDR, we use net household incomes according to the Zentralverwaltung für Statistik der DDR (1988) and for the FRG equivalized disposable household incomes according to the German Socio-Economic Panel Study (SOEP) (Wagner et al., 2007; Grabka, 2000).
} 
Finally, Table B1 also shows prices and consumption of exotic fruits. Western products were officially not available in the GDR. Only people with friends and relatives in West Germany had partially access to these products. Imports only came from "friendly" socialist countries such as the USSR or Cuba. Consequently, products such as exotic fruits were basically not available or only available at horrendous prices that normal people were not able to pay. The last row of Table B1 shows that GDR citizens had to pay an equivalent of $€ 12$ (\$16) for a can of pineapples which were only available in delicatessen stores. In the local currency the price was 18 Ostmark and represented $7.2 \%$ of the net weekly income of a single household. This equaled the price for a train ticket over 200km (124 mi) (Böhme, 1971; Schwarzer, 1999; Woll, 2012; Maecker, 2013).

In summary one can say that (i) people did not suffer hunger in the GDR but food choices were limited and mostly locally produced products available; (ii) Basic food such as potatoes, meat, eggs or sugar was subsidized by the government-in East more than in West Germanywhich kept prices low and made staple foods affordable even for low income households; (iii) it is reasonable to assume that the quality of basic food was comparable in East and West Germany; (iv) western products and imported products from non-communist countries were only available in West, but not in East Germany; ( $v$ ) meat consumption was comparable, potato consumption three times as high, sugar consumption lower, and exotic fruit consumption dramatically lower in the GDR as compared to the FRG.

In the following sections we study theoretically and empirically how the introduction of novelty (western) food affected East Germans' diet and health condition.

\section{A Dynamic Model of Novelty Consumption}

In this section we present a dynamic model of novelty consumption to study the effect of economic development on consumption and diet-related health. Our congruent real word example is the German reunification and East German consumption choices at the time of the reunification (when Novel Food entered the market) and in the subsequent periods (when the novelty effect faded away).

Consider a consumer whose utility function is $U\left(n_{t}, f_{t}, g_{t}, h_{t}, w_{t} ; N_{t}, F_{t}, Z_{i}\right)$. The term $n_{t}$ represents a vector of Novel Food that was available in East Germany only after the reunification, and available in West Germany both before and after the reunification. Examples of Familiar Food are boiled potatoes and meat. In contrast, $f_{t}$ is a vector of Familiar Food that was available before and after the reunification in both Germanies. Novel Food can be further subcategorized into western processed food such as fast food, and exotic high-quality food such as exotic fruits. The term $g_{t}$ represents a vector of non-food consumption (e.g., cars) and non-food activities (e.g., physical exercise), and $Z_{i}$ is a vector of individual characteristics which include being socialized in the pre-unification East Germany, gender and education.

We conceptualize the availability of Novel Food as a negative price shock which makes novelty consumption suddenly available and affordable for the general population. This allows to concisely summarize in a single economic variable-price-the variety of changes that accompany economic development, such as the reduction of prices relative to disposable income, the launching of new products for the mass market thanks to technological innovation or to the removal of barriers to trade, structural changes in the food industry, or decreases in transaction costs due to 
the diffusion of supermarkets and grocery stores. In the case of East Germany, a novel good conceptualization in form of price decrease is also very appropriate since, technically, products that existed in capitalist countries were also available on the East German black market, via personal connections or even in official stores, but at horrendous prices or transaction costs.

We capture the effect of novelty consumption by allowing consumers' preferences to depend on current consumption choices as well as on past consumption experiences. Let $F_{t}$ and $N_{t}$ represent the stock of past consumption of Familiar and Novel Food at time $t$. The distinction between Novel and Familiar Food is based on the fact that, at the time of the reunification $t=0, N_{0}=0$ and $F_{0}>0$ in East Germany. This means that $n$ represents Novel Food because, in the course of the reunification, it became suddenly available (by becoming affordable) and because previous consumption experiences of $n$ were virtually negligible; in contrast, consumers had experience with Familiar Food. We assume that food experiences evolve according to the following dynamics: $\dot{N}_{t}=n_{t}-\delta N_{t}$ and $\dot{F}_{t}=f_{t}-\delta F_{t}$.

Finally, let $h_{t}$ and $w_{t}$ denote health and body weight, respectively, and assume that they are endogenously determined depending on current and past choices, as well as on personal characteristics $Z_{i}: h_{t}=h\left(n_{t}, f_{t}, g_{t} ; N_{t}, F_{t}, Z_{i}\right)$ and $w_{t}=w\left(n_{t}, f_{t}, g_{t} ; N_{t}, F_{t}, Z_{i}\right)$.

Rewriting the utility function as $\mathcal{U}\left(n_{t}, f_{t}, g_{t} ; N_{t}, F_{t}, Z_{i}\right)=\mathcal{U}\left(n_{t}, f_{t}, g_{t}, h_{t}, w_{t} ; N_{t}, F_{t}, Z_{i}\right)$, the consumer chooses the path of food and non-food consumption that, given $N_{0}$ and $F_{0}$, maximizes the following intertemporal problem:

$$
\begin{aligned}
\max _{\left\{n_{t}, f_{t}, g_{t}\right\}} & \int_{0}^{\infty} e^{-\rho t} \mathcal{U}\left(n_{t}, f_{t}, g_{t} ; N_{t}, F_{t}, Z_{i}\right) d t \\
\text { s.t. } & \dot{A}_{t}=r_{t} A_{t}+M_{t}-p_{t}^{n} n_{t}-p_{t}^{f} f_{t}-p_{t}^{g} g_{t} \\
\dot{N}_{t} & =n_{t}-\delta N_{t} \\
& \dot{F}_{t}=f_{t}-\delta F_{t}
\end{aligned}
$$

where $\rho$ is the intertemporal discount factor and $r_{t}$ is the market interest rate. $A_{t}$ are available assets, $M_{t}$ is income and $p_{t}^{j}$ is the price of good $j$ at time $t$. Prices include the opportunity cost of time and the transaction costs required to obtain a good.

Let $\mathcal{V}\left(N_{t}, F_{t}, A_{t}\right)$ be the optimal value function associated with the consumer's problem. From the corresponding Hamilton-Jacobi-Bellman equation:

$$
\rho \mathcal{V}\left(N_{t}, F_{t}, A_{t}\right)=\max _{\left\{n_{t}, f_{t}, g_{t}\right\}}\left\{\mathcal{U}\left(n_{t}, f_{t}, g_{t} ; N_{t}, F_{t}, Z_{i}\right)+\mathcal{V}_{F} \dot{F}_{t}+\mathcal{V}_{N} \dot{N}_{t}+\mathcal{V}_{A} \dot{A}_{t}\right\}
$$

the following first order conditions determine the optimal paths of consumption choices:

$$
\begin{aligned}
& \mathcal{U}_{f}=p_{t}^{f} \mathcal{V}_{A}-\mathcal{V}_{F} \\
& \mathcal{U}_{n}=p_{t}^{n} \mathcal{V}_{A}-\mathcal{V}_{N} \\
& \mathcal{U}_{g}=p_{t}^{g} \mathcal{V}_{A}
\end{aligned}
$$

The terms $\mathcal{V}_{N}$ and $\mathcal{V}_{F}$ are the shadow prices of the stocks of food consumption $N_{t}$ and $F_{t}$, respectively. They measure how a marginal change in past consumption affects the intertemporal utility of the agent. $\mathcal{V}_{A}$ is the shadow price of assets. The conditions above show that, at each point 
in time, the optimal consumption of food and non-food depends not only on market prices, but also on the impact that current choices have on future utility via the accumulation of consumption experiences and of assets.

For analytical tractability and to obtain linear policy functions that can be empirically estimated, it is convenient to consider the following quadratic representation of the utility function (for a similar assumption, see Becker and Murphy, 1988):

$$
\mathcal{U}\left(n_{t}, f_{t}, g_{t} ; N_{t}, F_{t}, Z_{i}\right)=f_{t}\left(\hat{f}-\frac{f_{t}}{2}\right)+n_{t}\left(\hat{n}-\frac{n_{t}}{2}\right)+g_{t}\left(\hat{g}-\frac{g_{t}}{2}\right)+U_{f F} f_{t} F_{t}+U_{n N} n_{t} N_{t} .
$$

The positive parameters $\hat{f}, \hat{n}$ and $\hat{g}$ depend on the individual characteristics $Z_{i}$ and represent, absent budget constraints and past consumption experiences, the bliss consumption point of $n, f$ and $g \cdot 9$

Past food consumption experiences can endogenously affect the bliss points for food. This is captured by the two interaction terms, $U_{f F}$ and $U_{n N}$, which determine how past consumption experiences affect the marginal utility of consumption. When the interaction is negative, past consumption has a satiating effect, which reduces the marginal utility of consumption. This is a common assumption in the literature on habit formation (see, e.g, Abel, 1990; Overland et al., 2000; Carroll, 2000). When instead the interaction is positive, past consumption has a reinforcing effect on the marginal utility of consumption. This is a typical assumption of the literature on taste formation, learning in consumption, and rational addiction (Stigler and Becker, 1977; Becker and Murphy, 1988). Hence our specification allows for intertemporal non-separabilities, in that the past affects current preferences and current choices, but we do not make any a priori assumption on whether this effect should be modeled as a habit forming process or as a learning process.

\subsection{Novelty Consumption and Changes in Diet}

At each point in time, optimal consumption of Novel and Familiar Food can be explicitly expressed as follows: ${ }^{10}$

$$
\begin{aligned}
& n_{t}=\left(\delta+\lambda_{n}\right)\left(N_{0}-N_{s s}\right) e^{\lambda_{n} t}+\delta N_{s s} \\
& f_{t}=\left(\delta+\lambda_{f}\right)\left(F_{0}-F_{s s}\right) e^{\lambda_{f} t}+\delta F_{s s}
\end{aligned}
$$

where $\lambda_{n}$ and $\lambda_{f}$ are two negative eigenvalues. The long-run consumption of Novel and Familiar Food, $N_{s s}$ and $F_{s s}$, depend on prices and current income, among other factors. The terms $\delta+\lambda_{n}$ and $\delta+\lambda_{f}$ are particularly interesting because they determine the effect of past consumption experiences on current consumption: they are positive in case of learning in consumption (i.e., $U_{n N}>0$ and $U_{f F}>0$ ), and negative in case of habit formation (i.e., $U_{n N}<0$ and $U_{f F}<0$ ).

Consistent with the literature, our empirical exercise assumes that East and West Germans would not behave differently in the long run if they had access to the same goods. In terms of

\footnotetext{
${ }^{9}$ Non-satiation can be guaranteed, if necessary, by assuming that the bliss point is large enough to be economically unfeasible.

${ }^{10}$ All analytical details and proofs are in Appendix C.
} 
our dynamic model, this implies that, after the reunification, the long-run equilibrium consumption level (either of Novel or Familiar Food) will be the same in East and West Germany. The Proposition below shows how Novel Food is expected to respond on impact, i.e., right after the reunification, and along the transition path to the long-run equilibrium. A noteworthy result is that, based on the empirically observed East-West differences in consumption, one can infer the role of past consumption on individual preferences. Such preferences are generally not observable. As shown in the Appendix, post-reunification consumption differences between East and West can be expressed as:

$$
\begin{aligned}
\Delta n_{t} & =n_{t}^{E}-n_{t}^{W}=-\left(\delta+\lambda_{n}\right) N_{0}^{W} e^{\lambda_{n} t} \\
\Delta f_{t} & =f_{t}^{E}-f_{t}^{W}=\left(\delta+\lambda_{f}\right)\left(F_{0}^{E}-F_{0}^{W}\right) e^{\lambda_{f} t} .
\end{aligned}
$$

where $N_{0}^{W}>0$ is the West German "experience capital" of Novel Food, and $F_{0}^{E}>0$ and $F_{0}^{W}>0$ are the experience capitals of Familiar Food among East and West Germans, respectively, at the time of the reunification. As mentioned above, the signs of the terms $\left(\delta+\lambda_{n}\right)$ and $\left(\delta+\lambda_{f}\right)$ depend on whether food features learning or habit formation.

On the basis of equations (3) to (6), we can now state the following two main Propositions about consumption patterns of Novel and Familiar Food:

Proposition 1. Consider consumption of Novel Food in East Germany:

- Immediately after the reunification, consumption strongly increases.

- Along the transition path to the long-run equilibrium:

- Novel Food is habit forming if its consumption is higher among East than West Germans.

- Novel Food features learning if its consumption is lower among East than West Germans.

After the reunification, novelty consumption sharply increases and East Germans start to accumulate consumption experiences which affected their subsequent choices. The speed and time-trend of the adjustment path to the equilibrium depends on individual characteristics, and in particular on whether Novel Food features learning or habit formation.

Figure 2 illustrates dynamic consumption pattern of Novel Food in East and West Germany, $n_{t}^{E}-n_{t}^{W}$, which is the relevant measure for our empirical analysis. Before the reunification, the consumption differential is negative because in eastern consumption of Novel Food was essentially zero. After the reunification, novelty consumption unambiguously increases in the East. It can then either reach a higher or lower consumption level than in the West, depending on the sign of the cross derivative $U_{n N}$.

Overshooting occurs if Novel Food is habit forming, which means that the desirability of the good is high when consumption experience is low. When consumption experiences are accumulated, its consumption decreases. Undershooting occurs if Novel Food features learning, in which case the desirability of the good increases with the accumulation of consumption experiences. In both cases, in the long-run, the good will no longer be novel and consumption in the East will converge to consumption in the West. ${ }^{11}$

\footnotetext{
11 Our theoretical results are related to Becker and Murphy (1988)'s finding that present consumption is positively related to past consumption if reinforcement is large enough (which, in Becker and Murphy (1988)'s requires $U_{n N}>$
} 
Depending on the data frequency and speed of adjustment to the long-run equilibrium, the above Proposition shows that it is possible to infer how Novel Food depends on past consumption experience. A similar result holds when we consider Familiar Food. Since, in East Germany, the initial consumption experience for Familiar Food is positive at the time of the reunification (and not zero as for Novel Food), the results are slightly more complicated. Yet they are easily applicable to our empirical analysis because they state that the observed differences in consumption levels between East and West Germans contain enough information to characterize whether Familiar Food features habit formation or learning. Usually these are unobservable properties of the utility function.

Proposition 2. Consider consumption of Familiar Food in East Germany.

- If, pre-reunification, there was no consumption difference between East and West Germans, then no difference in consumption should be observed at or after the reunification.

- If pre-reunification, there was some consumption difference between East and West Germans, the change in consumption is ambiguous at the time of the reunification. Moreover, along the transition path to the long-run equilibrium:

- Familiar Food is habit forming if one of the following two cases occur:

* Pre-reunification, consumption is higher in East Germany but lower afterwards.

* Pre-reunification, consumption is lower in East Germany but higher afterwards.

- Familiar Food features learning if one of the following two cases occur:

* Consumption is higher in East Germany, both pre- and post reunification,

* Consumption is lower in East Germany, both pre-and post reunification.

The above Proposition provides testable implications for the empirical part when we study the dynamic patterns of Familiar Food consumption. First, the observation of no differences in consumption of Familiar Food before the reunification provides sufficient information to predict that no difference will be observed afterwards.

Second, if there are consumption differences before the reunification, then one can exploit the subsequent consumption patterns to make inferences on the underlying intertemporal preferences for food (see Figure 3). In particular, habit formation is revealed by consumption patterns that overreact to exogenous shocks in prices and are non-monotonic. Learning in consumption, instead, features a smoother response to the shock, as consumption reacts less at the time of the shock, and it is followed by a monotonic adjustment to the long run equilibrium. Notably, our theoretical predictions can be tested even if the data do not have a panel structure, because the relevant observations are relative consumption differences between East and West Germans at a given point in time. In fact, repeated cross-sections are sufficient to obtain information on the properties of intertemporally non-separable preferences.

$\left.-U_{N N} /(2 \delta+\rho)\right)$ and negatively related otherwise. In the former case the literature speaks of adjacent complementarity, while in the latter case of distant complementarity (Ryder and Heal, 1973). Note that in our setup $U_{N N}=0$. 


\subsection{Predicting Diet-Related Health Effects after Dietary Changes Due to Novelty Con- sumption}

An interesting feature of our model is that, although the solution of the individual intertemporal problem is optimal because it maximizes the agent's objective function, it may not necessarily optimize body weight or diet-related health. These are just components of a utility function which likewise considers the pleasure of consuming, i.e., consumption utility. Consequently, an increase in food consumption due to a price decrease may have ambiguous effects on body weight and diet-related health. To see this, let us focus on health and distinguish between two subcategories of novelty consumption: novel healthy food $n^{h}$ (such as exotic fruits) and novel unhealthy food $n^{j}$ (such as junk food). Now consider the simple case of a decrease in prices of both healthy and unhealthy novel food, $p^{n^{h}}$ and $p^{n^{j}}$. We know from the results derived in the previous section that the law of demand holds, $\partial n^{h} / \partial p^{n^{h}}<0$ and $\partial n^{j} / \partial p^{n^{j}}<0$. We also know that, by definition, $\partial h / \partial n^{h}$ is positive and $\partial h / \partial n^{j}$ is negative. Hence, even in a simplified case in which the prices and consumed quantities of all other goods remain constant, the impact on health is ambiguous because the two addends of the following expression have opposite signs:

$$
\mathrm{d} h=\frac{\partial h}{\partial n^{h}} \frac{\partial n^{h}}{\partial p^{n^{h}}} \mathrm{~d} p^{n^{h}}+\frac{\partial h}{\partial n^{j}} \frac{\partial n^{j}}{\partial p^{n^{j}}} \mathrm{~d} p^{n^{j}} \gtreqless 0 .
$$

We can therefore conclude that in general the following holds:

Prediction 1. After a decrease in the price of Novel Food, the effects on health and body weight are ambiguous.

\section{An Empirical Assessment of Changes in Food Consumption, BMI, and Diet-Related Health after the German Reunification}

\subsection{The Empirical Model}

In this Section we estimate the following empirical model:

$$
\begin{aligned}
y_{\text {ist }}= & \alpha+\beta \text { EastGerman }_{i}+\psi \text { EastGerman }_{i} \times y 1998_{t} \\
& +\gamma \text { Demographics }_{i}+\delta \text { Education }_{i}+\theta \text { Employment }_{i}+\eta \text { Income }_{i}+\rho_{t}+\epsilon_{i}
\end{aligned}
$$

where the dependent variable $y_{\text {ist }}$ stands for the following sets of dependent variables (see also Table B2 for summary statistics):

\section{A. Current Diet and Change in Diet}

- Level of consumption of food $s$ by individual $i$ at time $t, t=[1991,1998]$,

- Change in consumption of food $s$ by individual $i$ between $t-3$ and $t, t=[1991]$, i.e., between 1988 and 1991. 


\section{B. Current Weight and Change in Weight}

- Objective Body Mass Index (BMI), overweight and obesity measures of individual $i$ at time $t, t=[1991,1998,2005]$,

- Change in body weight of individual $i$ between $t-3$ and $t, t=[1991,1998]$, i.e., between 1988 and 1991, and between 1995 and 1998.

\section{Objective Diet-Related Health Measures}

- Objective diet-related medical conditions: blood cholesterol level, blood pressure and diabetes of individual $i$ at time $t, t=[1991,1998]$.

The main variable of interest is EastGerman ${ }_{i}$, which is an indicator variable indicating whether the respondent was living in East or West Germany prior to 1989. The coefficient $\beta$ represents EastWest level differences in food consumption and body mass in 1991 when exploiting the current food consumption and body weight measures as dependent variables. It can also be interpreted as a variant of an East-West difference-in-differences (DiD) estimator where the dependent variable elicits changes in food consumption and body mass. In addition, the interaction of EastGerman with the year dummy $y 1998_{t}$ measures consumption dynamics and the impact of consumption experience with novel food. Again, this can be thought of a DiD estimator variant assessing longterm effects of a treatment where East Germans are the treatment group and West Germans the control group.

Demographics $_{i}$ is a vector of six socio-demographic covariates, Education $n_{i}$ is a vector of three educational dummy variables, and Employment $t_{i}$ includes seven labor market related controls (see Tables B2 and B4 in the Appendix). We also add interaction terms between EastGerman $i$ and the sets of demographics in Table B3, and include month and year fixed effects to control for the interview month and year, which are represented by $\rho_{t}$. As usual, $\epsilon_{i}$ is the error term.

\subsection{Identification}

After having adjusted the sample with a set of 15 socio-demographic, educational, and workrelated variables, the coefficient $\beta$ identifies differences between East and West Germans in terms of $(A)$ consumption levels and changes in consumption, $(B)$ body weight measures and changes in body weight, and $(C)$ diet-related objective health measures. $\psi$ informs us about the consumption and health dynamics.

Since we use three cross-sectional data sets from 1991/1992, 1997/1998, and 2005 a strictly causal interpretation of $\beta$ and $\psi$ requires several assumptions. However, almost all assumptions are standard and well-established in the literature that uses the German reunification as a natural experiment (Frijters et al., 2004b,a, 2005; Fuchs-Schündeln and Schündeln, 2005; Alesina and Fuchs-Schündeln, 2007; Fuchs-Schündeln, 2008; Rainer, 2013; Brosig-Koch et al., 2011; Heineck, 2013; Bursztyn, 2015; Burchardi and Hassan, 2013; Friehe and Mechtel, 2014).

One first assumption states that the division of Germany and the erection of the Berlin Wall were unexpected and quasi-random events that divided an otherwise united, and thus similar, population. In one part of divided Germany, the GDR-a socialist regime, established a centrallyplanned economy with limited food variety. In the other part of divided Germany, the FRG-a 
Western capitalist economy, a large variety of Western food products existed. The Berlin Wall divided the GDR and the FDR from 1961 until 1989 for 28 years. During that time, it was basically impossible to migrate to West Germany. The fall of the Wall on November 9, 1989 was as unexpected as its construction (see Section 2.1).

Second, after the fall of the Wall, from 1989 to 2004, it is estimated that 3.4 million mostly young and well-educated East Germans migrated to West Germany (Hunt, 2009). Although our oldest dataset was in the field shortly after the reunification in East Germany, in 1991, we cannot capture East Germans who migrated to West Germany between 1989 and 1991, since the 1991 questionnaire only refers to the current residency of the respondents. In the first year after the reunification, it is estimated that 400,000 East Germans migrated to West Germany (Hunt, 2009). This migration introduces measurement error that is likely to downward bias the estimates obtained with the 1991 dataset (Wagner and Ziebarth, 2014). However, in the second and third dataset employed, we can clearly identify people who were socialized in the GDR, e.g., lived there before 1989. Actually, the third dataset from 2005 is rich enough to disentangle long-term weight effects of an eastern socialization from East-West migration: Fifteen years after the fall of the Wall, it allows us to compare the BMIs of (i) East Germans living in West Germany with (ii) East Germans living in East Germany and (iii) West Germans who stayed in West Germany. While the two datasets from 1998 and 2005 allow us to study long-term effects of eastern socialization, they do not allow us to unambiguously trace changes in food consumption and diet-related health back to one single impact factor.

This is because the third necessary assumption for a narrow causal interpretation of the treatment "switch from life under socialism to capitalism" is that unobserved developments after the reunification in East Germany did not lead to changes in the dependent variables. Obviously, this is a bigger concern the larger the time gap between the fall of the Wall and the survey. For example, the unemployment rate in East Germany has been consistently about twice as large as West Germany (Sinn, 2002; Uhlig, 2006; Burda, 2006). While many of the food consumption categories represent low budget staple foods that are unlikely to be strongly confounded by unemployment, researchers have shown that unemployment affects health (Sullivan and von Wachter, 2009; Browning and Heinesen, 2012; Marcus, 2013). However, note that we adjust differences in the outcome variables with a rich set of socioeconomic controls, among them several (un)employment and educational measures as well as household income measures (see Tables B2 and B2 in the Appendix). In addition, even 10 or 15 years after the reunification, one could still interpret differences in consumption patterns and health between East and West Germans as an overall reduced form "intention-to-treat" effect that incorporates changes in unemployment or environmental conditions since these changes were all exogenously triggered by life under socialism and the reunification. However, this latter effect would then represent the combined overall impact of "life under socialism plus all post-reunification adaptation processes to capitalism" on food consumption and health. Note that we can empirically test whether these potential confounding factors are likely to severely confound our main message of the change in diet among East Germans due to novelty consumption. For example, we show below that unemployed and blue collar workers were not the ones who predominantly changed their diet and gained weight in East Germany after the reunification - the effect was mainly driven by white collar workers and the better off. 
Finally, the core empirical analysis (and the model) cannot include thousands of specific measures of food quality and prices but incorporates changes in these two factors in a reduced-form manner by the variable EastGerman E $_{i}$ It is obvious that food availability dramatically increased overnight in the GDR. However, food quality and thousands of relative food prices also changed. One cannot comprehensively model the very complex simultaneous changes in quality, prices, and availability. However, one can interpret the observed change in consumption of selected food categories as an overall reduced form effect that normalizes the quality, price and availability change in the course of the reunification. This approach mirrors and links to our theoretical model in which we condensate all these economic development-related changes into one single specific price variable.

In the empirical model, to shut down as many potential confounding channels as possible, we focus on consumption of selected food items that stand representative for Familiar Food, such as boiled potatoes and meat, and for Novel Food, such as exotic fruits and convenience food. We provide information on pre and post-reunification prices and consumption in Section 2.2. It is reasonable to assume that the quality of Familiar Food did not change significantly after the reunification. In addition, for most staple Familiar Food price effects are unlikely to play a major confounding role due to arguably inelastic demand (Hsieh et al., 2009). To anticipate the empirical results, except for boiled potatoes, the consumption pattern for all types of familiar are found to be extremely stable over time.

To sum up, the coefficient $\beta$ measures differences in food consumption patterns, body mass, and objective diet-related health between East and West Germans right after the reunification. When the dependent variable elicits changes in consumption and body weight in 1991 (cf. Table B2), $\beta$ can be interpreted as a DiD estimator that yields the short-term effect of a sharp exogenous economic development shock on consumption. It assesses the change in consumption for East Germans minus the change for West Germans over time. When employing the pooled 1991 and 1998 data, the interaction term $\psi$ can also be thought of as a DiD model assessing the longterm effect of a sharp exogenous economic development shock on consumption. This longer-term adjustment is theoretically illustrated in Figure 2 and 3.

To the extent that the identification assumptions hold, the identified differences can be traced back to life under socialism vs. capitalism. One can interpret the exposure effect broadly and view all post-reunification events that also affected food consumption and diet-related health as the long-term effect of the division and subsequent reunification. Thus, the German example allows us to study the immediate and long-term effects of economic development-in the form an abrupt change from a communist to a capitalist economy-on food consumption and diet-related health measures. However, to be on the safe side, we interpret the long-term findings as strongly suggestive, instead of strictly causal, and we primarily intend to show that the empirical facts are in line and rationalizable with our theory of novelty consumption and model predictions.

\subsection{Data Used}

\subsubsection{German National Health Survey East-West 1991 (GNHSEW91)}

The first dataset is a nationwide population-based cross-section that was surveyed in East and West Germany between 1990 and 1992 (Robert Koch Institut, 2012b). The survey was designed 
to be representative both in East and West Germany. The main aim of the survey was to "gather reliable core indicators on the population's health status and health risks" (Robert Koch Institut, $2012 b$ ). Consequently, most information surveyed is health-related; it is based on (i) paper-andpencil self-reported questionnaire as well as (ii) objective clinical measures on the blood pressure, pulse, height and weight, and the blood cholesterol level.

Excluding individuals with missing responses response on relevant variables, the sample consists of 2,160 East and 4,390 West German respondents. We do not restrict the sample further.

\section{Dependent Variables}

The empirical section exploits a battery of food consumption-related outcome variables, in total 31, grouped into 4 main categories (see Table B2 in the Appendix). The first category comprises self-reported measures of current food consumption by categories. Table B2 plots the mean values according to which $54 \%$ of the population eat wholegrain bread daily, $26 \%$ eat nonprocessed-i.e. boiled, baked or smashed-potatoes daily, and 57\% eat fresh fruits daily. Meat is consumed by $75 \%$ on a weekly basis; eggs (23\%) as well as pie and cookies (36\%) are consumed by a significant share more than once a week.

The second category of outcome measures stem from self-reported information on whether respondents changed their diet and gained weight in the last three years. It also include objective information on current weight and height. East Germans were interviewed and medically examined between September 1991 and October 1992, i.e., shortly after the reunification. Thus, questions referring to a change in consumption and body weight in the last three years capture changes in consumption in the course of the reunification. For example, a quarter indicated more wholegrain consumption in the three years prior to the survey. Only $2 \%$ increased their meat consumption but a staggering $34 \%$ increased their fresh fruit consumption-an effect that is largely driven by East Germans.

Objectively measured height and weight shows that the average BMI is 27 , that $61 \%$ of all respondents are overweight, and that $21 \%$ are obese (Table B2). ${ }^{12}$ These values are close to those for the US population at that time (Burkhauser and Cawley, 2008; Ogden et al., 2014).

Finally, we construct a measure of calorie expenditure, Minutes active per week, and show that the weight gains are not driven by a lower degree of physical activity and calorie expenditures among East Germans, but by a change in their diet. The GNHSEW91 asks respondents specifically how many hours and minutes they spent on 20 different physical activities per week. The list of activities include, among others, walking (to go to work, for the pleasure of walking, for grocery shopping...), gardening, hiking, biking and different sports categories such as dancing, going to the gym, playing soccer, basketball, etc. For each respondent, we summed over the weekly minutes spent for each of the 20 categories. As seen in Table B2, Germans engage in 560 minutes of such physical activities per week, or 80 minutes per day.

The third category of outcome variables includes clinical diet-related objective health conditions which have been found to be associated with an unhealthy unbalanced diet (Niinikoski et al., 1996; American Heart Association, 2001; Pasanisi et al., 2001; Brinkworth et al., 2006; Nagashima et al., 2010). One of the measures investigated was taken via blood samples. The total

\footnotetext{
${ }^{12} \mathrm{~A}$ person is considered to be overweight if the BMI is between 25 and 30 , and obese if it is above 30 .
} 
blood cholesterol level has a mean value of $6.1 \mathrm{mmol} / \mathrm{l}$, but varies between 2.3 and 12.9. We follow the official definition and define values above 6.2 as 'high.' According to this definition, $44 \%$ of the population have high blood cholesterol levels.

Another clinical health indicator surveyed is blood pressure. The systolic and diastolic blood pressure was taken twice from each respondent; we use the second measure of each to define 'high blood pressure.' According to official definitions, blood pressure is 'high' when either the systolic value exceeds $160 \mathrm{~mm} \mathrm{Hg}$ or the diastolic value exceeds $100 \mathrm{~mm} \mathrm{Hg}$ (American Heart Association, 2014). Twenty-one percent of all Germans fall into the high blood pressure category. Finally, 5\% of all respondents reported a diabetes diagnosis.

The fourth category is Unawareness and medical check-up measures. First, we make use of questions asking respondents when certain medical measures were taken the last time by a health care professional. We then assign the four generated dummy variables a one if this happened 'more than one year ago' or 'never.' Only $25 \%$ had their blood pressure taken within the last year, but had $44 \%$ their blood cholesterol checked. Fifty-six percent got weighted and $87 \%$ received dietary advice within the last year.

Second, we exploit the fact that the survey asks respondents whether they were ever diagnosed with high blood pressure, high cholesterol, or obesity. Then we generate three unawareness dummies which have value equal to one if the respondents denied such a diagnosis but their objective health measure indicates that the health condition actually exists. According to this awareness measure, nine percent of all respondents were unaware of their high blood pressure, $29 \%$ were unaware of their high cholesterol, and $7 \%$ were unaware of their obesity.

\section{Covariates}

The covariates can be sub-classified into three main categories: (i) Demographics, (ii) Education, and (iii) Employment. All mean values are in Table B2. The first covariate category includes the dummy variables East German, Single, and Private Health Insurance, in addition to Age, \# household members, and \# kids.

The second group of covariates includes three educational dummies and the third group seven employment measures, such as Blue collar worker, White collar worker, Unemployed, or the Net household income in ten categories.

\subsubsection{German National Health Interview and Examination Survey 1998 (GNHIES98)}

The second dataset is very similar to the first dataset described above. In fact, although technically a different dataset, it can be seen as a follow-up survey of the GNHSEW91; most of the questions asked are identical. Consequently, the GNHIES98 is also a nationwide cross-sectional survey designed to be representative in East and West Germany. And again, the information surveyed are based on (i) paper-and-pencil questionnaire self-reports and (ii) objective clinical measures on the blood pressure, cholesterol, height and weight. More information is provided by the Robert Koch Institut (2012a). The sample used in this paper consists of 2,216 East and 4,203 West Germans. All interviews were carried out between October 1997 and March 1999. 


\section{Dependent Variables}

We generate categories of dependent variables, analogously to the GNHSEW91 above. However, some food-related questions slightly changed. In addition, the retrospective questions on food consumption were no longer asked. The descriptive statistic of all variables are in Table B4 in the Appendix.

As above, the first set of dependent variables includes measures on the current consumption of (i) meat, (ii) (boiled) potatoes, (iii) fruits, (iv) wholegrain bread, (v) eggs, and (vi) pie.

A second set of dependent variables includes self reported measures on (i) weight gain in the last three years as well as (ii) diagnosed diabetes. In addition we exploit objective and exact clinical height, weight, and health measures and we generate, analogously to the GNHSEW91, the four dummies (iii) overweight, (iv) obese, (v) high cholesterol and (vi) high blood pressure.

\section{Covariates}

The covariates were also selected and generated according to the categorization in the GNHSEW91. Since identical or very similar questions were asked in the GNHIES98 six years later, as Table B4 shows, the list of control variables is almost identical.

\subsubsection{German Microcensus 2005}

The third and final dataset is the German Microcensus which is a mandatory representative survey of $1 \%$ of the German population. Currently, 380,000 households with 820,000 respondents participate every year. We make use of the survey year 2005.

The main reason for using this third survey is to assess the medium-term effects of transitioning from life under socialism to capitalism on body mass. In addition, since the survey is compulsory, it minimizes potential biases due to differential East-West non-response rates. A final main argument for using the Microcensus is that the large number of observations, along with the type of questions asked, allows us to disentangle potential selection effects due to migration. As discussed below, we are able to compare the body mass of (i) individuals who socialized in East Germany and then migrated to West Germany with (ii) those who were socialized under capitalism, and with (iii) those who were socialized and stayed in East Germany after the reunification.

\section{Dependent Variables}

We exploit self-reported weight and height measures and calculate the respondents' BMI. Table B5 in the Appendix shows that the mean BMI is 25. The binary variable overweight indicates that $48 \%$ of the sample were overweight (BMI $>25)$, whereas $33 \%$ were obese (BMI $>30)$.

\section{Disentangling East-West German migration pattern}

We employ two main dummy variables and their interaction to disentangle selection effects due to migration. First, the variable Living in East Germany is one for respondents who currently live in one of the six East German states that formerly belonged to the GDR. This applies to $22 \%$ or 69,818 respondents (Table B5 in the Appendix). 
Second, we exploit information on the respondents' educational degrees to elicit whether a respondent obtained an educational degree in the GDR. Educational degrees are surveyed precisely in the Microcensus. Obtaining a GDR educational degree implies that the respondent was socialized in the GDR and hence between the age of 15 and 20 before the Wall came down. 24,584 respondents or $8 \%$ of the sample fall into this category.

\section{Covariates}

The list of covariates used is also in Table B5 in the Appendix. As seen, we correct the sample composition for factors such as age (mean: 49 years), gender (51\% female), labor market status (6.2\% unemployed), household composition (62\% with partner in household) and marital status (27\% single).

\subsection{Results}

\subsubsection{How East Germans' Changed Their Diet Shortly Around the Reunification (1991/1992)}

Table B1 shows descriptive statistics for selected main food categories: meat, potatoes, eggs, sugar, and fresh fruits. For all categories we have consistent administrative information on consumption and prices, for East as well as for West Germany, before the reunification in 1989 (Zentralverwaltung für Statistik der DDR, 1988, 1990, 1991; Gedrich and Albrecht, 2003). For four of those food categories we can also exploit consistently surveyed data for 1991 and 1998 from the GNHSEW91 and the GNHIES98.

\section{Availability, Prices and Consumption Pre-Reunification}

Table B1 shows pre-1989 information on four different types of Familiar Food (meat, potatoes, eggs and sugar) and one type of Novel Food (exotic fruits).

(a) Meat was available under socialism as well as capitalism and it is fair to assume that the product quality was comparable. Interestingly, meat prices were also quite similar in East and West Germany in 1989 (€5.19 vs. $€ 4.49)$ as was per capita meat consumption $(5.25 \mathrm{~kg} / \mathrm{month}$ vs. $4.49 \mathrm{~kg} / \mathrm{month})$.

(b) Potatoes were cheaper under socialism, although the quality was arguably comparable in West Germany. Per capita potato consumption was three times higher under socialism and, given the very inelastic potato demand elasticities (Hsieh et al., 2009), prices differences are unlikely to explain the major differences in consumption.

(c) Similar findings hold for eggs and sugar which are both familiar staple food products with comparable quality and presumably very low price elasticities in East and West Germany. Consumption was roughly comparable, although slightly higher in West Germany.

(d) Exotic fruits were unavailable under socialism (or only available to horrendous prices or through personal relationships, see Section 2.2). Accordingly, exotic fruit consumption was basically zero in the East, but $1.75 \mathrm{~kg} /$ month in the West in 1989. 


\section{Short-Term Changes in Food Consumption after the Fall of the Wall}

Now we empirically assess whether and how East Germans' diet changed in the transition period from socialism to capitalism using a regression framework as formalized by equation (8). Table 1 makes use of the GNHSEW91. Panel A displays current food consumption in 1991; the six food categories used as dependent variables are indicated in the column headers. The first three columns of Panel B exploit direct survey questions on increased food consumption of specific food categories in the three years prior to the interview (see Section 4.3.1 for details).

Hence the displayed East German coefficient in Panel A measures differences in 1991 food consumption between East and West Germans. It also represents personal experiences with the transition from socialism to capitalism, and from a limited socialist food basket to a much larger capitalistic one. In Panel B when changes in consumption are elicited, the coefficient $\beta$ in equation (8), and hence East German in Panel B of Table GNHSEW91, can be interpreted as a type of DiD estimator indicating the difference in changes between East and West German food consumption. In this case as well, East Germans experienceed the transition from socialist to capitalist food baskets, while this was not the case for West Germans.

Let us first consider three specific types of food that we have been using as examples throughout the paper: meat, boiled potatoes, and fruits.

(a) There is no evidence that meat consumption differed between East and West Germans in 1991 (Panel A, column (1)), or that it significantly increased in the course of the reunification (Panel B, column (1)). The East German coefficient estimate in column (1) of Panel A is small in size ( $4 \%$ of the mean) and not statistically significant. Similarly, and in line with this finding, the DiD more meat coefficient in column (1) of Panel B is not significant as well. Notably, this empirical finding is perfectly consistent with Proposition 2 of the model which predicts that, after the reunification, there will be no difference in Familiar Food consumed in the East and in the West if there was no difference before the reunification. As shown in the previous subsection and in Table B1, this is indeed the case because, before the fall of the Wall, prices and consumption of meat were comparable in East and West Germany.

(b) The East German 1991 current consumption coefficient for (unprocessed) potato consumption is negative, about $10 \%$ of the mean and statistically significant (column (2) of Panel A), suggesting that East Germans ate less unprocessed potatoes than West Germans in 1991. Together with the fact that potato consumption was three times higher in East Germany in 1989 (Table B1), this finding shows that consumption sharply decreased in the transition phase from socialism to capitalism. As discussed, this was very likely not due to a change in quality or potato prices, but to the increase in alternative affordable western food products and novelty consumption. The subsequent rebound in consumption to West German levels between 1991 and 1998-identified below in Section 4.4.6-suggests that nonprocessed potatoes feature habit formation (see Panel B of Figure 3 and Proposition 2).

\section{[Insert Table 1 about here]}

(c) The fresh fruits daily estimate in column (3) of Panel A is large in size (16\% of the mean) and highly significant at the 1\% level. This finding is strongly reinforced by column (3) of Panel B that specifically and directly elicits fruit consumption increases. The share of East Germans who said that they increased their fruit consumption in the three years prior to the survey is a highly 
significant 16ppt higher as compared to West Germans, which equals almost an $50 \%$ difference. Since exotic fruits where barely available in the GDR, this finding yields strong evidence that East Germans consumed fresh exotic fruits at a much higher rate right after the fall of the Wall. Anecdotal evidence strongly supports this notion as well (see e.g. quotes above).

This clear central quantitative and qualitative finding validates our novelty consumption model. According to Proposition (1), novelty consumption increases when novel food products become available. In addition, the finding that consumption of fresh fruit was persistently higher in the East in 1991 suggests that it is a habit forming good (see Figure 2). Once more we would like to stress that we exploit the German reunification as a fast motion experiment of economic development. In our classification, exotic fruits fall into the subcategory of exotic high-quality Novel Food (another example would be Salmon) that, thanks to free trade and technological innovation, are now affordable for everybody. Mirroring exactly the development in the former GDR, in the US, the real price of pineapples decreased by at least a factor of 3.5 between 1975 and today; and fresh fruit consumption per capita increased by 28\% between the mid 1975 and 2012 in the US (United States Department of Agriculture (USDA), 2014).

(d) Wholegrain bread and egg consumption did not differ between East and West in 1991 (columns (4) and (5) of Panel A) and are unlikely to have changed after the fall of the Wall (column (2) of Panel B). The coefficient sizes for all three Familiar Food types are small and not statistically different from zero. As for the case of meat consumption, the absence of differences in consumption levels after the reunification is consistent with the theoretical prediction contained in Proposition 2 and the lack of differences before the reunification. The latter is demonstrated by the direct information on little changes in wholegrain bread consumption in Panel B and by Table B1, which shows that eggs consumption was comparable between East and West in 1989.

(e) In contrast, in 1991, pie and cookie consumption was a significant 6.7ppt higher in East Germany. Labeling this category of food is somehow ambiguous since the wording of the survey question potentially allows for Familiar as well as for Novel Food. Note that raw sugar consumption, which mostly includes raw sugar for home-baked pie, was 30\% lower in East Germany before the reunification (see Table B1). In addition, pre-1989, the availability of industrial sweets (not baked at home) was certainly significantly higher in capitalist West as compared to East Germany. Accordingly, it seems reasonable to conclude that pie and cookie consumption increased in East Germany after the Fall of the Wall between 1989 and 1991, thereby suggesting that pie and cookies feature habit formation (see Panel A of Figure 3)

(f) The last three columns of Panel B directly elicit general dietary changes by asking respondents whether they (i) changed their diet in general, and (ii) ate more or less food in the last three years. As above, the identified $\beta$ coefficients for these models (equation (8)) can be interpreted as DiD model variants since changes for East Germans are contrasted to changes for West Germans.

Interestingly, and in line with the food category specific findings above, East Germans were much more likely to have changed their diet in the years around the reunification (column (4)): the East German coefficient estimate is 13.3ppt (33\%) and significant at the 1\% level.

Next we test whether East Germans ate quantitatively more or less food, or just different food. Column (5) provides an imprecisely estimated East German coefficient for more food which is, however, large in size (40\%). The less food coefficient is smaller but still of relevant size $(22 \%)$ and marginally significant. 
Overall, these findings suggest that significantly more East Germans changed their diet in the transition phase from life under socialism to capitalism, where some East Germans ate more, and some East Germans ate less as a consequence. Note that this finding is again entirely in line with Prediction 1 and reinforces our novelty consumption theory according to which people's consumption choices change with the arrival of novelty food, but with different time patterns according to individual preferences.

\subsection{2 (How) Did the Dietary Changes Translate into Weight Changes?}

As a next step, we would like to know whether and how the dietary changes triggered by the reunification translated into changes in body mass. Our model in Section 3 suggests ambiguous health effects stemming from changes in diet as a result of novelty consumption. This is because people maximize their individual preference-dependent utility and the pleasure of eating can be in contrast with the corresponding health consequences. Hence, even though utility is maximized, it is not necessarily the case that diet-related health is maximized as well.

Panel C of Table 1 tests first whether, in 1991, East Germans gained and lost weight at a higher rate than their West German counterparts, and whether weight loss intentions differed (columns (1) to (3)). The findings show indeed that, on average, more East Germans not only changed their diet but also gained significantly more weight. The weight gain differential to West Germans is a significant $5.9 \mathrm{ppt}$, or $27 \%$. This is reinforced by a similarly high weight loss intention differential (6.7ppt or $46 \%$ ), which is likewise significant at the $5 \%$ level. The statistical power of our model in column (2) of Panel C is not high enough to definitely say whether a large share of East Germans also lost weight, not just ate significant less food (column (6) of Panel B); however, the coefficient estimate has a positive sign.

Below in further refined analyses, we will link individual quantifies of food consumption, weight gains, and weight loss intentions to specific food categories. The findings show that people who gained weight are indeed those who ate more-in particularly more fat but not more fruits (Figure A2), are overweight and obese, and are planning to lose weight (Figure 6). Analogously, weight losers ate less food-but more wholegrain and fruits (Figure 7), are mostly overweight, and plan to even lose more weight in the future (Figure A3). Interestingly, East German weight gainers were predominantly better educated white-collar men, and East German weight losers were predominantly non-unemployed women.

Columns (4) and (5) of Panel C formally test whether East Germans had a higher BMI and whether more East Germans were obese in 1991. Note that these findings are based on objective clinical height and weight measures which were carried out by professional health care interviewers. Figure 4a plots the entire BMI distribution for East and West Germans; the unconditional picture strongly suggests that less East Germans had normal weight but more were overweight and obese in 1991 and 1992.

\section{[Insert Figure 4 about here]}

Columns (4) and (5) of Panel C provide the results when correcting the BMI distributions for differences in socio-demographics. The findings show that the body masses between East and West Germans were indeed significantly different in 1991. According to column (4), the average 
BMI among East Germans was only slightly, but significantly, higher ( 0.7 index points) than the average BMI for West Germans. However, the obesity rate was a staggering 33\% higher.

Since body mass is determined by the net calorie intake, i.e., the difference between input and output, one potential explanation for higher body mass levels is more calorie intake. Another is less physical activity. We test calorie output differences using the detailed physical activity assessment contained in the GNHSEW91. Respondents had to estimate their weekly time spent for 20 different physical activities (see Section 4.3.1 above). We summed over each category and find that, on average, Germans spent 560 minutes per week (80 minutes per day) on physical activities such as hiking, walking or practicing sports. Interestingly, and maybe contrary to expectations, Figure $4 \mathrm{~b}$ descriptively shows that East Germans were a lot more physically active than West Germans. The right tail of the Weekly Physical Activity distribution for East Germans lies significantly above the one for West Germans. This is confirmed in column (6) of Panel C which shows that the difference amounts to a highly significant 233 minutes per week (33 minutes per day) even after considering socio-demographic differences and differences in the employment structure. Hence higher calorie expenditures can definitely not explain the body mass differential between East and West Germans in 1991. If - ceteris paribus-physical activity levels had been comparable in the two Germanies, the body mass differentials would have been even larger after the reunification.

\subsubsection{Did Dietary Changes and Weight Gain Result in Worse Diet-Related Health?}

Table 2 sheds light on the hypothesis that dietary changes and weight gain are also reflected in worse diet-related health measures. Nutritional science has clearly shown that an unbalanced diet leads to higher blood pressure, higher blood cholesterol, and may eventually result in diabetes (Appel et al., 1997; Trayhurn and Beattie, 2001; Mohn et al., 2005; Buettner et al., 2007). The GNHSEW91 surveyed the objective blood pressure and blood cholesterol levels of the respondents, who were also asked if they were diagnosed with diabetes. The high blood pressure and high cholesterol dummy variables were constructed according to official definitions as explained in Section 4.3.1. Using these three diet-related health measures as dependent variables, Panel A of Table 2 shows the regressions results based on equation (8).

\section{[Insert Table 2 about here]}

Column (1) shows that, in 1991, East Germans were 7ppt. more likely to have a high blood pressure. Related to a population mean of 0.21, this equals an East-West blood pressure gap of $34 \%$. A similarly large percentage point gap is found for high cholesterol, but since the population prevalence of this condition was 0.44 , the East-West gap in percent is 'only' $12 \%$. In contrast, no East-West differential for diabetes can be identified in 1991. Note that diabetes typically develops slowly over time and only breaks out after years of an unbalanced diet (Trayhurn and Beattie, 2001; Kahn et al., 2009).

\subsubsection{Were People Aware of Their Diet-Related Medical Conditions and Was Health Care Ac- cess a Barrier to Knowledge?}

An interesting question we can tackle is whether East and West Germans with unhealthy dietrelated medical conditions were aware of their conditions. This is obviously a crucial first step in 
order to change behavior. One possibility is that awareness among East Germans was lower due to, e.g., institutional barriers and a worse access to the health care system. Another alternative is that they were not aware because their health condition had recently and rapidly worsened.

Concerning the first hypothesis, one can note that the GDR had a surprisingly well integrated health care system with regular check-ups and a high degree of preventive care (Busse and Riesberg, 2004). This is reflected in Figure 5 where we plot the answers given by respondents about their last check-up by a physician or health care worker. Interestingly, and maybe surprisingly, all health care indicators are much better for East Germans: In 1991, it was significantly more likely that East Germans had their blood pressure taken (32\% vs. 22\%, Figure 5a). They were also more likely to had their cholesterol checked ( $49 \%$ vs. $42 \%$ ) and their body weight measured (62\% vs. $54 \%$ ). Lastly, it was also more likely that East Germans had received dietary advice (although this difference is not statistically significant). We conclude that health care system access barriers were not responsible for a possible unawareness about East Germans' health conditions.

\section{[Insert Figure 5 about here]}

The second hypothesis concerns recent changes in the medical condition, which can possibly explain why a person is unaware of her medical condition. Hence, unawareness in the East would be consistent with the notion that East Germans developed their medical condition only recently, potentially as a result of their recent weight gain. Indeed, Panel B of Table 2 clearly shows that, in 1991, the unawareness levels in East Germany were significantly higher. The three dummy outcome variables are 1 if the respondent objectively had a certain medical condition, but subjectively denied that this is the case (see Section 4.3.1). About 7\% of East Germans were not aware of their high blood pressure but only about $3 \%$ of West Germans. This is a huge-highly significantdifferential, particularly in light of the better health care access in the East. As for high cholesterol, the percentage point gap is even 18ppt-the unawareness rate among East Germans was almost $40 \%$ but below $25 \%$ in the West (column (2)). Finally, the obesity unawareness gap between obese East and West Germans was 7ppt as column (3) shows. ${ }^{13}$ It fits nicely that the East-West obesity differential is also 7ppt, and that 6ppt. more East Germans gained weight in the transition phase from socialism to capitalism (Panel C of Table 1).

\subsubsection{Who Changed their Diet, Gained and Lost Weight, and Why?}

Next, we further investigate who changed diet, and gained or lost weight. For this purpose, we run regressions of three outcome variables, change in diet, weight gain, and weight loss, on our rich set of socio-demographics. In addition, we interact several socio-demographics with the East German dummy to assess whether different socio-demographic groups underwent dietary changes in East and West.

Table B3 shows the results and let us conclude the following: (i) Relatively few socio-demographics and (ii) relatively few interaction terms are significantly correlated with the outcome variables of interest. It is the case for EastGerman $\times$ Unemployed, and the direction of the effect may be surprising. A priori one could have guessed that unemployment in East Germany may be one

\footnotetext{
${ }^{13}$ Note that, theoretically, BMI rates above 30 could also be due to an abnormal level of muscular mass, not body fat (Burkhauser and Cawley, 2008). However, even professional bodybuilders rarely have BMIs above 30 (Biggly.com, 2014).
} 
confounding factor for the dietary changes found. However, as the last row of Table B3 demonstrates, unemployed East Germans were significantly less likely to have changed their diet (as were East German singles), and also to lose weight, whereas white collar East Germans predominantly gained weight, not blue collar East Germans. East German females, by contrast, lost weight at a higher rate post reunification.

All other determinants do not differ by East and West: Women in general are more likely to change their diet and also gain weight, whereas older people are slightly less likely to gain weight, maybe due to more solidified eating habits. The main driving forces of both, a change in diet and weight gain, is the educational level; the more years of schooling, the more likely are Germans to change their diet and gain weight. Weight gain is also positively associated with income.

Overall, gender clearly seems to play a role when it comes to dietary changes and weight gains. In addition, the better educated and better off white collar workers were more likely to undergo dietary changes and to gain weight, not the unemployed or blue collar workers.

\section{[Insert Figure 6 about here]}

As a next exercise, we nonparametrically plot the self-reported weight gains and losses in kilograms along with a set of dietary outcome variables. This exercise also serves as a falsification test to see whether people who reported having gained weight are truly those who ate more and changed their diet. It also double checks the potential for measurement errors, under- or overreporting.

Figure 6 nicely shows that weight gain is indeed, almost linearly, associated with (a) the likelihood to report an increase in food consumption, (b) an increase in the body mass index (which crosses the $30 \mathrm{BMI}$ threshold for weight gains of more than 10 kilograms), and (c) a strong increase in the wish to lose weight again. In addition, one (d) fails to find an association with caloric expenditures in the form of minutes of physical activities per week. This is additional strong evidence for the notion that the weight gains resulted from changes in diet, not changes in caloric expenditures. All four finding strongly reinforce the validity of the research design and do not yield evidence for significant measurement issues.

Figure A2 in the Appendix has a similar setup, but the outcome measures are (a) more fat, (b) more meat, (c) more wholegrain, and (d) more fruit consumption. It is easy to observe, intuitively plausible, and reassuring that people who gained weight also consumed more fat and meat, whereas there exists no relationship between weight gain and wholegrain or fruit consumption. It is also easy to observe that the measures of specific food categories become more noisy the larger the weight increase.

\section{[Insert Figure 7 about here]}

Figures 7 and A3 repeat the above exercises with measures of self-reported weight loss. Recall that our theoretical model predicts that after new food products become available and affordable, their consumption increases (see Proposition 1). Deliberately, the model does not make any prediction about the type of novelty consumption, i.e., whether the new food is healthy (such as fruits) or unhealthy (such as sweets or convenience food). This is the reason why the resulting health effects could either be positive or negative, depending on the (change in the) basket of food that is consumed under the existence of novelty food as compared to before. 
Figure A3 reinforces what we found above and shows that people who lost weight also ate (a) less food. Moreover, (b) their average body mass falls into the overweight category, but they are not obese, and (c) they are planning to even lose more weight. Again, as in the weight gain case, there $(d)$ is no relationship between physical activity and weight loss, strongly suggesting that those people indeed lost weight due to a change in diet and because they ate less. The last statement is strongly reinforced by Figure 7 which shows that, in contrast to the weight gainers, weight losers were clearly more likely to eat more whole grain and fruits, but not fat and meat.

Summarizing Figures 6 and 7 (as well as A2 and A3), one can say that our measures capture the expected and intuitive findings, and that measurement errors do not seem to play a significant role here: Weight gainers ate more food, in particular fat and meat, and have higher BMIs, to a large degree above 30. Weight losers ate less food, but more whole grain and fruits, and have lower but still elevated BMIs. Moreover, weight losers are planning to lose even more weight. For both, weight gainers and losers, there exists no relationship with detailed measures of physical activity, strongly suggesting - along with the dietary change findings - that their body mass changed due to a change in caloric input, not output. The finding that increases in obesity rates are a result of increased calorie intake, and not reduced output, is in line with existing research on the US (Cutler and Garber, 2003; Bleich et al., 2008).

\subsubsection{Long-Term Food Consumption Dynamics: Re-Assessment in 1998}

One particular feature of our theoretical model of novelty consumption is the dynamic aspect. When previously unavailable and unaffordable novel products enter the market, thanks to innovations or trade, novelty consumption increases sharply in the short-run. The longer-run dynamics, by contrast, let us infer whether goods feature learning or habit formation in consumption (see Figure 2). In this subsection, we exploit the GNHIES98 and the fact that very similar food consumption pattern were elicited from East and West Germans in 1998 in order to empirically assess the longer-run consumption dynamics and make inferences derived from our dynamic model predictions.

As discussed, a technically different, yet almost identical health survey was in the field in 1998/1999, the GNHIES98 (see Section 4.3.2). For those outcome variables that were surveyed in an identical manner, we can pool the GNHSEW91 and GNHIES98, and formally test changes between 1991 and 1998 within a regression model as in equation (8). Table 3 displays the formal regression results and Figure A4 in the Appendix shows unconditional bar diagrams along with confidence intervals. Table 4 categorizes all specific good categories that we investigate and summarizes the empirical consumption pattern over time. These results are used to infer whether the goods under examination feature habit formation or learning in consumption.

Changes in Weight, BMI, and Diet-Related Health. Figure A4a shows that the weight gain gap between East and West basically closed between 1991 and 1998. In general, more people gained weight, which is consistent with increasing BMI rates over time. However, the East-West differential disappeared in 1998. This is not the case for the other three measures: (b) obesity, (c) high cholesterol, and (d) diabetes. Interestingly, the East-West obesity gap as well as obesity levels remained basically constant over time: the share of obese East Germans only very sightly decreased, despite the higher weight loss intentions among East Germans in 1991 (Panel C of Table 
1). For cholesterol, we observe that levels generally came down a little bit, but the East-West gap remained in 1998 as large it was in 1991 (Figure A4c).

And finally, while diabetes levels were comparable in East and West in 1991, they shot up over time in East Germany between 1991 and 1998 and produced a significant East-West gap. The finding suggests that the higher rates of diet-related medical conditions, as indicated by high cholesterol or high body weight, may have manifested themselves in higher diabetes rates over time. This is consistent with the results presented by the medical literature, and showing that type-II diabetes is a condition that slowly develops over time due to an unhealthy diet (Trayhurn and Beattie, 2001; Kahn et al., 2009).

\section{[Insert Table 3 about here]}

Changes in Food-Specific Consumption Pattern. Panel A of Table 3 shows changes over time for category-specific food consumption. Overall, not many changes are identifiable. In contrast, one could say that the consumption patterns remained remarkably stable between 1991 and 1998 after they changed significantly for some East Germans after the reunification. This implies a strong persistence for almost all goods: no EastGerman $\times 1998$ coefficient is statistically significant, with potatoes being the only notable exception. After potato consumption sharply decreased immediately after the reunification, it increased again between 1991 and 1998. This result suggests that potatoes not only feature habit formation, but also that the intensity of past consumption on current preferences is the largest among the types of food we have considered. Potatoes are the only good whose equilibrium adjustment speed is detectable even after seven years. As shown in Table 4, all other Familiar Food types-meat, eggs, and wholegrain-show no significant changes from before to shortly after the reunification, or from shortly after the reunification to 1998. All described pattern are consistent with Proposition 2.

Panel B of Table 4 summarizes the dynamic consumption pattern for Novel Food. First, the evidence is very clear for fresh fruit: consumption increased sharply in the East after 1989 and remained at a significantly higher level than in West Germany in 1998. This suggests that (i) the long-run equilibrium had not been reached by then, even 9 years after the reunification, and (ii) healthy high-quality exotic Novel Food such as fresh fruits feature habit formation (Proposition 1). Above we have shown that fresh fruits are particularly consumed by weight losers and that East German weight losers were primarily working women.

In contrast, consumption of a presumably less healthy Novel Food category, Pies and Cookies followed a very similar pattern. It increased in the East after 1989 and remained at a significantly higher level in 1998, which is again consistent with a habit formation and persistent patterns of consumption over time.

Lastly, consumption of the food category 'convenience food' was only elicited in 1998 in the GNHIES98. Processed convenience food-pre-prepared food for home consumption that only needs to be warmed up-was not available in the GDR. But it was available in the West and also marketed in Western television. According to survey data, western households spent $€ 50$ per capita and month on it in 1983-a value that increased to $€ 80$ in 1993 (Gedrich and Albrecht, 2003). According to the GNHIES98, in 1998, 13\% of West Germans consumed processed food once a week but $16 \%$ of East Germans. This differential remains stable, even increases slightly, when considering socio-demographics in the regression framework in column (6) of Panel A. The 4ppt 
differential is highly significant at the $1 \%$ level. Hence we can infer that, among East Germans, convenience food consumption must have sharply increased after the reunification and was still higher than in West Germany in 1998.

To sum up, it is fascinating to see that all Novel Food products whose dynamic consumption pattern we can elicit follow the same pattern, which corroborates our Theory of Novelty Consumption. When economic development makes new products available and affordable to the masses, consumption goes up in the short-run. For the categories that we can empirically study, consumption levels were still higher 9 years after the unexpected transition to capitalism, suggesting that previous consumption experience-as theoretically modeled in Section 3-has a long lasting impact. In our particular cases, all types of food suggest habit formation in consumption. However, as a cautionary note, this may not be generalizable as the type of surveyed food may be endogenous. In surveys like ours, that are explicitly designed to elicit and compare East-West consumption patterns, popular food categories are more likely to be surveyed. Many new products are introduced in the market every year, and the less popular ones may have disappeared.

Finally, it is also interesting to observe that basic staple food such as eggs, wholegrain products and meat obviously do not underlie significant consumption swings over just a decade, even when the surrounding economic environment changes significantly. In contrast, unprocessed potato consumption sharply decreased, overreacted in the short-run, and then rebounded to the western equilibrium. For Germans, potatoes are the main daily staple food. One possible explanation is that, in the short-run, unprocessed potato consumption was substituted by novel consumption opportunities, e.g. by potato-based processed western convenience food. Subsequently, this pattern reversed and eastern potato consumption converged to western consumption levels.

\subsubsection{The Long-Run BMI Impact of East-West Socialization: Exploiting Migration Patterns}

As a very last step, we exploit the Microcensus 2005, which is a representative and compulsory cross-sectional survey of $1 \%$ of the German population (see Section 4.3.3). The dependent variables used in this last model are the continuous BMI, an overweight dummy and an obesity dummy.

In addition to the large and representative number of observations, and the opportunity to study potential long-term effects 16 years after the fall of the Wall, we exploit a unique additional feature of the Microcensus: The Microcensus 2005 elicits in a remarkably precise manner the educational degrees of the respondents, and it is clearly identifiable whether the degrees were earned in the GDR or the FRG prior to 1990. This allows us to not only identify the respondents' current residency status, but also respondents who were socialized and educated in the GDR and who then migrated to West Germany where they currently live (see also Section 4.3.3 and Table B5 for details).

\section{[Insert Table 5 and Figure 8 about here]}

Figure 8 plots BMI distributions by East-West socialization and migration pattern. The BMI distribution that is most shifted to the left is the one for respondents living in West Germany without a GDR degree, i.e., people socialized under capitalism. The next BMI distribution, from left to right, falls upon those who were socialized in the GDR but live in West Germany. Note that these 
migrants are younger, better educated, healthier, and obviously more mobile than East Germans who stayed in East Germany despite higher unemployment rates. Still, their BMI distributions seem to differ from those of 'native' West Germans. Finally, the BMI distribution that is the most rightward shifted stems from people living in the GDR and who were also socialized in the GDR.

Table 5 yields the regression equivalents for the three outcome measures BMI, overweight, and obesity. The model is similar to the one in equation (8) but includes an additional dummy Educational degree of GDR and its interaction with Living in East Germany. The socio-demographic control variables can be found in Table B5. The constant yields the baseline body mass levels for people living in West Germany without GDR degree and with zeros on their covariates (single, not unemployed, etc.).

Adding the Living in East Germany coefficient provides results for people who currently live in East Germany but did not obtain a GDR degree, which could be due to several reasons linked to, e.g., age or migration to East Germany. The most saturated specifications in columns (3), (6), and (9) show that this coefficient is highly significant at the $1 \%$ level for all models. This sociodemographic group has a BMI that is 0.27 index points higher; they are $5 \%$ more likely to be overweight and 17\% more likely to be obese as compared to West Germans in West Germany.

Next, the plain Educational degree of GDR coefficient identifies people who were definitely socialized in the GDR and earned their educational degree there. However, sometime between 1989 and 2005, most likely in the 1990s, they migrated to West Germany and still live there. The stunning finding shows that, although this is a positively selected group-in the sense that they are younger, healthier and better educated-their body mass significantly lies above the body mass of West Germans who were socialized under capitalism. The BMI is 0.34 index points higher and they are $8.5 \%$ more likely to be overweight and an imprecisely estimated $7 \%$ more likely to be obese.

Finally, adding up both coefficients, Living in East Germany and Educational degree of GDR, and also adding their interaction, yields the body mass for people who were educated in the GDR and still live in East Germany. Their body mass is by far the highest, which is likely due to a combination of socialization and selection effects, and the impact of the transition and adjustment from socialism to capitalism over 16 years.

\section{Discussion and Conclusion}

This work builds upon and merges rich strands of recent economic research that intend to carve out explanatory factors for the strong increase in obesity rates in all industrialized countries. One main strand of research exploits narrow, but causally very cleanly identified, impact factors such as an increased density of fast-food restaurants, larger portion sizes, or changes in gasoline prices. The cleanly identified contributions of these single specific factors to the overall rise in body weight are typically very small. Another strand of research does not cleanly identify causal effects in a reduced form manner, but it exploits aggregated data and correlations to argue that technological change is a main driving force of the increases in body weight in the industrialized world.

This paper bridges both approaches and investigates how the availability of novel food products changes dietary consumption, body weight and may lead to worse diet-related health. To 
test our theory of novelty consumption, we exploit a historical event that allows us to study economic development-typically evolving over decades-in fast motion of just several months: In 1989, the Berlin Wall unexpectedly and suddenly fell, and East and West Germany were peacefully reunited. The communist regime in the East collapsed and East Germany became a capitalist economy, obtaining access to international markets and free trade. Under socialism, trade opportunities were limited to trade with socialist countries, mostly the USSR and Cuba. Consequently, food choices were limited as well. As a result of the reunification, formerly unavailable western food products became available over night to East Germans.

In the first part of the paper we propose a theoretical model where consumers' preferences depend on past consumption experiences. This allows to explicitly consider the stylized fact that, as a consequence of the reunification, Eastern Germans could suddenly access a variety of goods without former consumption experience. We denote such goods as 'novel goods', and we make predictions about consumers' novelty consumption, both at time of the reunification and in subsequent years when the novelty effect progressively fades away. We also show that, despite the fact that consumers know and take into consideration the health consequences of their consumption choices, diet-related health can deteriorate as a result of novelty consumption.

In the empirical part of the paper, we exploit three different datasets that are representative for East and West Germany. The data include unique and rich self-reported dietary information, information on dietary changes, as well as objective diet-related health measures that are associated with an unbalanced diet such as the body mass index, blood pressure, or blood cholesterol. Our empirical findings can be summarized as follows:

First, in the transition period from limited food choice under communism to unlimited food choice under capitalism, East Germans were significantly more likely to change their diet as compared to West Germans. Some East Germans ate healthier and lost weight, but the majority of them gained weight. Weight gainers were not the unemployed or blue collar workers but employed male white collar workers and the better off. East German females were more likely to take advantage of the healthy consumption opportunities offered by the reunification. While weight gainers increased fat and meat consumption, weight losers were more likely to increase their fruit and wholegrain consumption. We also show that physical activity and food expenditures play no relevant confounding role.

Second, digging deeper and assessing how the consumption of different food categories changed, one finds the model predictions confirmed: The consumption of previously unavailable and unaffordable Novel Food such as newly available exotic high-quality food (e.g., exotic fruits) or western processed food (e.g. convenience food) increased significantly, whereas the consumption of cheap and always available Familiar Food, like nonprocessed potatoes, declined. Meat, egg, and wholegrain consumption remained remarkably stable over time.

Third, on average, East Germans gained weight. We find that their obesity rates and BMI levels lay significantly above those of West Germans in 1991. The body mass differential persisted until 1998, despite the higher rate of weight loss intentions in the East in 1991, which underscores the importance of self-control issues. By exploiting the representative Microcensus data that allow us to disentangle potential selection effects due to East-West migration, we show that the East-West BMI gap persisted at least until 2005 and that even the positively selected group of East Germans 
who migrated to West Germany were more likely to be overweight than West Germans. This effect is still sizable 16 years after the reunification.

Fourth, all types of food that we study feature habit formation rather than learning in consumption. Consumption of Familiar Food, such as potatoes, was higher in the East before the reunification. It decreased sharply after the Wall fell when new consumption opportunities appeared. After that, potato consumption increased again and converged to western levels nine years after the reunification. Exotic fruits and convenience food were both unavailable under socialism. They represent two distinct subcategories of Novel Food: (a) presumably healthy highquality exotic food, and (b) presumably less healthy processed engineered food. Both Novel Food types become available to the masses because of economic development in the form of trade and technological innovation. We find that consumption of both, exotic fruits and convenience food, sharply increased after the reunification and was still higher in the East in 1998 as compared to the West. Our model implies that all food categories investigated feature habit formation. In addition, the long-term impact of past consumption experiences is illustrated since we can identify persistent consumption differences many years after the rapid transition to an open market economy. Other papers come to similar conclusion with respect to values and conspicuous consumption (Alesina and Fuchs-Schündeln, 2007; Friehe and Mechtel, 2014).

Finally, the dietary changes and weight gains are also reflected in worse diet-related medical conditions among East Germans. Already in 1991, objective health data show that East Germans had higher blood cholesterol levels and a higher blood pressure-two medical conditions that are clearly associated with an unbalanced diet. Interestingly, although Germans had better health care access and more regular medical check-ups than West Germans, they showed significantly higher rates of unawareness about their medical conditions as well as their obesity levels in 1991. This is consistent with the idea that they developed these conditions only recently, when they passed from a socialist regime with very limited consumption opportunities to a capitalist economy with free trade and larger consumption opportunities.

Although we cannot nail single impact factors during the huge transition phase to capitalism, our study illustrates in a remarkably precise way how food consumption and body mass changes when a country undergoes economic development due to technological advances. Even though consumer welfare increases with more consumption opportunities, this may not be necessarily the case for population health. Depending on consumer preferences, some population subgroup's health may decrease while others may increase. This is exactly what we find. An important related topic of inquiry would be to study how such health and body mass changes affect sociodemographic inequality and segregation.

\section{References}

Abel, A. B. (1990). Asset prices under habit formation and catching up with the Joneses. The American Economic Review, 38-42.

Acemoglu, D. (2010). When does labor scarcity encourage innovation? Journal of Political Economy 118(6), $1037-1078$.

Acemoglu, D., U. Akcigit, and M. A. Celik (2014). Young, restless and creative: Openness to disruption and creative innovations. Technical report, NBER Working Paper 19894.

Acemoglu, D., K. Bimpikis, and A. Ozdaglar (2011). Experimentation, patents, and innovation. American Economic Journal: Microeconomics 3(1), 37-77. 
Acemoglu, D. and S. Johnson (2007). Disease and development: The effect of life expectancy on economic growth. Journal of Political Economy 115(6), 925-985.

Alesina, A. and N. Fuchs-Schündeln (2007). Good bye lenin (or not?): The effect of communism on people's preferences. American Economic Review 97(4), 1507-1528.

American Heart Association (2001). American Heart Association To Your Health! A Guide to HeartSmart Living. Clarkson Potter.

American Heart Association (2014). Understanding blood pressure readings. http://www . heart. org, last accessed on November 11, 2014.

Anderson, M. L. and D. A. Matsa (2011). Are restaurants really supersizing America? American Economic Journal: Applied Economics 3(1), 152-88.

Appel, L. J., T. J. Moore, E. Obarzanek, W. M. Vollmer, L. P. Svetkey, F. M. Sacks, G. A. Bray, T. M. Vogt, J. A. Cutler, M. M. Windhauser, P.-H. Lin, N. Karanja, D. Simons-Morton, M. McCullough, J. Swain, P. Steele, M. A. Evans, E. R. Miller, and D. W. Harsha (1997). A clinical trial of the effects of dietary patterns on blood pressure. New England Journal of Medicine 336(16), 1117-1124.

Becker, G. S. and K. M. Murphy (1988). A theory of rational addiction. Journal of Political Economy 96(4), 675-700.

Bethlehem, S. (1999). Heimatvertreibung, DDR-Flucht, Gastarbeiterzuwanderung. Klett-Cotta, Stuttgart.

Biggly.com (2014). Bodybuilder's body mass index. http: / /www . biggly . com/bmi . html, last accessed on November 11, 2014.

Blatt, B. (2014). "Unacceptable Ingredients:" How many of the groceries sold at Walmart would be banned by Whole Foods? Slate magazine. http://www.slate.com/articles/life/ culturebox/2014/02/whole_foods_and_walmart_how_many_groceries_sold_ at_walmart_would_be_banned.htmī, last accessed at September 28, 2014.

Bleich, S. N., D. Cutler, C. Murray, and A. Adams (2008). Why is the developed world obese? Annual Review of Public Health 29(1), 273-295.

Bochniak, M. (2009). Katalog der Hausbrandkarten DDR 1950 - 1990. International Journal of Rationing 1(2), 43-63.

Böhme, H. (1971). Gebrauchswert und Preispolitik im sozialistischen Wirtschaftssystem. Weltwirtschaftliches Archiv (Review of World Economics) 106(1), 78-127.

Bornkessel, S., S. Bröring, and O. S. Omta (2014). Analysing industry convergence in probiotics. mimeo. http://www.berenschot.nl/publish/pages/2174/analysing_industry_ convergence_in_probiotics_-_bornkessel_broring_omta.docx., last accessed at September 28, 2014 .

Brinkworth, G., M. Noakes, J. Buckley, and P. Clifton (2006). Weight loss improves heart rate recovery in overweight and obese men with features of the metabolic syndrome. American Heart Journal 152(4), 693.e1-693.e6.

Brosig-Koch, J., C. Helbach, A. Ockenfels, and J. Weimann (2011). Still different after all these years: Solidarity behavior in East and West Germany. Journal of Public Economics 95(11), 1373 1376.

Browning, M. and E. Heinesen (2012). Effect of job loss due to plant closure on mortality and hospitalization. Journal of Health Economics 31(4), 599-616.

Buettner, R., J. Schälmerich, and L. C. Bollheimer (2007). High-fat diets: Modeling the metabolic disorders of human obesity in rodents. Obesity 15(4), 798-808.

Burchardi, K. B. and T. A. Hassan (2013). The economic impact of social ties: Evidence from German reunification. Quarterly Journal of Economics 128(3), 1219-1271.

Burda, M. C. (2006). Factor reallocation in eastern Germany after reunification. American Economic Review 96(2), 368-374. 
Burkhauser, R. V. and J. Cawley (2008). Beyond BMI: The value of more accurate measures of fatness and obesity in social science research. Journal of Health Economics 27(2), 519-529.

Bursztyn, L.; Cantoni, D. (2015). A tear in the iron curtain: The impact of Western television on consumption behavior. Review of Economics and Statistics. forthcoming.

Busse, R. and A. Riesberg (2004). Health care systems in transition: Germany. WHO Regional Office for Europe on behalf of the European Observatory on Health Systems and Policies.

Carroll, C. D. (2000). Solving consumption models with multiplicative habits. Economics Letters $68(1), 67-77$.

Cawley, J. (2004). The impact of obesity on wages. Journal of Human Resources 39(2), 451-474.

Cawley, J., D. Frisvold, and C. Meyerhoefer (2013). The impact of physical education on obesity among elementary school children. Journal of Health Economics 32(4), 743 - 755.

Cawley, J. and C. Meyerhoefer (2012). The medical care costs of obesity: An instrumental variables approach. Journal of Health Economics 31(1), 219-230.

Cawley, J., J. A. Rizzo, and K. Haas (2007). Occupation-specific absenteeism costs associated with obesity and morbid obesity. Journal of Occupational E Environmental Medicine: 49(12), 1317-1324.

CIA World Factbook (1990). German Democratic Republic - 1990. http: / /www . theodora.com/ wfb/1990/index.html, last accessed on December 4, 2013.

Classora Knowledge Base (2014). Ranking of the World's Richest Countries by GDP (1990). http: //en.classora.com, last accessed on December 4, 2013.

Congressional Research Service (2013). Consumers and food price inflation. Crs report for congress. http://fas.org/sgp/crs/misc/R40545.pdf, last accessed on November 15, 2014.

Courtemanche, C. (2009). Rising cigarette prices and rising obesity: Coincidence or unintended consequence? Journal of Health Economics 28(4), 781-798.

Courtemanche, C. (2011). A silver lining? The connection between gasoline prices and obesity. Economic Inquiry 49(3), 935-957.

Courtemanche, C., G. Heutel, and P. McAlvanah (2015). Impatience, incentives and obesity. The Economic Journal 125(582), 1-31.

Curran, C.-S., S. Bröring, and J. Leker (2010). Anticipating converging industries using publicly available data. Technological Forecasting and Social Change 77(3), 385 - 395.

Currie, J., S. DellaVigna, E. Moretti, and V. Pathania (2010). The effect of fast food restaurants on obesity and weight gain. American Economic Journal: Economic Policy 2(3), 32-63.

Cutler, D., E. Glaeser, and J. Shapiro (2003). Why have Americans become more obese? Journal of Economic Perspectives 17(3), 93-118.

Cutler, D. M. and A. M. Garber (2003). Employee costs and the decline in health insurance coverage. Frontiers in Health Policy Research 6(3), 27-53.

Dodgson, M., D. M. Gann, and N. Phillips (2014). The Oxford Handbook of Innovation Management (1 ed.). Oxford University Press. Oxford Handbooks.

Dubois, P., R. Griffith, and A. Nevo (2014). Do prices and attributes explain international differences in food purchases? American Economic Review 104(3), 832-67.

Fishman, C. (2006). The Wal-Mart Effect: How the World's Most Powerful Company Really Works-and How It's Transforming the American Economy (Reprint edition ed.). Penguin Books (Bern).

Fletcher, J. M., D. E. Frisvold, and N. Tefft (2010). The effects of soft drink taxes on child and adolescent consumption and weight outcomes. Journal of Public Economics 94(11-12), 967 - 974. 
Fontaine, K. R., D. T. Redden, C. Wang, A. O. Westfall, and D. B. Allison (2003). Years of life lost due to obesity. JAMA 289(2), 187-193.

Food Marketing Institute (2014a). Food Marketing Industry Speaks, Food Retailing Industry Speaks reports, various years. made available by email request on November 11, 2014.

Food Marketing Institute (2014b). Supermarket Facts: Industry Overview 2013. http://www.fmi.org/research-resources/supermarket-facts, lastaccessedat November28,2014.

Friehe, T. and M. Mechtel (2014). Conspicuous consumption and political regimes: Evidence from East and West Germany. European Economic Review 67(C), 62-81.

Frijters, P., J. P. Haisken-DeNew, and M. A. Shields (2004a). Investigating the patterns and determinants of life satisfaction in Germany following reunification. Journal of Human Resources 39(3), 649-674.

Frijters, P., J. P. Haisken-DeNew, and M. A. Shields (2004b). Money does matter! Evidence from increasing real income and life satisfaction in East Germany following reunification. American Economic Review 94(3), 730-740.

Frijters, P., J. P. Haisken-DeNew, and M. A. Shields (2005). The causal effect of income on health: Evidence from German reunification. Journal of Health Economics 24(5), 997-1017.

Fuchs-Schündeln, N. (2008). The response of household saving to the large shock of German reunification. American Economic Review 98(5), 1798-1828.

Fuchs-Schündeln, N. and M. Schündeln (2005). Precautionary savings and self-selection: Evidence from the German reunification experiment. Quarterly Journal of Economics 120(3), 1085-1120.

Ganter, T. M. (2008). Searching for a New German Identity (1 ed.). Peter Lang (Bern). East German Studies/DDR Studien.

Gedrich, K. and M. Albrecht (2003). Datenrecherche der Entwicklung der Haushaltsausgaben für Ernährung in der zweiten Hälfte des 20. Jahrhunderts. Materialienband Nr. 3, Technische Univ. München, Lehrstuhl fr Wirtschaftslehre des Haushalts. Www . ernaehrungswende. de/pdf / MB 320TUM_final.pdf, last accessed at February 9, 2014.

Grabka, M. M. (2000). Einkommensverteilung in Deutschland: stärkere Umverteilungseffekte in Ostdeutschland. DIW Wochenbericht 67(19), 291-297.

Grossman, M. (1972). On the concept of health capital and the demand for health. Journal of Political Economy 80(2), 223-55.

Grossman, M., E. Tekin, and R. Wada (2014). Food prices and body fatness among youths. Economics \& Human Biology 12(C), 4-19.

Heineck, G.; Süssmuth, B. (2013). A different look at Lenin's legacy: Social capital and risk taking in the two Germanies. Journal of Comparative Economics 41(3), 789-803.

Henson, C. (2008). The real price of Atlantic salmon. Sustainable Development Law \& Policy 9, 12.

Hertle, H.-H.; Nooke, M. (2009). Die Todesopfer an der Berliner Mauer 1961-1989. Ein biographisches Handbuch (1 ed.). Ch. Links, Berlin.

Hsieh, M.-F., P. D. Mitchell, and K. W. Stiegert (2009). Potato demand in an increasingly organic marketplace. Agribusiness 25(3), 369-394.

Hunt, J. (2009). Staunching emigration from East Germany: Age and the determinants of migration. Journal of the European Economic Association 4(5), 1014-1037.

Jeitschko, T. D. and R. A. Pecchenino (2006). Do you want fries with that? An exploration of serving size, social welfare, and our waistlines. Economic Inquiry 44(3), 442-450.

Kahn, S. E., R. L. Hull, and K. M. Utzschneider (2009). Mechanisms linking obesity to insulin resistance and type 2 diabetes. Nature 444(7121), 840-846. 
Kesternich, I., B. Siflinger, J. P. Smith, and J. K. Winter (2014). The effects of World War II on economic and health outcomes across europe. The Review of Economics and Statistics 96(1), 103118.

Kesternich, I., B. Siflinger, J. P. Smith, and J. K. Winter (2015). Individual behavior as a pathway between early-life shocks and adult health: Evidence from hunger episodes in post-war germany. The Economic Journal. forthcoming.

Lakdawalla, D. and T. Philipson (2009). The growth of obesity and technological change. Economics and Human Biology 7(3), 283-293.

Lakdawalla, D., T. Philipson, and J. Bhattacharya (2005). Welfare-enhancing technological change and the growth of obesity. American Economic Review 95(2), 253-257.

Lindeboom, M., F. Portrait, and G. J. van den Berg (2010). Long-run effects on longevity of a nutritional shock early in life: The Dutch potato famine of 1846-1847. Journal of Health Economics 29(5), 617-629.

Maecker, R. (2013). Preise in der DDR: Warengruppe Lebensmittel (35). http://www . aus-der-ddr.de/preise/lebensmittel.html, lastaccessedatNovember28, 2013.

Marcus, J. (2013). The effect of unemployment on the mental health of spouses-evidence from plant closures in Germany. Journal of Health Economics 32(3), 546-558.

Mee, C. L. (1977). Die Teilung der Beute: Die Potsdamer Konferenz 1945. Fritz Molden, Muenchen.

Mohn, A., M. Catino, R. Capanna, C. Giannini, M. Marcovecchio, and F. Chiarelli (2005). Increased oxidative stress in prepubertal severely obese children: Effect of a dietary restriction-weight loss program. The Journal of Clinical Endocrinology E Metabolism 90(5), 2653-2658.

Nagashima, J., H. Musha, H. Takada, K. Takagi, T. Mita, T. Mochida, T. Yoshihisa, Y. Imagawa, N. Matsumoto, N. Ishige, R. Fujimaki, H. Nakajima, and M. Murayama (2010). Three-month exercise and weight loss program improves heart rate recovery in obese persons along with cardiopulmonary function. Journal of Cardiology 56(1), 79-84.

National Heart, Lung, and Blood Institute (1998). Clinical guidelines on the identification, evaluation, and treatment of overweight and obesity in adults: The evidence report. www.ncbi . nlm.nih.gov/books/n/obesity/pdf/, last accessed on November 7, 2014.

Niinikoski, H., J. Viikari, T. Rönnemaa, H. Lapinleimu, E. Jokinen, P. Salo, R. Seppänen, A. Leino, J. Tuominen, I. Välimäki, and O. Simell (1996). Prospective randomized trial of low-saturatedfat, low-cholesterol diet during the first 3 years of life: The strip baby project. Circulation 94(6), 1386-1393.

Ogden, C., M. D. Carroll, B. K. Kit, and K. Flegal (2014). Prevalence of childhood and adult obesity in the United States, 2011-2012. JAMA 311(8), 806-814.

Overland, J., C. D. Carroll, and D. N. Weil (2000). Saving and growth with habit formation. American Economic Review 90(3), 341-355.

Pasanisi, F., F. Contaldo, G. de Simone, and M. Mancini (2001). Benefits of sustained moderate weight loss in obesity. Nutrition, metabolism, and cardiovascular diseases : NMCD 12(6), 401-406.

Patent, K. (2013). The difficult relationship between East and West Germans: Examples from ethnological field research. In J. Barkhoff and H. Eberhart (Eds.), Networking across boarders and frontiers, Grazer Beiträge zur Europäischen Ethnologie, pp. 141-150. Peter Lang, Frankfurt.

Philipson, T. J. and R. A. Posner (1999). The long-run growth in obesity as a function of technological change. NBER Working Papers 7423.

Puhl, R. M. and C. A. Heuer (2009). The stigma of obesity: A review and update. Obesity 17(5), 941-964.

Rainer, H.; Siedler, T. (2013). Does democracy foster trust? Journal of Comparative Economics 37(2), 251-269. 
Robert Koch Institut (2012a). German National Health Interview and Examination Survey 1998 (GNHIES98), Public Use File. Robert Koch Institut. http://www.rki.de/EN/Content/ Health_Monitoring/HealthSurveys/GNHIES98/GNHIES98_node.html, last accessed on November 11, 2013.

Robert Koch Institut (2012b). German National Health Survey East-West 1991 (GNHSEW91), Public Use File OW91. Robert Koch Institut. http://www.rki.de/DE/Content/ Gesundheitsmonitoring/PublicUseFiles/informationen_datensaetze/info_ datensaetze_node.html, last accessed on November 11, 2013.

Ruhm, C. J. (2012). Understanding overeating and obesity. Journal of Health economics 31(6), 781796.

Ryder, Harl E, J. and G. M. Heal (1973). Optimum growth with intertemporally dependent preferences. Review of Economic Studies 40(1), 1-33.

Sarma, S., G. S. Zaric, M. K. Campbell, and J. Gilliland (2014). The effect of physical activity on adult obesity: Evidence from the Canadian NPHS panel. Economics \& Human Biology, Elsevier 14(C), 1-21.

Sassi, F. (2010). Obesity and the Economics of Prevention: Fit not Fat. OECD Publishing.

Scholte, R., G. J. van den Berg, M. Lindeboom, and D. J. H. Deeg (2014). Does the size of the effect of adverse events at high ages on daily-life physical functioning depend on the economic conditions around birth? IZA Discussion Papers 8075.

Schwarzer, O. (1999). Sozialistische Zentralplanwirtschaft in der SBZ/DDR. Ergebnisse eines ordnungspolitischen Experiments (1945 - 1989) (1 ed.). Franz Steiner Verlag.

Sinn, H.-W. (2002). Germany's economic unification: An assessment after ten years. Review of International Economics 10(1), 113-128.

Stigler, G. J. and G. S. Becker (1977). De gustibus non est disputandum. The American Economic Review, 76-90.

Strulik, H. (2014). A mass phenomenon: The social evolution of obesity. Journal of Health economics 33, 113-125.

Sullivan, D. and T. von Wachter (2009). Job displacement and mortality: An analysis using administrative data. The Quarterly Journal of Economics 124(3), 1265-1306.

Surwit, R. S., C. M. Kuhn, C. Cochrane, J. A. McCubbin, and M. N. Feinglos (1988). Diet-induced type II diabetes in C57BL/6J mice. Diabetes 37(9), 1163-1167.

Trayhurn, P. and J. H. Beattie $(2001,8)$. Physiological role of adipose tissue: White adipose tissue as an endocrine and secretory organ. Proceedings of the Nutrition Society 60, 329-339.

Uhlig, H. (2006). Regional labor markets, network externalities and migration: The case of German reunification. American Economic Review 96(2), 383-387.

United States Census Bureau (1980). Money income in 1978 of households in the United States. Current population reports. www2. census.gov/prod2/popscan/p60-121.pdf, last accessed on November 15, 2014.

United States Census Bureau (2014). Income and poverty in the United States: 2013. Current population reports. http://www. census.gov/content/dam/Census/library/ publications/2014/demo/p60-249.pdf, last accessed on November 15, 2014.

United States Department of Agriculture (USDA) (2014). ERS Food Availability (Per Capita) Data System (FADS). http: //www.ers.usda.gov/data-products/food-availability-o 28per-capita\%29-data-system/. aspx, last accessed on October 4, 2014.

US Food and Drug Administration (2014). An overview of Atlantic salmon, its natural history, aquaculture, and genetic engineering. Veterinary Medicine Advisory Committee. http://www. fda.gov/AdvisoryCommittees/CommitteesMeetingMaterials/ VeterinaryMedicineAdvisoryCommittee/ucm222635.htm, last accessed on October 4, 2014. 
van den Berg, G. J., M. Lindeboom, and F. Portrait (2006). Economic conditions early in life and individual mortality. American Economic Review 96(1), 290-302.

van den Berg, G. J., P. Pinger, and J. Schoch (2015). Instrumental variable estimation of the causal effect of hunger early in life on health later in life. The Economic Journal. forthcoming.

Wagner, G. G., J. R. Frick, and J. Schupp (2007). The German Socio-Economic Panel Study (SOEP): Scope, evolution, and enhancements. Journal of Applied Social Science Studies (Schmollers Jahrbuch: Zeitschrift für Wirtschafts- und Sozialwissenschaften) 127(1), 139-169.

Wagner, G. G. and N. R. Ziebarth (2014). The shaping of attitudes toward doping: Evidence from divided Germany. mimeo. http://www.human. cornell.edu/pam/people/nicolas_ ziebarth. cfm, last accessed on January 29, 2015.

Woll, E. (2012). Wer Schreibt, Der Bleibt: Erinnerungen ab der 1930er Jahre (1 ed.). Norderstedt Books.

World Health Organization (2015). Fact sheet 311: Obesity and overweight. Technical report. http://www.who.int/mediacentre/factsheets/fs311/en/ (accessed28 January2015).

World Intellectual Property Organization (WIPO) (2014). WIPO IP Statistics Data Center. http: //ipstats.wipo.int/ipstatv2/index.htm, last accessed on October 4, 2014.

Zentralverwaltung für Statistik der DDR (1988). Statistisches Jahrbuch der Deutschen Demokratischen Republik - 1987 (1 ed.). Staatsverlag der Deutschen Demokratischen Republik.

Zentralverwaltung für Statistik der DDR (1990). Statistisches Jahrbuch der Deutschen Demokratischen Republik - 1990 (1 ed.). Staatsverlag der Deutschen Demokratischen Republik.

Zentralverwaltung für Statistik der DDR (1991). Statistisches Jahrbuch der Deutschen Demokratischen Republik - 1991 (1 ed.). Staatsverlag der Deutschen Demokratischen Republik.

Figure 1: Development of obesity rates in OECD countries

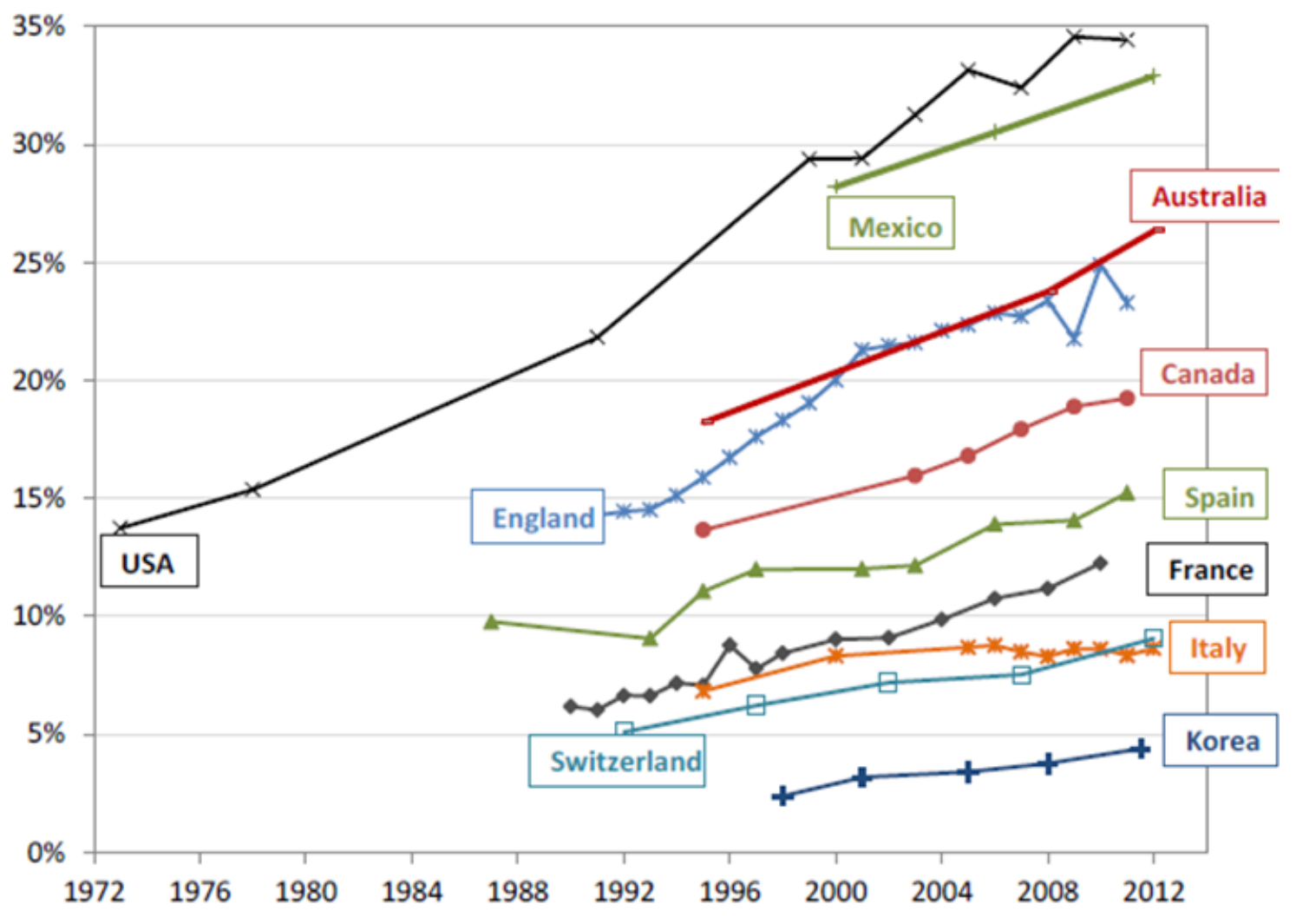

Source: OECD, 2014 
Figure 2: Time Paths of Novelty Consumption before and after the Reunification

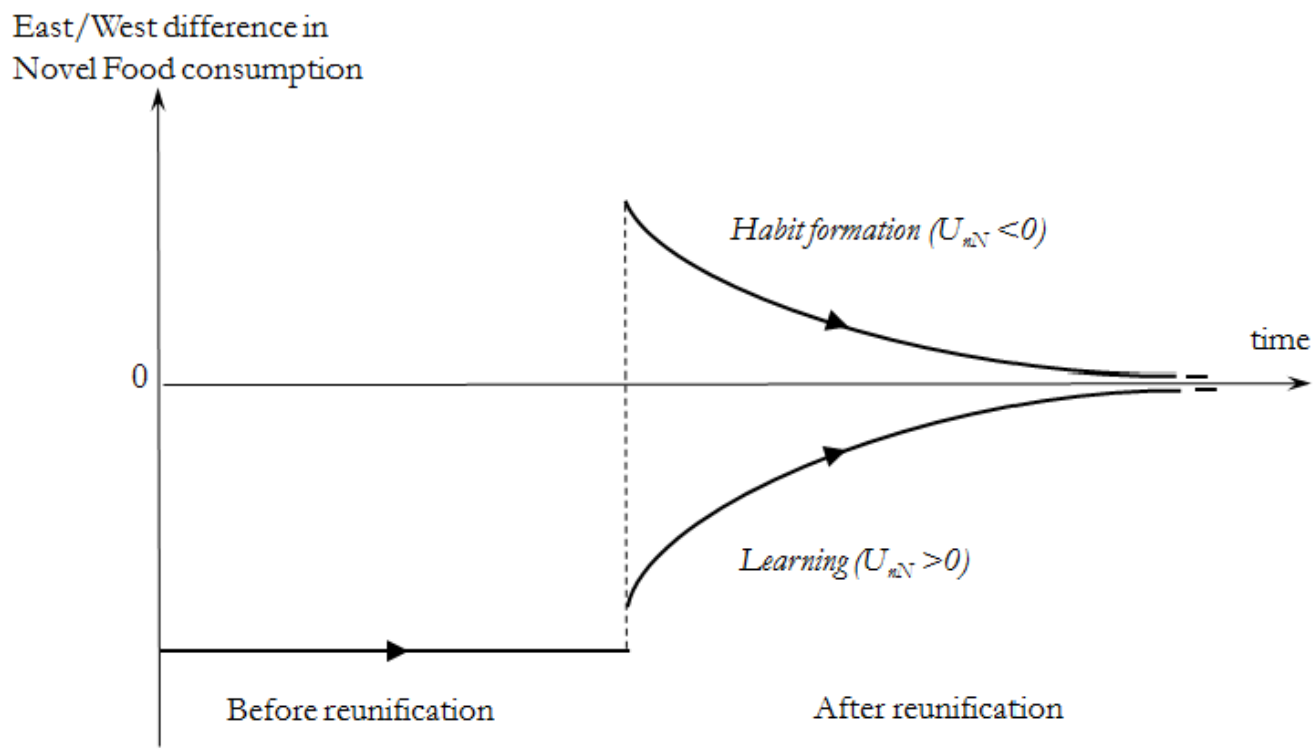

Note: The Figure represents the differences in Novel Food consumption between East and West Germans at each point in time. In East Germany, novelty consumption is zero before the reunification and it sharply increases after the reunification. The adjustment path to the equilibrium is increasing if Novel Food features learning $\left(U_{n N}>0\right)$. It is decreasing in case of habit formation $\left(U_{n N}<0\right)$. The speed of adjustment depends on individual characteristics, income and market prices. 


\section{Figure 3: Time Paths of Familiar Food Consumption before and after the Reunification}
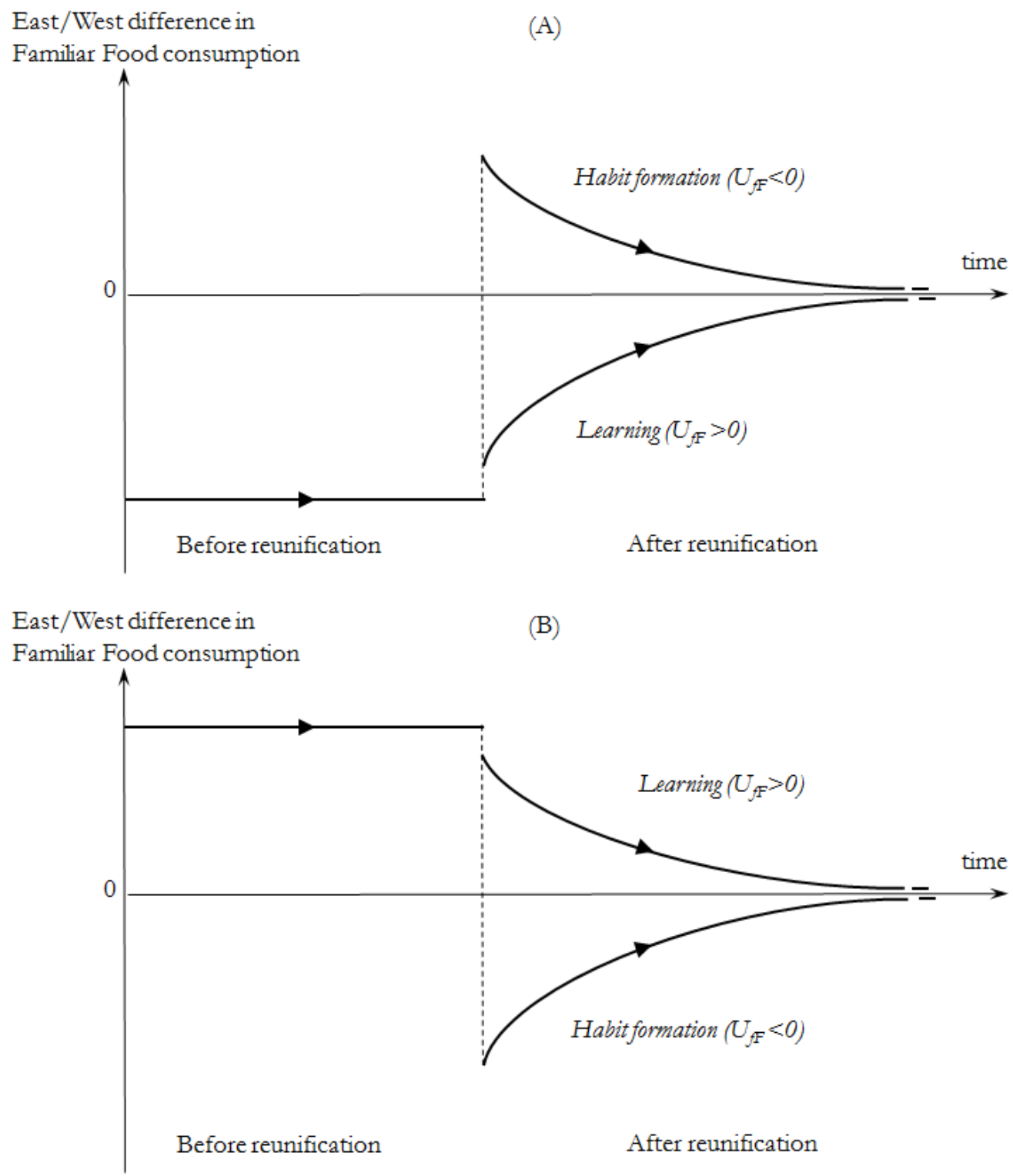

Note: The Figure represents the differences in Familiar Food consumption between East and West Germans at each point in time. Panel A represents the case in which, before the reunification, Familiar Food consumption is lower in East than in West Germany. Panel B represents the opposite case, in which Familiar Food consumption is higher in the East before the reunification. Empirically observing consumption differences before and after the reunification allows to infer whether Familiar Food is habit forming or features learning. 
Figure 4: Distributions (1991/1992) of (a) BMI from Objective Height and Weight Data, (b) Minutes of Physical Activity
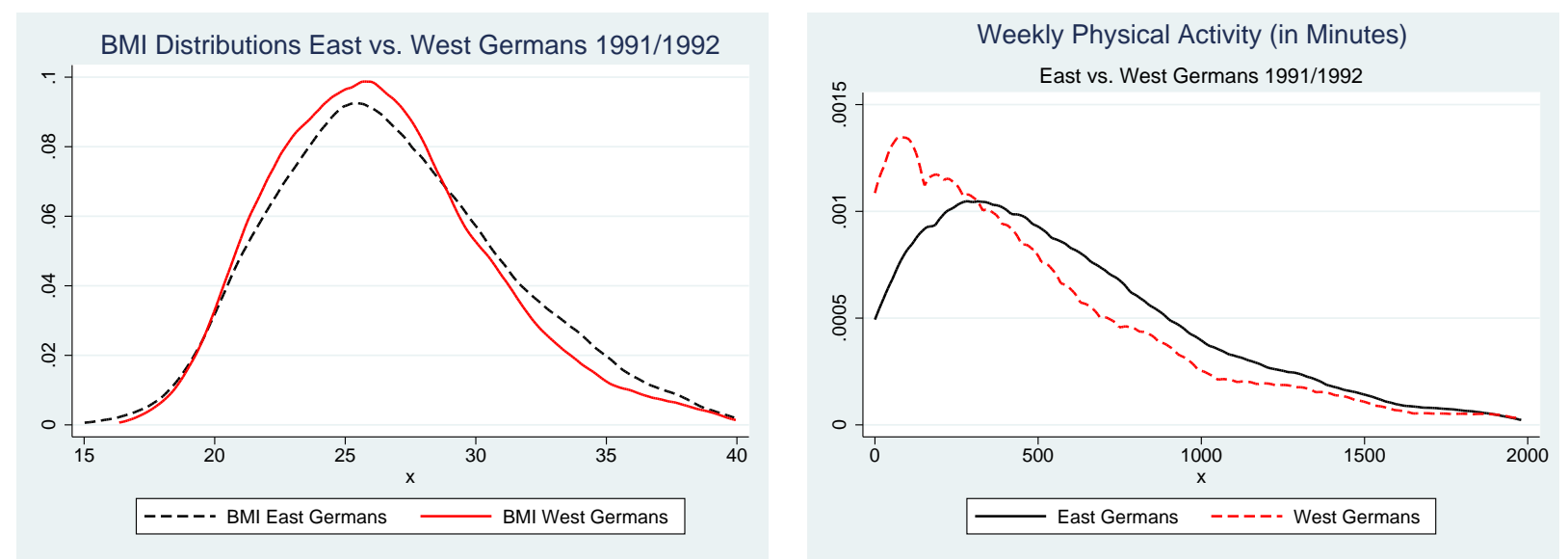

Source: Robert Koch Institut (2012b), German National Health Survey East-West 1991 (GNHSEW91)

Figure 5: East-West Differences in (a) Blood Pressure Taken, (b) Cholesterol Measured, (c) Weighted, and (d) Dietary Advice by Health Care Worker in Last Year (1991/1992)
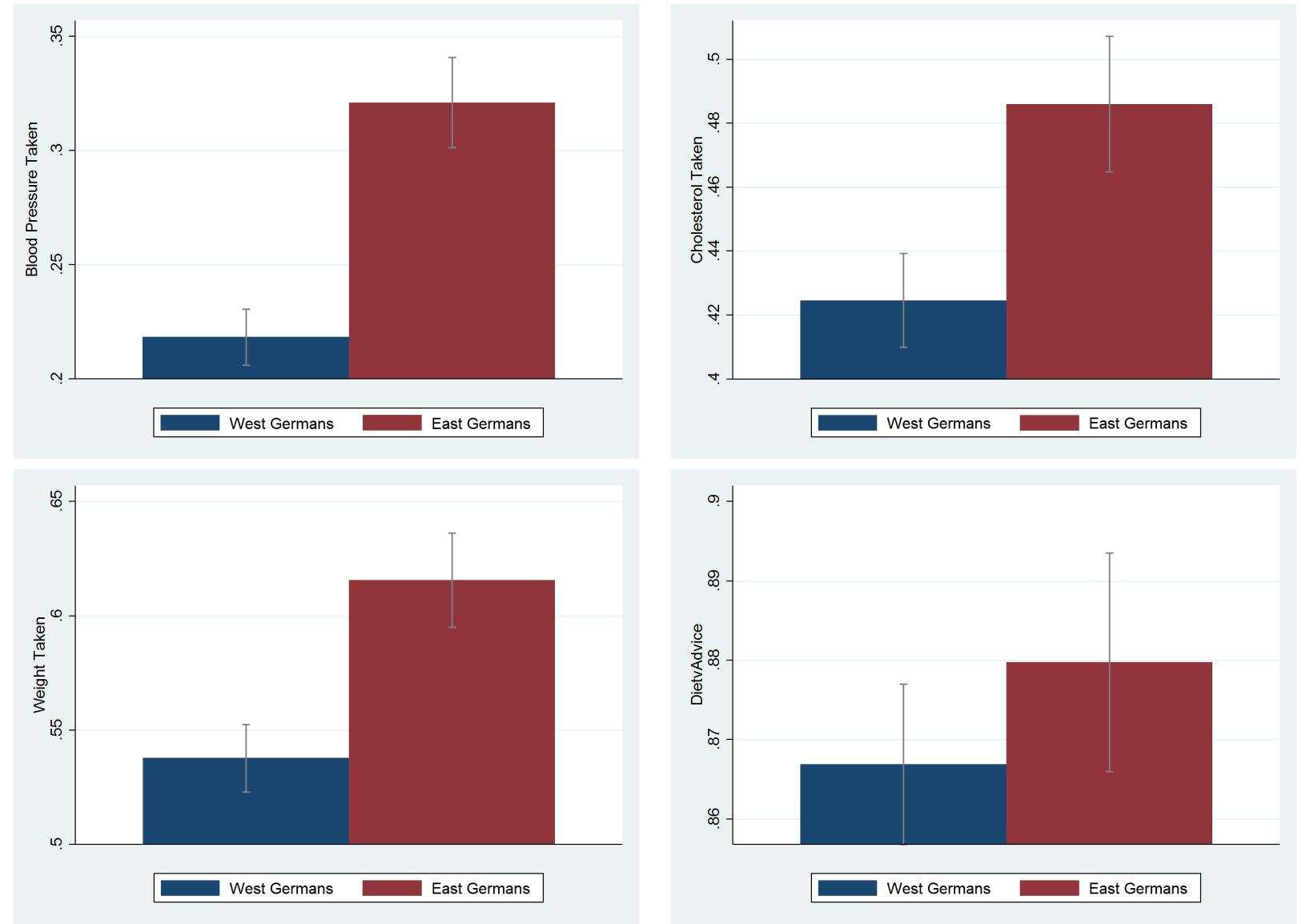
Figure 6: Relationship between Weight Gain and (a) Increase in Food Consumption, (b) BMI, (c) Planned Weight Loss, and (d) Physical Activity (1991/1992)

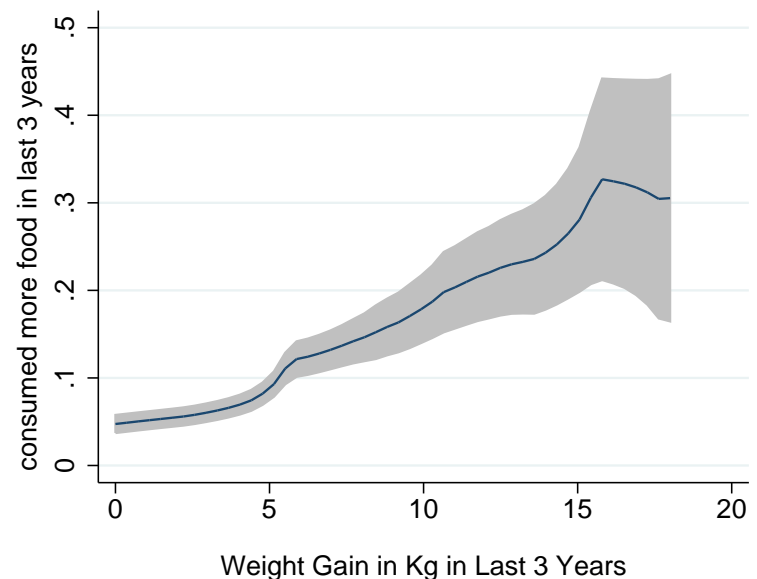

Weight Gain in $\mathrm{Kg}$ in Last 3 Years

kernel = epanechnikov, degree $=0$, bandwidth $=2.52$, pwidth $=3.78$

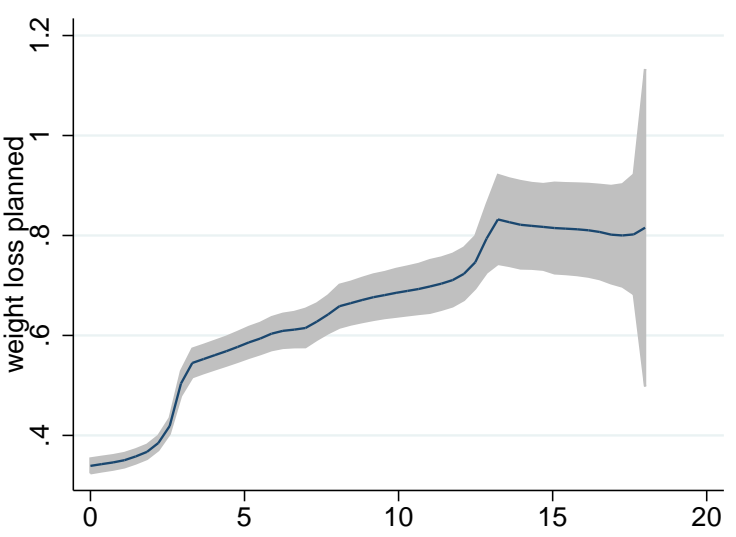

Weight Gain in Kg in Last 3 Years

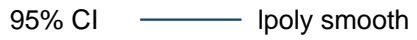

kernel $=$ epanechnikov, degree $=0$, bandwidth $=1.34$, pwidth $=2.02$

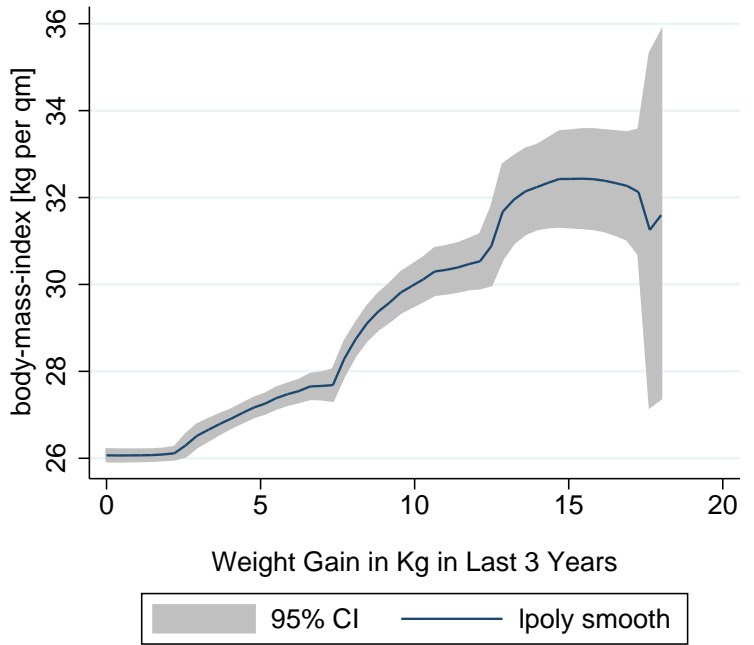

kernel $=$ epanechnikov, degree $=0$, bandwidth $=1.17$, pwidth $=1.75$

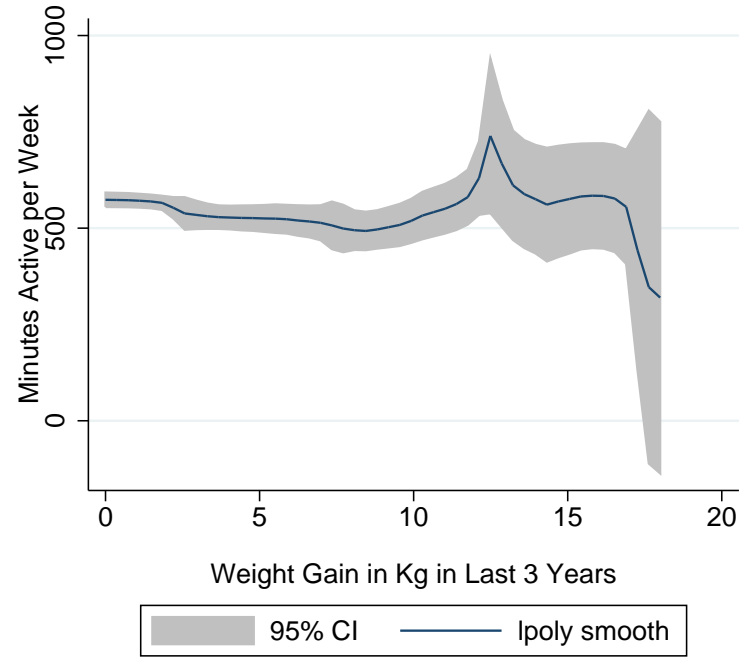

kernel $=$ epanechnikov, degree $=0$, bandwidth $=1.04$, pwidth $=1.55$ 
Figure 7: Relationship between Weight Loss and More Consumption of (a) Fat, (b) Meat, (c) Fruit, and (d) Wholegrain Products (1991/1992)

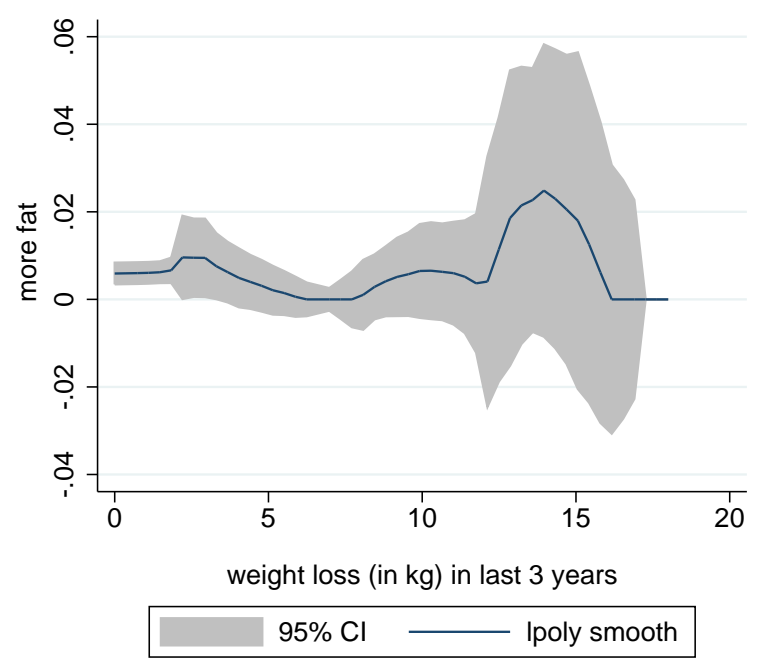

kernel $=$ epanechnikov, degree $=0$, bandwidth $=.92$, pwidth $=1.38$

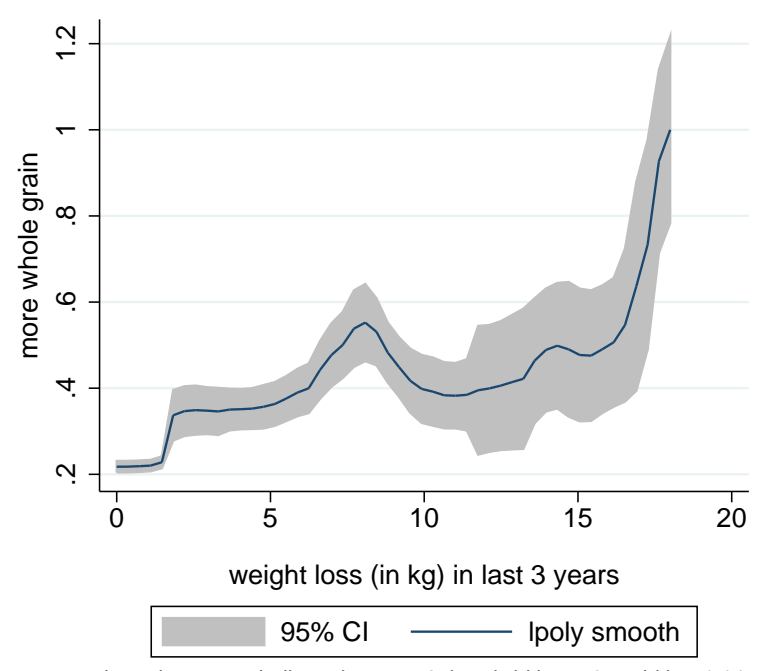

kernel $=$ epanechnikov, degree $=0$, bandwidth $=.76$, pwidth $=1.14$

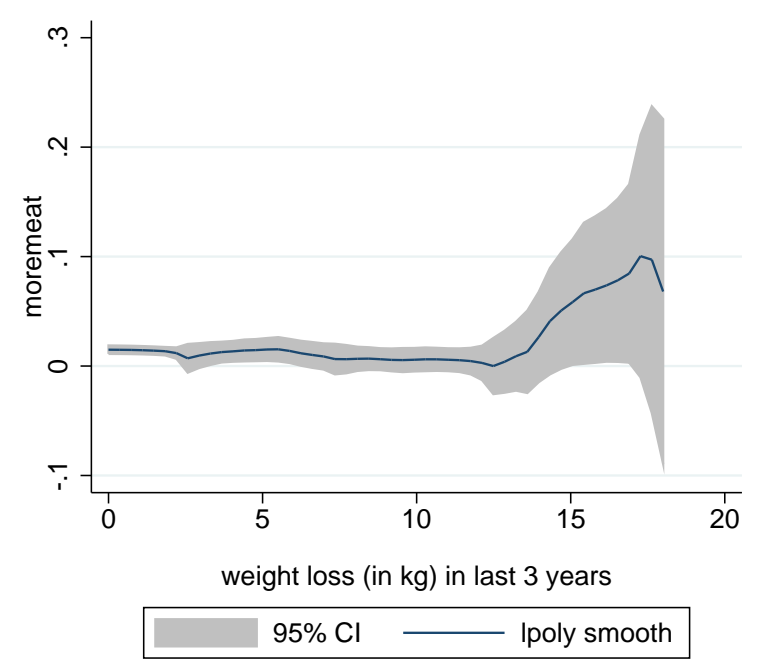

kernel $=$ epanechnikov, degree $=0$, bandwidth $=1.06$, pwidth $=1.59$

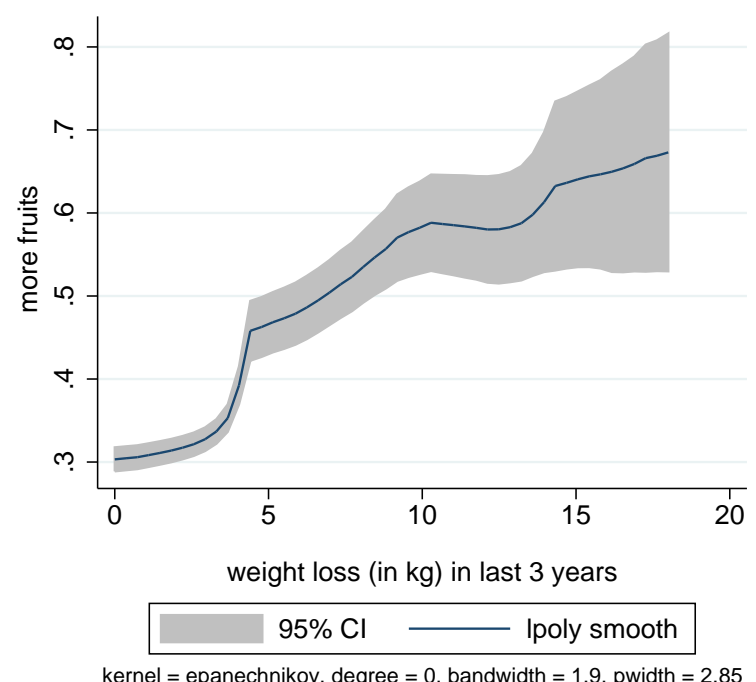

kernel $=$ epanechnikov, degree $=0$, bandwidth $=1.9$, pwidth $=2.85$ 
Figure 8: East-West BMI Distributions 2005, Disentangled by East-West Migration

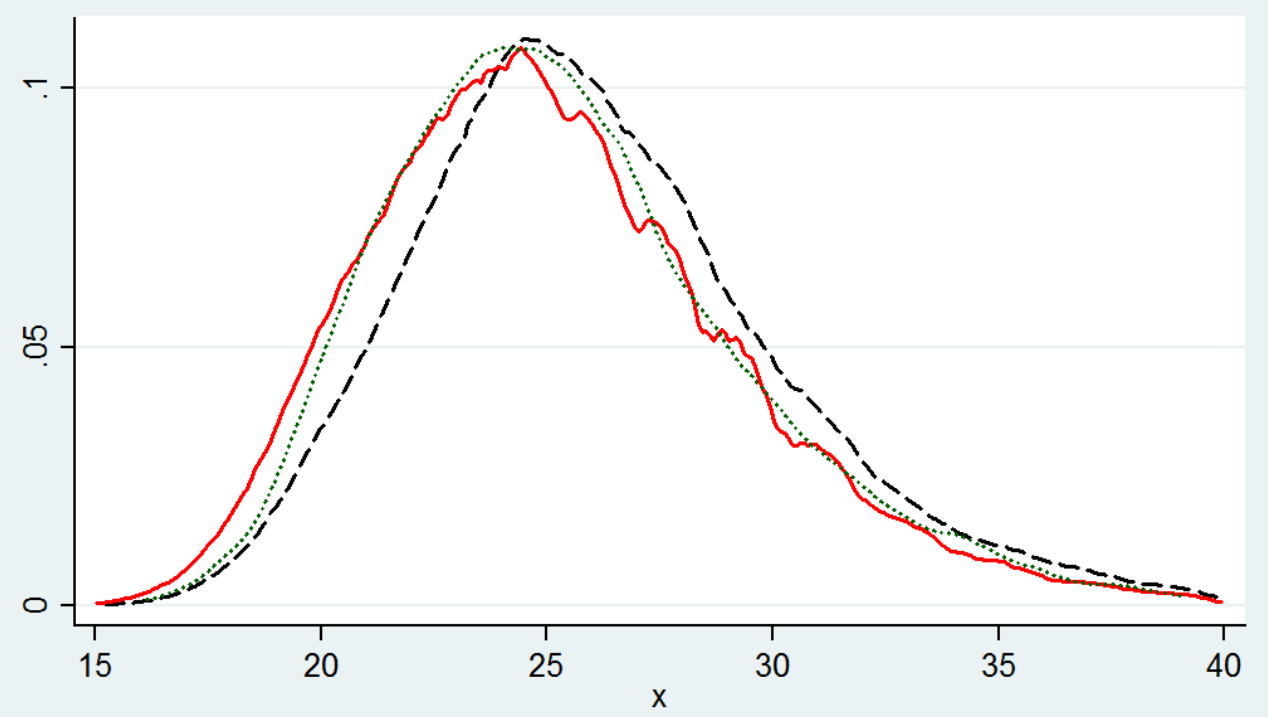

-- -- - Living in East Germany with GDR degree

Living in West Germany w/o GDR degree

Living in West Germany with GDR degree

Source: German Microcensus 2005 
Table 1: How East Germans' Diet and Body Mass Changed Shortly after the Reunification (1991/1992)

\begin{tabular}{|c|c|c|c|c|c|c|}
\hline Panel A: Current diet & $\begin{array}{l}\text { meat weekly } \\
(1)\end{array}$ & $\begin{array}{l}\text { (boiled) potatoes } \\
\text { daily }\end{array}$ & $\begin{array}{l}\text { fresh fruits daily } \\
\text { (3) }\end{array}$ & $\begin{array}{l}\text { wholegrain bread } \\
\text { daily (4) }\end{array}$ & $\begin{array}{l}\text { eggs regularly } \\
\text { (5) }\end{array}$ & $\begin{array}{l}\text { pie regularly } \\
\text { (6) }\end{array}$ \\
\hline East German & $\begin{array}{l}0.0280 \\
(0.0285)\end{array}$ & $\begin{array}{l}(2) \\
-0.0266^{* *} \\
(0.0282)\end{array}$ & $\begin{array}{l}0.0928^{* * *} \\
(0.0313)\end{array}$ & $\begin{array}{l}-0.0053 \\
(0.0331)\end{array}$ & $\begin{array}{l}0.0248 \\
(0.0277)\end{array}$ & $\begin{array}{l}0.0671^{* *} \\
(0.0319)\end{array}$ \\
\hline $\begin{array}{l}\text { mean } \\
\Delta\end{array}$ & $\begin{array}{l}0.74 \\
4 \%\end{array}$ & $\begin{array}{l}0.26 \\
-10 \%\end{array}$ & $\begin{array}{l}0.57 \\
16 \%\end{array}$ & $\begin{array}{l}0.54 \\
-1 \%\end{array}$ & $\begin{array}{l}0.23 \\
11 \%\end{array}$ & $\begin{array}{l}0.36 \\
19 \%\end{array}$ \\
\hline Panel B: Change in die & $\begin{array}{l}t \text {, last } 3 \text { years } \\
\text { more meat } \\
(\mathbf{1})\end{array}$ & $\begin{array}{l}\text { more whole- } \\
\text { grain(2) }\end{array}$ & $\begin{array}{l}\text { more fruits } \\
(3)\end{array}$ & $\begin{array}{l}\text { change in diet } \\
(4)\end{array}$ & $\begin{array}{l}\text { more food } \\
(5)\end{array}$ & $\begin{array}{l}\text { less food } \\
(6)\end{array}$ \\
\hline East German & $\begin{array}{l}0.0251 \\
(0.0288)\end{array}$ & $\begin{array}{l}0.0105 \\
(0.0096)\end{array}$ & $\begin{array}{l}0.1622^{* * *} \\
(0.0310)\end{array}$ & $\begin{array}{l}0.1330^{* * *} \\
(0.0323)\end{array}$ & $\begin{array}{l}0.0111 \\
(0.0109)\end{array}$ & $\begin{array}{l}0.0472^{*} \\
(0.0266)\end{array}$ \\
\hline $\begin{array}{l}\text { mean } \\
\Delta \text { (coefficient } / \text { mean })\end{array}$ & $\begin{array}{l}0.02 \\
52 \%\end{array}$ & $\begin{array}{l}0.25 \\
10 \%\end{array}$ & $\begin{array}{l}0.34 \\
48 \%\end{array}$ & $\begin{array}{l}0.40 \\
33 \%\end{array}$ & $\begin{array}{l}0.028 \\
40 \%\end{array}$ & $\begin{array}{l}0.21 \\
22 \%\end{array}$ \\
\hline Panel C: Change and & $\begin{array}{l}\text { lifferences in } b c \\
\text { weight gain } \\
\text { (1) }\end{array}$ & $\begin{array}{l}\text { SS } \\
\text { weight loss } \\
(2)\end{array}$ & $\begin{array}{l}\text { weight loss } \\
\text { planned (3) }\end{array}$ & $\begin{array}{l}\text { BMI } \\
(4)\end{array}$ & $\begin{array}{l}\text { obese } \\
\text { (5) }\end{array}$ & $\begin{array}{l}\text { minutes active } \\
\text { (6) }\end{array}$ \\
\hline East German & $\begin{array}{l}0.0589^{* *} \\
(0.0295)\end{array}$ & $\begin{array}{l}0.0072 \\
(0.0240)\end{array}$ & $\begin{array}{l}0.0676^{* *} \\
(0.0330)\end{array}$ & $\begin{array}{l}0.6838^{* *} \\
(0.2909)\end{array}$ & $\begin{array}{l}0.0668^{* *} \\
(0.0262)\end{array}$ & $\begin{array}{l}232.79^{* * *} \\
(37.7708)\end{array}$ \\
\hline $\begin{array}{l}\text { mean } \\
\Delta(\text { coefficient } / \text { mean })\end{array}$ & $\begin{array}{l}0.27 \\
22 \%\end{array}$ & $\begin{array}{l}0.15 \\
5 \%\end{array}$ & $\begin{array}{l}0.46 \\
15 \%\end{array}$ & $\begin{array}{l}27.7 \\
2 \%\end{array}$ & $\begin{array}{l}0.21 \\
33 \%\end{array}$ & $\begin{array}{l}560 \\
42 \%\end{array}$ \\
\hline
\end{tabular}

Source: Robert Koch Institut (2012b), German National Health Survey East-West 1991 (GNHSEW91), own calculations and illustrations; ${ }^{*} \mathrm{p}<0.1,{ }^{* *} \mathrm{p}<0.05,{ }^{* * *} \mathrm{p}<0.01 ;$ standard errors in parentheses. The descriptive statistics are in the Appendix (Table B2). Each column in each panel represents one model, estimated by OLS, with the dependent variable in the column header and the independent variables as listed in Table B2. The self-reported dependent variables used in Panel A and B are all dummy variables. The original questions have more than two answer categories which we collapse: Panel A: (i) daily, (ii) several times a week, (iii) once a week, (iv) 2-3 times a month, (v) once a month, (vi) never. "Regularly" refers to consumption "several times a week or daily", i.e., (i) and (ii). The questions exploited in Panel B, columns (1) to (3), have answer categories (i) more, (ii) same, (iii) less [consumption of food category X in last 3 years]. Panel B, columns (4) to (6) exploit whether respondents changed their diet, and consumed overall more or less food. Panel C, columns (1) to (3) are based on self-reports about weight gains or losses in the last 3 years as well as planned weight losses. Columns (4) and (5) of Panel C are based on objective height and weight measures, and column (6) sums over the amount of hours and minutes typically spent per week for 20 different physical activities. Section 4.3 provides more information on the variables. The number of observations for all columns and panels is 6,550. The R-squared in Panel A lies between 0.02 (column (2)) and 0.11 (column (6)), in Panel B it lies between 0.01 (column (4)) and 0.04 (column (6)) and in Panel C between 0.05 (column (6)) and 0.16 (column (4)). The "mean" refers to the mean of the dependent variable in the column header. 
Table 2: East Germans' Diet-Related Objective Health Measures and their Awareness of their Medical Conditions Shortly after the Reunification (1991/1992)

\begin{tabular}{|c|c|c|c|}
\hline \multicolumn{4}{|l|}{ Panel A: Clinical objec } \\
\hline & $\begin{array}{l}\text { High blood } \\
\text { pressure (1) }\end{array}$ & $\begin{array}{l}\text { High cholesterol } \\
\text { (2) }\end{array}$ & $\begin{array}{l}\text { Diabetes } \\
\text { (3) }\end{array}$ \\
\hline East German & $\begin{array}{l}0.0716^{* * *} \\
(0.0258)\end{array}$ & $\begin{array}{l}0.0524^{*} \\
(0.0310)\end{array}$ & $\begin{array}{l}0.0028 \\
(0.0138)\end{array}$ \\
\hline mean & 0.21 & 0.44 & 0.046 \\
\hline$\Delta$ (coefficient/mean $)$ & $34 \%$ & $12 \%$ & $6.5 \%$ \\
\hline \multicolumn{4}{|c|}{ Panel B: Unawareness of hypertension, high cholesterol, and obesity } \\
\hline & $\begin{array}{l}\text { Unaware high } \\
\text { blood pressure (1) }\end{array}$ & $\begin{array}{l}\text { Unaware high } \\
\text { cholesterol (2) }\end{array}$ & $\begin{array}{l}\text { Unaware obese } \\
\text { (3) }\end{array}$ \\
\hline East German & $\begin{array}{l}0.0619^{* * *} \\
(0.0191)\end{array}$ & $\begin{array}{l}0.1813^{* * *} \\
(0.0296)\end{array}$ & $\begin{array}{l}0.0739^{* * *} \\
(0.0173)\end{array}$ \\
\hline mean & 0.09 & 0.29 & 0.07 \\
\hline$\Delta$ (coefficient/mean) & $69 \%$ & $63 \%$ & $100 \%$ \\
\hline
\end{tabular}

Source: Robert Koch Institut (2012b), German National Health Survey East-West 1991 (GNHSEW91), own calculations and illustrations; ${ }^{*} \mathrm{p}<0.1,{ }^{* *} \mathrm{p}<0.05,{ }^{* * *} \mathrm{p}<0.01$; standard errors in parentheses. The descriptive statistics are in the Appendix (Table B2). Each column in each panel represents one model, estimated by OLS, with the dependent variable in the column header. All covariates listed in Table B2 are considered. The dependent binary variables in the first two columns of Panel A are based on objective clinical health measures, the diabetes measure in column (3) is self-reported. The dependent variables in Panel B measure the difference between the medical indication based on the clinical measures taken, and the self-reports about diagnoses. For more information on how the variables were generated, see Section 4.3.1. The number of observations for all models is 6,550. The "mean" refers to the mean of the dependent variable in the column header. 
Table 3: Assessing Changes in East Germans' Dietary and Diet-Related Medical Conditions between 1991 and 1998

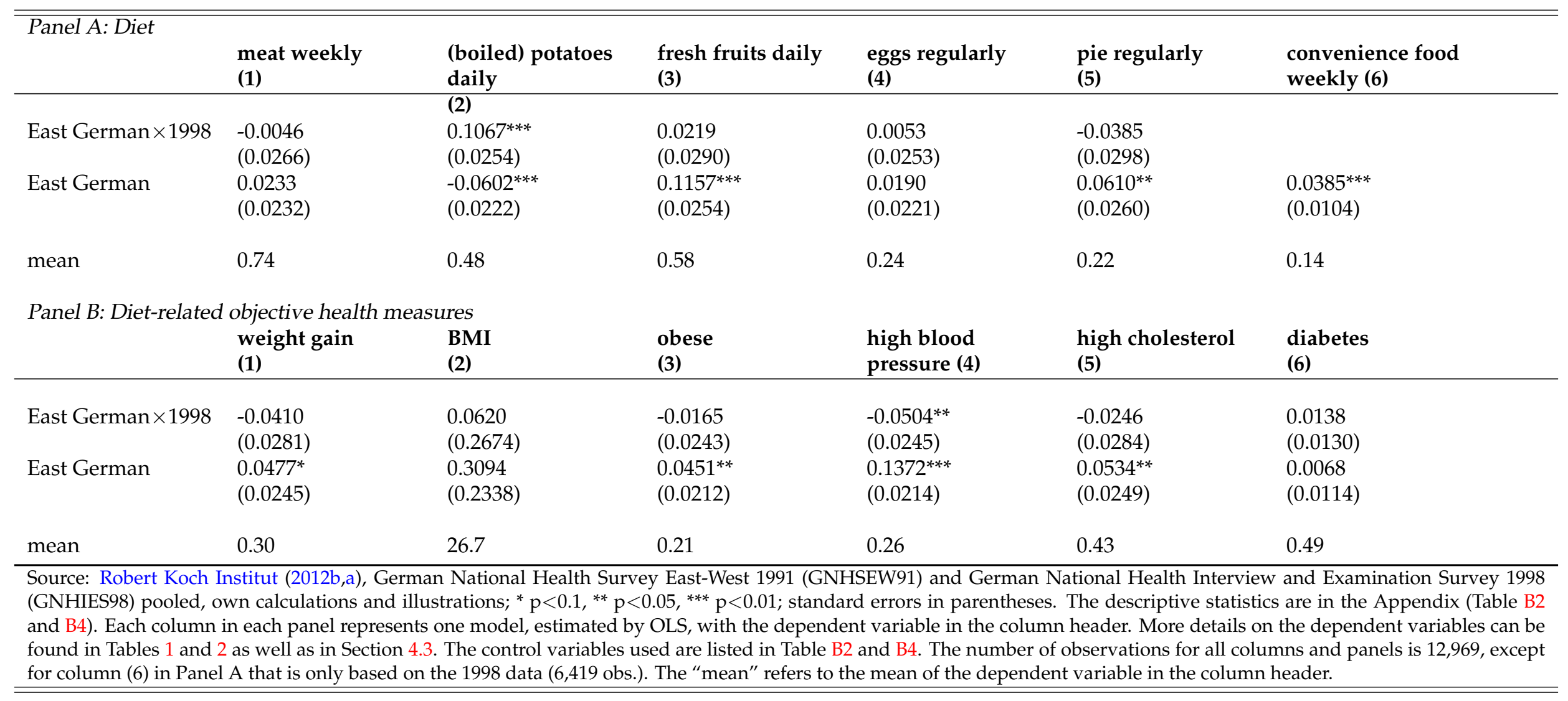


Table 4: Categorization of Investigated Food Consumption Dynamics in the Short- and Long-Run

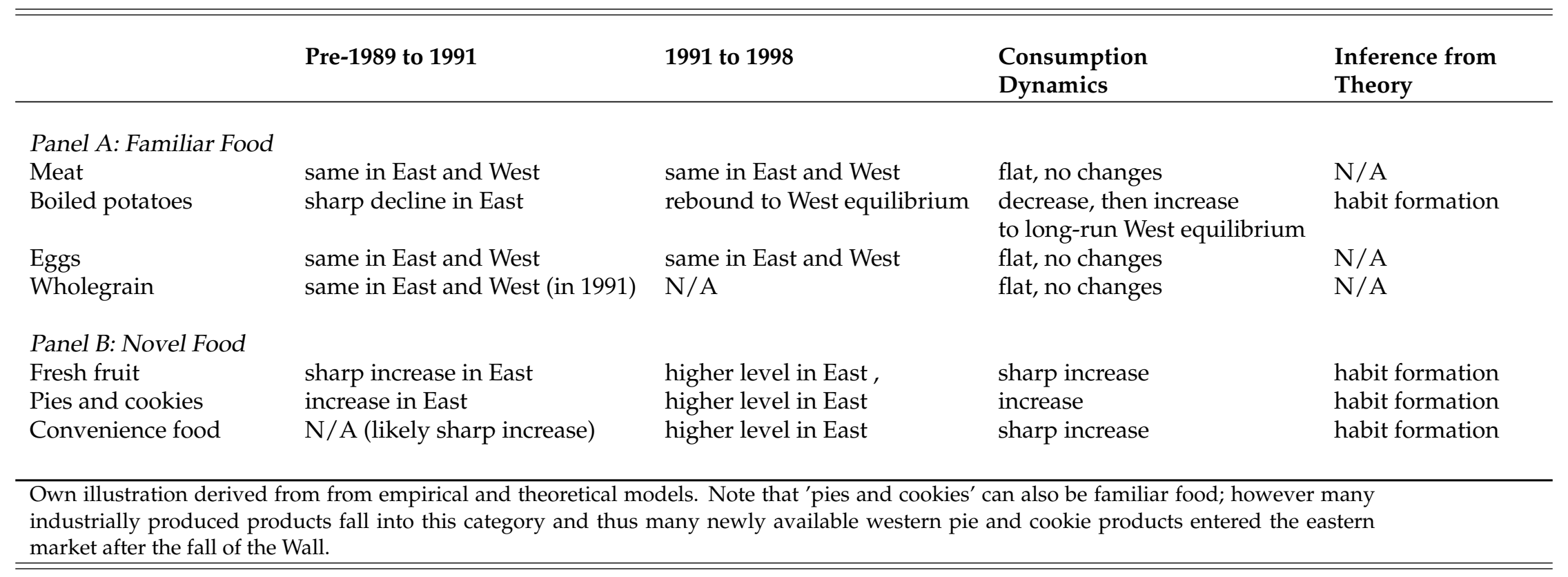


Table 5: Microcensus 2005: East-West Socialization and Body Mass in the Long-Run, Disentangled by East-West Migration

\begin{tabular}{|c|c|c|c|c|c|c|c|c|c|}
\hline & \multicolumn{3}{|c|}{ BMI } & \multicolumn{3}{|c|}{ overweight } & \multicolumn{3}{|c|}{ obese } \\
\hline & (1) & (2) & (3) & (4) & (5) & (6) & (7) & (8) & (9) \\
\hline Living in East Germany & $\begin{array}{l}0.4217^{* * *} \\
(0.0177)\end{array}$ & & $\begin{array}{l}0.2660^{* * *} \\
(0.0206)\end{array}$ & $\begin{array}{l}0.0411^{* * *} \\
(0.0020)\end{array}$ & & $\begin{array}{l}0.0253^{* * *} \\
(0.0024)\end{array}$ & $\begin{array}{l}0.0260^{* * *} \\
(0.0014)\end{array}$ & & $\begin{array}{l}0.0224^{* * *} \\
(0.0017)\end{array}$ \\
\hline Educational degree of GDR & & $\begin{array}{l}0.6620^{* * * *} \\
(0.0276)\end{array}$ & $\begin{array}{l}0.1736^{* *} \\
(0.0748)\end{array}$ & & $\begin{array}{l}0.0647^{* * * *} \\
(0.0032)\end{array}$ & $\begin{array}{l}0.0107 \\
(0.0086)\end{array}$ & & $\begin{array}{l}0.0268^{* * *} \\
(0.0022)\end{array}$ & $\begin{array}{l}0.0023 \\
(0.0061)\end{array}$ \\
\hline EastGermany×GDRdegree & & & $\begin{array}{l}0.3414^{* * *} \\
(0.0821)\end{array}$ & & & $\begin{array}{l}0.0411^{* * *} \\
(0.0094)\end{array}$ & & & $\begin{array}{l}0.0097 \\
(0.0067)\end{array}$ \\
\hline Constant & $\begin{array}{l}23.3873^{* * *} \\
(0.0365)\end{array}$ & $\begin{array}{l}23.3725^{* * *} \\
(0.0366)\end{array}$ & $\begin{array}{l}23.3560^{* * *} \\
(0.0366)\end{array}$ & $\begin{array}{l}0.2700^{* * *} \\
(0.0042)\end{array}$ & $\begin{array}{l}0.2685^{* * *} \\
(0.0042)\end{array}$ & $\begin{array}{l}0.2670^{* * *} \\
(0.0042)\end{array}$ & $\begin{array}{l}0.0410^{* * *} \\
(0.0030)\end{array}$ & $\begin{array}{l}0.0418^{* * *} \\
(0.0030)\end{array}$ & $\begin{array}{l}0.0403^{* * *} \\
(0.0030)\end{array}$ \\
\hline Socio-demographic controls & yes & yes & yes & yes & yes & yes & yes & yes & yes \\
\hline Observations & 312,983 & 312,983 & 312,983 & 312,983 & 312,983 & 312,983 & 312,983 & 312,983 & 312,983 \\
\hline R-squared & 0.1184 & 0.1185 & 0.1191 & 0.1168 & 0.1168 & 0.1173 & 0.0229 & 0.0223 & 0.0229 \\
\hline
\end{tabular}

Source: Microcensus2005, own calculations and illustrations; ${ }^{*} \mathrm{p}<0.1,{ }^{* *} \mathrm{p}<0.05,{ }^{* * *} \mathrm{p}<0.01$; standard errors in parentheses. The descriptive statistics are in the Appendix (Table B5). Each column in each panel represents one model, estimated by OLS, with the dependent variables in the column header. More details on the dependent body mass variables and the covariates employed can be found in Table B5 and in Section 4.3 . The constant identifies the body mass of West Germans who live in West Germany with zeros on all covariates considered (see Table B5). Adding the Living in East Germany coefficient yields the body mass for people living currently in East Germany but without a GDR educational degree (e.g., due to age or migration to East Germany). Adding all four coefficients yields the body mass for people living in East Germany with a GDR educational degree. And just adding the Educational degree of GDR coefficient yields the body mass for people who were socialized in the former GDR but migrated to West Germany where they currently live. 


\section{For Online Publication}

\section{Appendix A: Figures}

Figure A1: Division of Germany, 1961

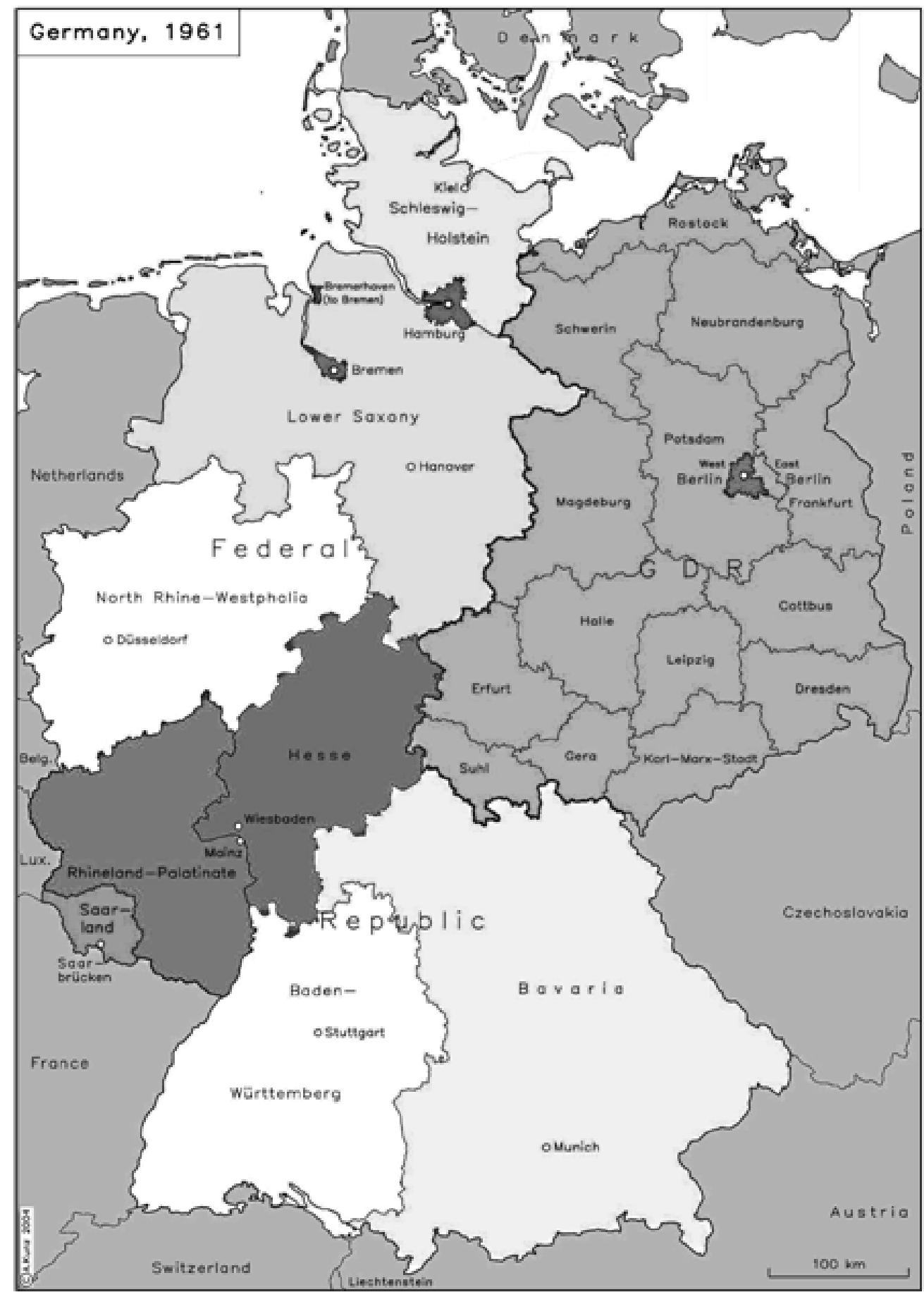

Source: IEG-Maps, Institute of European History, Mainz; available at http://germanhistorydocs.ghi-dc.org/, last accessed on March 6, 2013. 
Figure A2: Relationship between Weight Gain and More Consumption of (a) Fat, (b) Meat, (c) Fruit, and (d) Wholegrain Products (1991/1992)

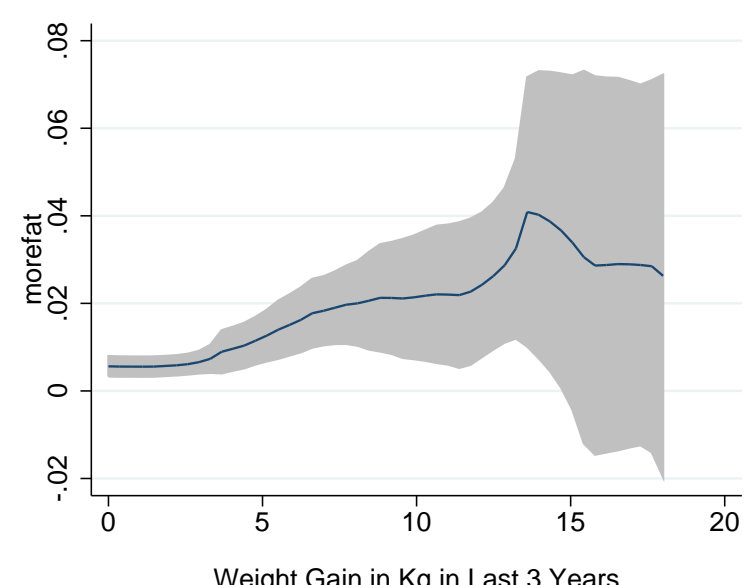

Weight Gain in Kg in Last 3 Years
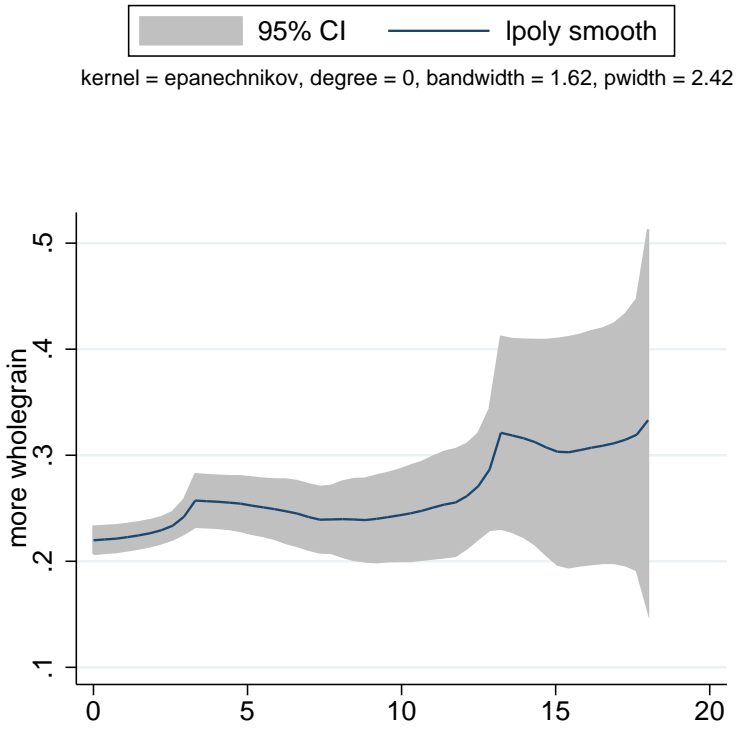

Weight Gain in Kg in Last 3 Years $95 \% \mathrm{Cl} \longrightarrow$ Ipoly smooth

kernel $=$ epanechnikov , degree $=0$, bandwidth $=1.43$, pwidth $=2.15$

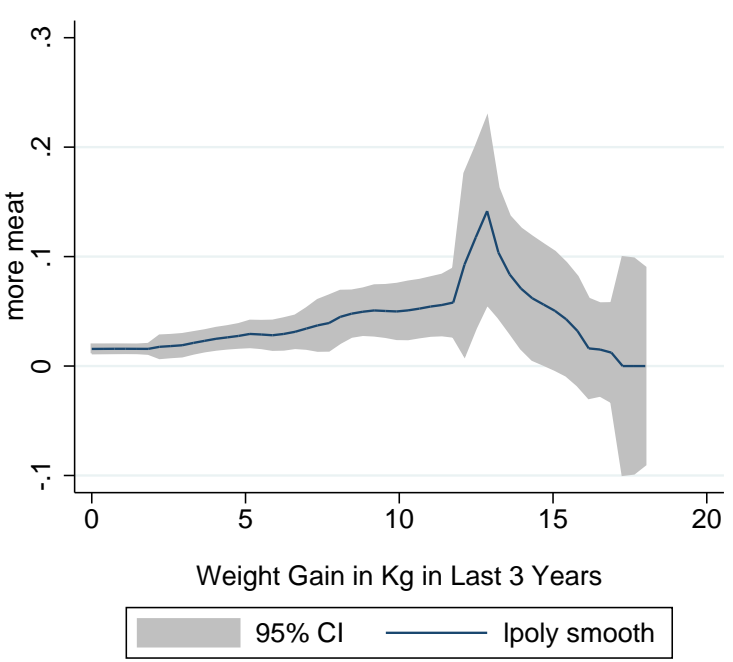

kernel $=$ epanechnikov, degree $=0$, bandwidth $=.95$, pwidth $=1.42$

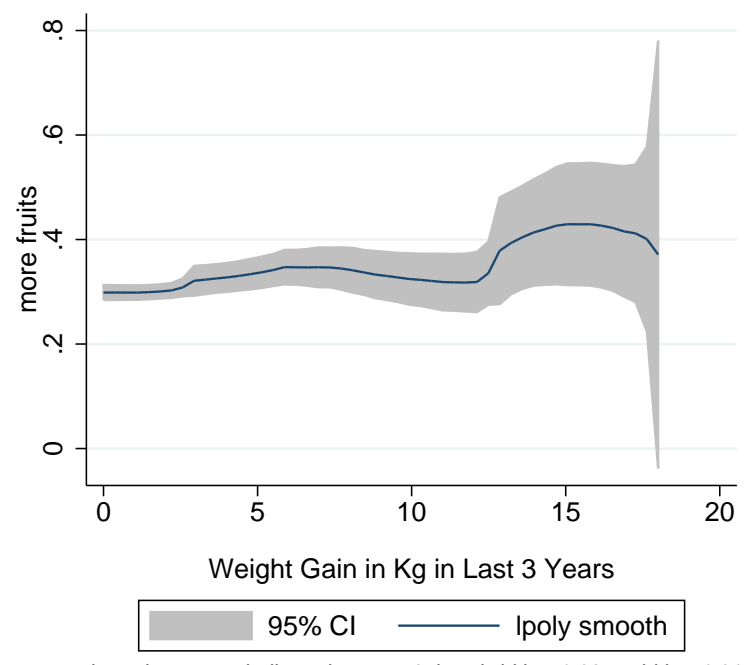

kernel $=$ epanechnikov, degree $=0$, bandwidth $=1.28$, pwidth $=1.91$ 
Figure A3: Relationship between Weight Loss and (a) Decrease in Food Consumption, (b) BMI, (c) Planned Weight Loss, and (d) Physical Activity (1991/1992)

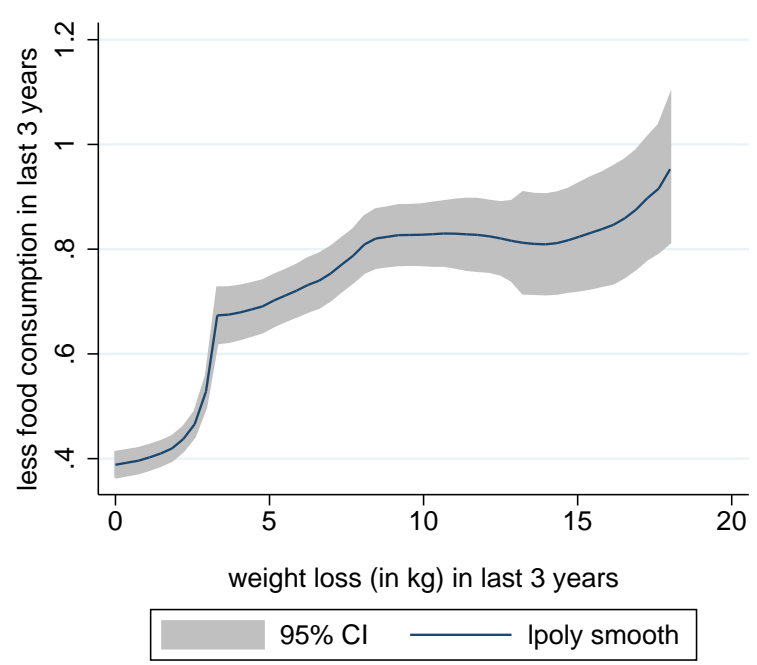

kernel $=$ epanechnikov, degree $=0$, bandwidth $=1.44$, pwidth $=2.15$

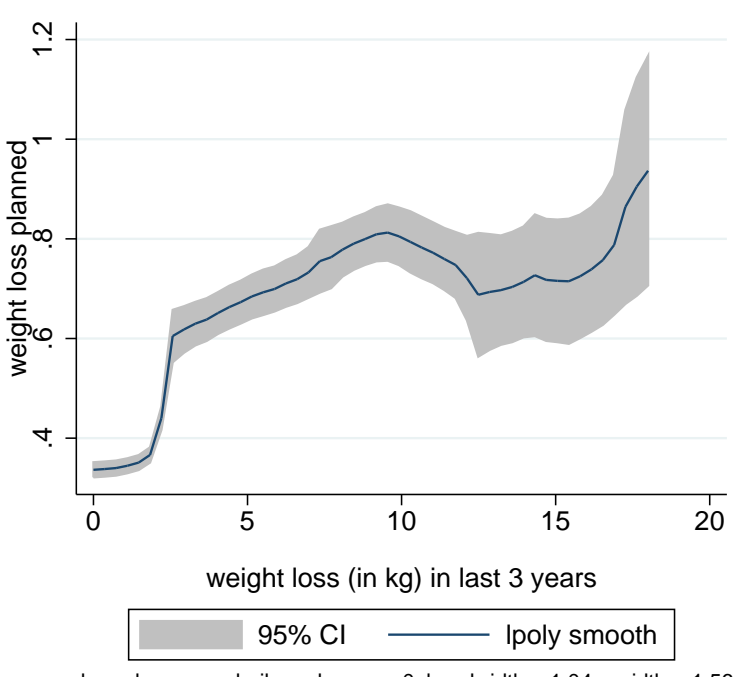

kernel $=$ epanechnikov, degree $=0$, bandwidth $=1.04$, pwidth $=1.56$

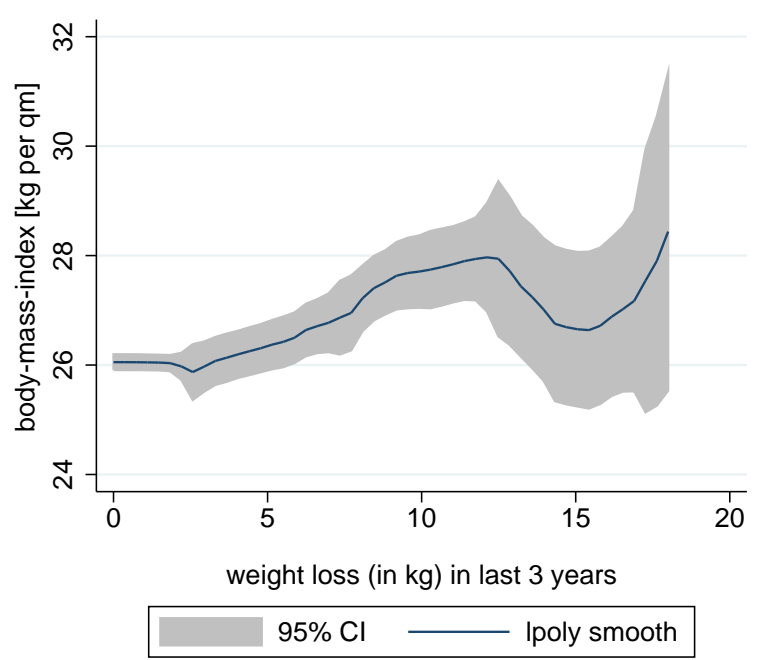

kernel $=$ epanechnikov, degree $=0$, bandwidth $=1.03$, pwidth $=1.54$

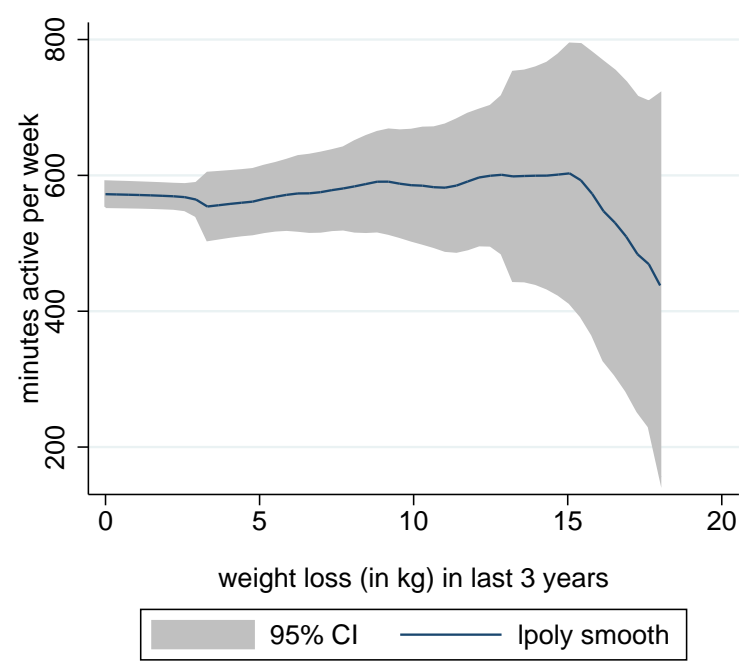

kernel $=$ epanechnikov, degree $=0$, bandwidth $=1.43$, pwidth $=2.14$ 
Figure A4: East-West Differences and Changes over Time (1991 vs. 1998): (a) Weight Gain (last 3 years), (b) Obesity, (c) High Cholesterol Level, (d) Diabetes
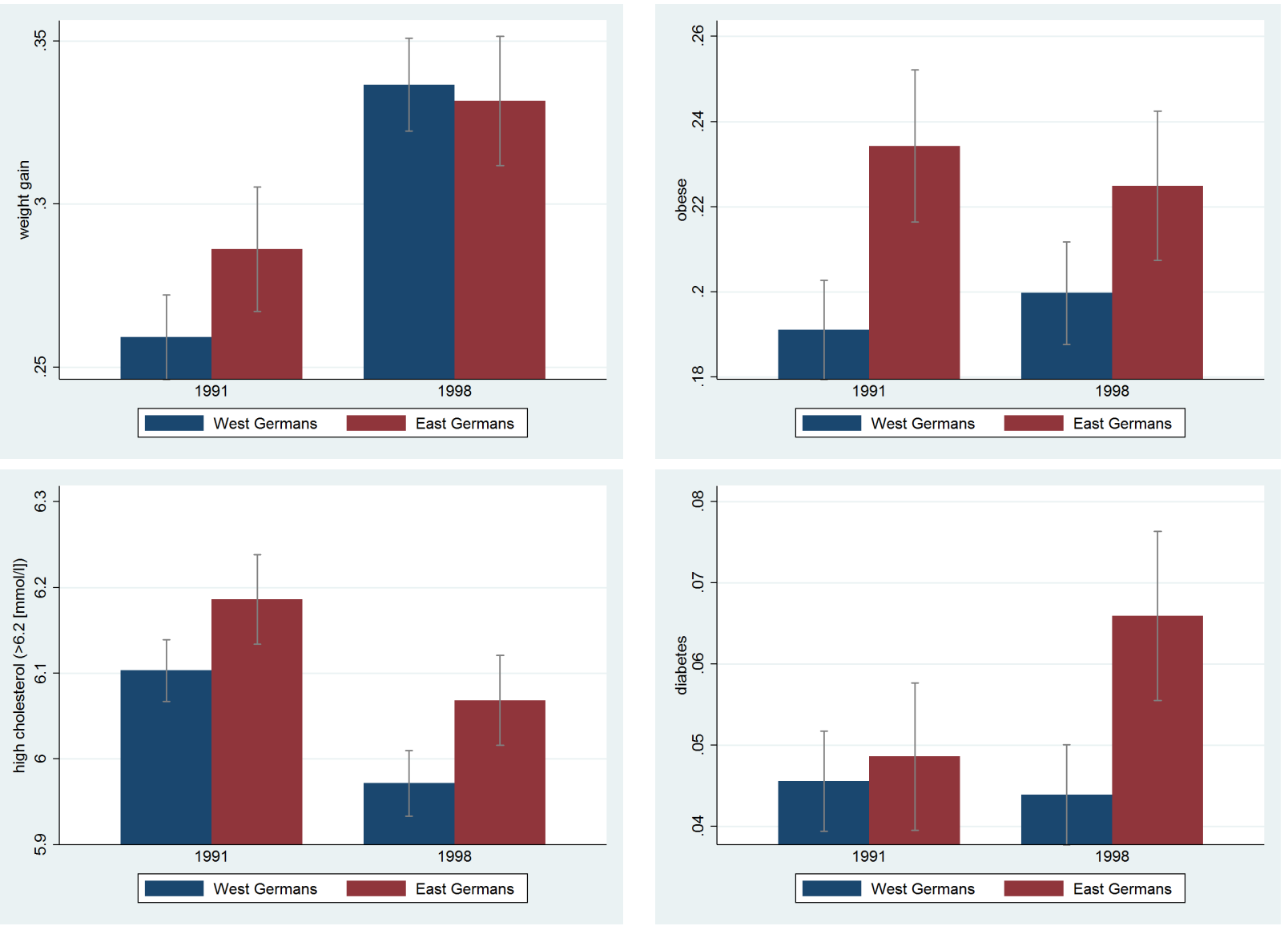


\section{Appendix B: Tables}

Table B1: Consumption and Prices of Selected Food Categories per Month and Capita: GDR vs. FRG

\begin{tabular}{|c|c|c|c|c|c|c|}
\hline \multirow[t]{2}{*}{ Food Category } & \multicolumn{3}{|c|}{ GDR/East Germany (1989) } & \multicolumn{3}{|c|}{ FRG/West Germany (1988) } \\
\hline & $\begin{array}{l}\text { Consumption } \\
\text { per month (in } \mathrm{kg} \text { ) } \\
(1)\end{array}$ & $\begin{array}{l}\text { Price per kg } \\
\text { (in } 2000 € \text { ) } \\
(2)\end{array}$ & $\begin{array}{l}\text { Price per } \mathrm{kg} \\
\text { (in \% of net } \mathrm{HH} \\
\text { income) (3) }\end{array}$ & $\begin{array}{l}\text { Consumption } \\
\text { per month (in } \mathrm{kg} \text { ) } \\
\text { (4) }\end{array}$ & $\begin{array}{l}\text { Price per kg } \\
\text { (in } 2000 € \text { ) } \\
(5)\end{array}$ & $\begin{array}{l}\text { Price per kg } \\
\text { (in \% of net } \mathrm{HH} \\
\text { Income) (6) }\end{array}$ \\
\hline Meat & 5.25 & 5.19 (pork chop) & $0.8 \%$ & 4.49 & 6.63 & $0.5 \%$ \\
\hline Potatoes & 9.7 & 0.11 & $0.02 \%$ & 3.03 & 0.6 & $0.04 \%$ \\
\hline Eggs & 25.4 eggs & 0.22 & $0.03 \%$ & 31 & 0.13 & $0.01 \%$ \\
\hline Sugar & 1.18 & 1.00 & $0.15 \%$ & 1.56 & 1.10 & $0.08 \%$ \\
\hline Exotic fruits & $0(N / A)$ & $\begin{array}{l}11.67 \\
\text { (pineapple can) }\end{array}$ & $1.8 \%$ & 1.75 & 1.59 & $0.1 \%$ \\
\hline \multicolumn{7}{|c|}{$\begin{array}{l}\text { Source: Böhme (1971); Zentralverwaltung für Statistik der DDR (1988, 1990,1991); Schwarzer (1999); Grabka (2000); Gedrich and } \\
\text { Albrecht (2003); Woll (2012); Maecker (2013), own calculations and illustrations. Consumption is per capita and month. GDR } \\
\text { net household income is taken from Zentralverwaltung für Statistik der DDR (1991) and refers to a one-person household in } \\
\text { 1988. FRG household income is taken from Grabka (2000) and refers to equivalent disposable household income according to } \\
\text { the SOEP in } 1988 \text { and } 1997 \text { (in } 1995 \text { prices). Food prices are taken from Zentralverwaltung für Statistik der DDR (1988, 1990); } \\
\text { Gedrich and Albrecht (2003); Woll (2012); Maecker (2013). Time values of prices and income have been adjusted assuming an } \\
\text { inflation rate of } 2 \% \text {, an East-West German exchange rate of 1:1 and a } €-D M \text { exchange rate of 1:1.95883. One kilogram (kg) equals } \\
2.2 \text { pounds (lbs). }\end{array}$} \\
\hline
\end{tabular}


Table B2: Descriptive Statistics German National Health Survey East-West 1991 (GNHSEW91)

\begin{tabular}{cccccc}
\hline \hline Variable & Mean & Std. Dev. & Min. & Max. & N \\
\hline
\end{tabular}

\section{A. Outcome Measures}

\section{Current diet}

Meat weekly

Boiled potatoes daily

Fresh fruits daily

Wholegrain bread daily

Eggs regularly (more than once a week)

Pies and cookies (more than once a week)

Change in diet and body mass, last 3 years

More meat (at least once a week)

More fresh fruits

More wholegrain

Change in diet

More food

Less food

Weight gain

Weight gain (in $\mathrm{kg}$ )

Weight loss

Weight loss (in kg)

Weight loss planned

Body-mass-index [kg pro qm]

Overweight (BMI>25)

Obese (BMI>30)

Minutes active per week

Diet-related objective health conditions

Total blood cholesterol [ $>6.2 \mathrm{mmol} / \mathrm{l}]$

High total blood cholesterol [>6.2 mmol/1]

Hypertension

Diabetes (self-reported)

Unawareness and medical check-up measures

Blood pressure taken in last year

Cholesterol taken in last year

Weight taken in last year

Dietary advice in last year

Unaware high hypertension

Unaware high cholesterol

Unaware obese

\section{B. Covariates}

\section{Demographics}

East German

Age

Female

\# household members

\# own kids

Single

Private health insurance

\section{Education}

8 school years

10 school years

13 school years

\section{Employment}

Physical work

Blue collar worker

$\begin{array}{lllll}0.7447 & 0.436 & 0 & 1 & 6,55 \\ 0.2557 & 0.4363 & 0 & 1 & 6,55 \\ 0.5759 & 0.4942 & 0 & 1 & 6,55 \\ 0.5359 & 0.4987 & 0 & 1 & 6,55 \\ 0.2252 & 0.4177 & 0 & 1 & 6,55 \\ 0.3602 & 0.4801 & 0 & 1 & 6,55\end{array}$

6,550

6,550

6,550

6,550

6,550

$\begin{array}{lllll}0.0211 & 0.1436 & 0 & 1 & 6,550\end{array}$

$\begin{array}{lllll}0.3385 & 0.4732 & 0 & 1 & 6,550\end{array}$

$\begin{array}{lllll}0.2544 & 0.4355 & 0 & 1 & 6,550\end{array}$

$\begin{array}{lllll}0.4044 & 0.4908 & 0 & 1 & 6,550\end{array}$

$\begin{array}{lllll}0.0276 & 0.1639 & 0 & 1 & 6,550\end{array}$

$\begin{array}{lllll}0.2055 & 0.4041 & 0 & 1 & 6,550\end{array}$

$\begin{array}{lllll}0.2681 & 0.4430 & 0 & 1 & 6,550\end{array}$

$\begin{array}{lllll}1.96 & 3.84 & 0 & 65 & 5,454\end{array}$

$\begin{array}{lllll}0.2681 & 0.4430 & 0 & 1 & 6,550\end{array}$

$\begin{array}{lllll}1.45 & 3.79 & 0 & 91 & 4,682\end{array}$

$\begin{array}{lllll}0.4586 & 0.4983 & 0 & 1 & 6,550\end{array}$

$\begin{array}{lllll}26.6839 & 4.6293 & 15.02 & 75.467 & 6,550\end{array}$

$\begin{array}{lllll}0.6099 & 0.4878 & 0 & 1 & 6,550\end{array}$

$\begin{array}{lllll}0.2053 & 0.404 & 0 & 1 & 6,550\end{array}$

$\begin{array}{lllll}559.94 & 572.65 & 0 & 6780 & 6,550\end{array}$

$\begin{array}{lllll}6.1306 & 1.2287 & 2.33 & 12.9 & 6,550\end{array}$

$\begin{array}{lllll}0.4407 & 0.4965 & 0 & 1 & 6,550\end{array}$

$\begin{array}{lllll}0.2108 & 0.4079 & 0 & 1 & 6,550\end{array}$

$\begin{array}{lllll}0.0466 & 0.2107 & 0 & 1 & 6,550\end{array}$

$\begin{array}{lllll}0.2522 & 0.4343 & 0 & 1 & 6,550\end{array}$

$\begin{array}{lllll}0.4448 & 0.4969 & 0 & 1 & 6,550\end{array}$

$\begin{array}{lllll}0.5634 & 0.4959 & 0 & 1 & 6,550\end{array}$

$\begin{array}{lllll}0.8711 & 0.3350 & 0 & 1 & 6,550\end{array}$

$\begin{array}{lllll}0.0936 & 0.2912 & 0 & 1 & 6,550\end{array}$

$\begin{array}{lllll}0.2946 & 0.4559 & 0 & 1 & 6,550\end{array}$

$\begin{array}{lllll}0.0748 & 0.2631 & 0 & 1 & 6,550\end{array}$
0.3298

44.9421

0.5116

2.838

1.6313

0.1435

0.0933

0.5379

0.2708

0.1644

0.1179

0.4107
0.4702

12.626

0.4999

1.2246

1.2717

0.3506

0.2909

0.4986

0.4444

0.3707
6,550

6,550

6,550

6,550

6,550

6,550

6,550

6,550

6,550

6,550

6,550

6,550 
... table B2 continued

\begin{tabular}{lccccc}
\hline \hline \multicolumn{1}{c}{ Variable } & Mean & Std. Dev. & Min. & Max. & N \\
\hline White collar worker & 0.4209 & 0.4937 & 0 & 1 & 6,550 \\
Civil servant & 0.0609 & 0.2392 & 0 & 1 & 6,550 \\
Trained for job & 0.4496 & 0.4975 & 0 & 1 & 6,550 \\
Unemployed & 0.0484 & 0.2146 & 0 & 1 & 6,550 \\
Net household income in DM (10 categories) & 5.1685 & 2.3833 & 1 & 10 & 6,550 \\
\hline Sources: Robert Koch Institut (2012b), German National Health Survey East-West 1991 (GNHSEW91)
\end{tabular}

Sources: Robert Koch Institut (2012b), German National Health Survey East-West 1991 (GNHSEW91) 
Table B3: Who Changed their Diet, Gained and Lost Weight Shortly after the Reunification?

\begin{tabular}{|c|c|c|c|}
\hline Variable & $\begin{array}{l}\text { change diet } \\
\text { (1) }\end{array}$ & $\begin{array}{l}\text { weight gain } \\
(2)\end{array}$ & $\begin{array}{l}\text { weight loss } \\
(3)\end{array}$ \\
\hline \multicolumn{4}{|l|}{ Personal characteristics } \\
\hline East German & $\begin{array}{l}0.0815 \\
(0.1067)\end{array}$ & $\begin{array}{l}0.1243 \\
(0.0975)\end{array}$ & $\begin{array}{l}0.0134 \\
(0.0792)\end{array}$ \\
\hline Agegroup2 & $\begin{array}{l}0.0131 \\
(0.0192)\end{array}$ & $\begin{array}{l}-0.0084 \\
(0.0175)\end{array}$ & $\begin{array}{l}-0.0179 \\
(0.0142)\end{array}$ \\
\hline Agegroup3 & $\begin{array}{l}0.0167 \\
(0.0260)\end{array}$ & $\begin{array}{l}-0.0663^{* * * *} \\
(0.0238)\end{array}$ & $\begin{array}{l}-0.0107 \\
(0.0193)\end{array}$ \\
\hline East German × Agegroup2 & $\begin{array}{l}-0.0291 \\
(0.0332)\end{array}$ & $\begin{array}{l}0.0023 \\
(0.0304)\end{array}$ & $\begin{array}{l}-0.0047 \\
(0.0247)\end{array}$ \\
\hline East German $\times$ Agegroup2 & $\begin{array}{l}-0.0535 \\
(0.0463)\end{array}$ & $\begin{array}{l}0.0195 \\
(0.0423)\end{array}$ & $\begin{array}{l}0.0413 \\
(0.0343)\end{array}$ \\
\hline Female & $\begin{array}{l}0.0935^{* * *} \\
(0.0155)\end{array}$ & $\begin{array}{l}0.0813^{* * *} \\
(0.0141)\end{array}$ & $\begin{array}{l}-0.0048 \\
(0.0115)\end{array}$ \\
\hline East German $\times$ Female & $\begin{array}{l}0.0138 \\
(0.0267)\end{array}$ & $\begin{array}{l}-0.0135 \\
(0.0244)\end{array}$ & $\begin{array}{l}0.0346^{*} \\
(0.0198)\end{array}$ \\
\hline Single & $\begin{array}{l}0.0236 \\
(0.0231)\end{array}$ & $\begin{array}{l}0.0074 \\
(0.0211)\end{array}$ & $\begin{array}{l}-0.0111 \\
(0.0172)\end{array}$ \\
\hline East German $\times$ Single & $\begin{array}{l}-0.0903^{* *} \\
(0.0423)\end{array}$ & $\begin{array}{l}0.0174 \\
(0.0387)\end{array}$ & $\begin{array}{l}0.0020 \\
(0.0314)\end{array}$ \\
\hline Household net income & $\begin{array}{l}0.0027 \\
(0.0036)\end{array}$ & $\begin{array}{l}0.0108^{* * * *} \\
(0.0033)\end{array}$ & $\begin{array}{l}-0.0021 \\
(0.0026)\end{array}$ \\
\hline East German $\times$ HHNetIncome & $\begin{array}{l}0.0114 \\
(0.0072)\end{array}$ & $\begin{array}{l}0.0055 \\
(0.0066)\end{array}$ & $\begin{array}{l}-0.0044 \\
(0.0053)\end{array}$ \\
\hline Educational characteristics & & & \\
\hline 8 years of completed schooling & $\begin{array}{l}0.0876^{* *} \\
(0.0441)\end{array}$ & $\begin{array}{l}0.0736^{*} \\
(0.0403)\end{array}$ & $\begin{array}{l}0.0308 \\
(0.0328)\end{array}$ \\
\hline East German $\times 8$ SchoolYrs. & $\begin{array}{l}-0.0250 \\
(0.0836)\end{array}$ & $\begin{array}{l}-0.0275 \\
(0.0764)\end{array}$ & $\begin{array}{l}0.0068 \\
(0.0621)\end{array}$ \\
\hline 10 years of completed schooling & $\begin{array}{l}0.1467^{* * *} \\
(0.0470)\end{array}$ & $\begin{array}{l}0.0761^{*} \\
(0.0430)\end{array}$ & $\begin{array}{l}0.0484 \\
(0.0350)\end{array}$ \\
\hline East German $\times 10$ SchoolYrs. & $\begin{array}{l}-0.0343 \\
(0.0862)\end{array}$ & $\begin{array}{l}-0.0605 \\
(0.0788)\end{array}$ & $\begin{array}{l}-0.0194 \\
(0.0640)\end{array}$ \\
\hline 13 years of completed schooling & $\begin{array}{l}0.1687^{* * * *} \\
(0.0484)\end{array}$ & $\begin{array}{l}0.0838^{*} \\
(0.0442)\end{array}$ & $\begin{array}{l}0.0263 \\
(0.0360)\end{array}$ \\
\hline East German $\times 13$ SchoolYrs. & $\begin{array}{l}-0.0392 \\
(0.0911)\end{array}$ & $\begin{array}{l}-0.0842 \\
(0.0832)\end{array}$ & $\begin{array}{l}0.0095 \\
(0.0676)\end{array}$ \\
\hline Job characteristics & & & \\
\hline Blue Collar Worker & $\begin{array}{l}0.0058 \\
(0.0247)\end{array}$ & $\begin{array}{l}0.0408^{*} \\
(0.0226)\end{array}$ & $\begin{array}{l}0.0293 \\
(0.0183)\end{array}$ \\
\hline East German $\times$ BlueCollar & $\begin{array}{l}0.0669 \\
(0.0491)\end{array}$ & $\begin{array}{l}-0.0740^{*} \\
(0.0448)\end{array}$ & $\begin{array}{l}-0.0068 \\
(0.0364)\end{array}$ \\
\hline White Collar Worker & $\begin{array}{l}0.0162 \\
(0.0238)\end{array}$ & $\begin{array}{l}0.0110 \\
(0.0217)\end{array}$ & $\begin{array}{l}0.0182 \\
(0.0176)\end{array}$ \\
\hline East German $\times$ WhiteCollar & $\begin{array}{l}0.0884^{*} \\
(0.0477)\end{array}$ & $\begin{array}{l}-0.0298 \\
(0.0436)\end{array}$ & $\begin{array}{l}0.0049 \\
(0.0354)\end{array}$ \\
\hline Unemployed & $\begin{array}{l}0.1462^{* * *} \\
(0.0484)\end{array}$ & $\begin{array}{l}-0.0026 \\
(0.0443)\end{array}$ & $\begin{array}{l}0.0666^{*} \\
(0.0361)\end{array}$ \\
\hline East German $\times$ Unemployed & $\begin{array}{l}-0.1068^{*} \\
(0.0605)\end{array}$ & $\begin{array}{l}0.0561 \\
(0.0552)\end{array}$ & $\begin{array}{l}-0.0909^{* *} \\
(0.0450)\end{array}$ \\
\hline
\end{tabular}

Source: Robert Koch Institut (2012b), German National Health Survey East-West 1991 (GNHSEW91), own calculation and illustration; ${ }^{*} \mathrm{p}<0.1,{ }^{* *} \mathrm{p}<0.05,{ }^{* * *} \mathrm{p}<0.01$; standard errors in parentheses. The descriptive statistics are in the Appendix (Table B2). The model is estimated by OLS; the three binary outcome variables are 1 if respondents indicated to have changed their diet, gained or lost weight, respectively. For more information on how the variables were generated, see Section 4.3.1. Not shown, non-significant, additional control variables and their interactions with East German are: \# household members, \# own kids, private health insurance, civil servant, trained for job, physical work, month fixed effects, and year fixed effects. The number of observations is 6,550 and the R-squared lies between 4 (columns (1)) and 0.7 (column (3)) percent. 
Table B4: German National Health Interview and Examination Survey 1998 (GNHIES98)

\begin{tabular}{|c|c|c|c|c|c|}
\hline Variable & Mean & Std. Dev. & Min. & Max. & $\mathbf{N}$ \\
\hline \multicolumn{6}{|l|}{ A. Outcome Measures } \\
\hline \multicolumn{6}{|l|}{ Current diet } \\
\hline Meat weekly (at least once a week) & 0.7267 & 0.4456 & 0 & 1 & 6,419 \\
\hline Boiled Potatoes daily & 0.219 & 0.4136 & 0 & 1 & 6,419 \\
\hline Fresh fruits fruits daily & 0.5788 & 0.4938 & 0 & 1 & 6,419 \\
\hline Wholegrain bread daily & 0.4161 & 0.4930 & 0 & 1 & 6,419 \\
\hline Eggs regularly (more than once a week) & 0.2074 & 0.4054 & 0 & 1 & 6,419 \\
\hline Pies and cookies regularly (more than once a week) & 0.3912 & 0.4881 & 0 & 1 & 6,419 \\
\hline Convenience food weekly (at least once a week) & 0.1436 & 0.3507 & 0 & 1 & 6,419 \\
\hline \multicolumn{6}{|l|}{ Clinical objective health measures } \\
\hline Weight gain (in last 3 yrs., self-reported) & 0.3349 & 0.472 & 0 & 1 & 6,419 \\
\hline Overweight $(\mathrm{BMI}>25)$ & 0.6007 & 0.4898 & 0 & 1 & 6,419 \\
\hline Obese $(\mathrm{BMI}>30)$ & 0.2083 & 0.4061 & 0 & 1 & 6,419 \\
\hline High total cholesterol $[>6.2 \mathrm{mmol} / \mathrm{l}]$ & 6.0046 & 1.2631 & 2.01 & 16.8 & 6,419 \\
\hline High blood pressure & 0.2359 & 0.4246 & 0 & 1 & 6,419 \\
\hline Diabetes (self-reported) & 0.0514 & 0.2208 & 0 & 1 & 6,419 \\
\hline \multicolumn{6}{|l|}{ B. Covariates } \\
\hline \multicolumn{6}{|l|}{ Demographics } \\
\hline East German & 0.3452 & 0.4755 & 0 & 1 & 6,419 \\
\hline Age & 45.3317 & 15.6451 & 17 & 79 & 6,419 \\
\hline Female & 0.5097 & 0.4999 & 0 & 1 & 6,419 \\
\hline \# household members & 2.8032 & 1.2756 & 1 & 12 & 6,419 \\
\hline \# own kids & 0.5921 & 0.9276 & 0 & 9 & 6,419 \\
\hline Single & 0.2228 & 0.4161 & 0 & 1 & 6,419 \\
\hline Private health insurance & 0.0469 & 0.2114 & 0 & 1 & 6,419 \\
\hline \multicolumn{6}{|l|}{ Education } \\
\hline 8 school years & 0.3991 & 0.4898 & 0 & 1 & 6,419 \\
\hline 10 school years & 0.1905 & 0.3927 & 0 & 1 & 6,419 \\
\hline 13 school years & 0.3664 & 0.4819 & 0 & 1 & 6,419 \\
\hline \multicolumn{6}{|l|}{ Employment } \\
\hline Physical work & 0.2276 & 0.4193 & 0 & 1 & 6,419 \\
\hline Blue collar worker & 0.3332 & 0.4714 & 0 & 1 & 6,419 \\
\hline White collar worker & 0.4102 & 0.4919 & 0 & 1 & 6,419 \\
\hline Civil servant & 0.0495 & 0.217 & 0 & 1 & 6,419 \\
\hline Unemployed & 0.2898 & 0.4537 & 0 & 1 & 6,419 \\
\hline Net household income in DM (13 categories) & 6.6235 & 2.9263 & 1 & 13 & 6,419 \\
\hline
\end{tabular}


Table B5: German Microcensus 2005

\begin{tabular}{lccccc}
\hline \hline \multicolumn{1}{c}{ Variable } & Mean & Std. Dev. & Min. & Max. & N \\
\hline A. Outcome Measures & & & & & \\
\hline BMI & & & & & \\
Overweight & 25.3578 & 4.375 & 7.4651 & 82.1828 & 312,983 \\
Obese & 0.4814 & 0.4997 & 0 & 1 & 312,983 \\
& 0.132 & 0.3385 & 0 & 1 & 312,983 \\
B. Covariates & & & & \\
\hline Socialized in GDR vs. living in East Germany & & & & \\
Living in East Germany & 0.2231 & 0.4163 & 0 & 1 & 312,983 \\
Educational degree of GDR & 0.0785 & 0.269 & 0 & 1 & 312,983 \\
Living in East Germany $\times$ GDRdegree & 0.0688 & 0.2531 & 0 & 1 & 312,983 \\
& & & & \\
Demographics & & & & \\
Age & 49.1783 & 18.6993 & 16 & 95 & 312983 \\
Female & 0.513 & 0.4998 & 0 & 1 & 312983 \\
Unemployed & 0.0629 & 0.2429 & 0 & 1 & 312983 \\
Partner in household & 0.6205 & 0.4853 & 0 & 1 & 312983 \\
Single & 0.2666 & 0.4422 & 0 & 1 & 312983 \\
& & & & & \\
\hline Sources: German Microcensus 2005, own illustration & & & & \\
\hline \hline
\end{tabular}




\section{Appendix C: Solution of the Theoretical Model}

In this section we first derive the policy functions expressing optimal food consumption of Novel and Familiar Food as a function of the stock of consumption experiences. Then we express optimal consumption as a function of time and of the initial and terminal conditions. This allows us to make predictions on how consumption responds to the reunification, and how the empirical differences in the consumption levels observed before and after the reunification can be used to infer whether goods are habit forming or feature learning.

Consider the following quadratic specification for the value function (time notation is dropped for notational simplicity):

$$
\mathcal{V}(F, N, A)=\alpha_{1} F+\alpha_{2} F^{2}+\alpha_{3} N+\alpha_{4} N^{2}+\alpha_{5}+\mu A .
$$

From the first order conditions with respect to $n, f$ and $q$, the optimal consumption of food and non food obtains as a function of the (yet unspecified) parameters of the optimal value function:

$$
\begin{aligned}
& n=\alpha_{3}+\hat{n}+\left(2 \alpha_{4}+U_{n N}\right) N-\alpha_{5} p^{n} \\
& f=\alpha_{1}+\hat{f}+\left(2 \alpha_{2}+U_{f F}\right) F-\alpha_{5} p^{f} \\
& g=\hat{g}-\mu p^{g} .
\end{aligned}
$$

Notice that $\mu$ must be positive to ensure that the marginal utility of the utility function (2) with respect to non food is positive: $\partial \mathcal{U} / \partial g=\hat{g}-g=\mu p^{g}>0$.

Replacing the above expressions in the HJB equation yields a function which depends on state variables and parameters only. Let $r=\rho, \Omega_{f}=\sqrt{(\rho+2 \delta)\left(\rho+2 \delta-4 U_{f F}\right)}>$ and $\Omega_{n}=$ $\sqrt{(\rho+2 \delta)\left(\rho+2 \delta-4 U_{n N}\right)}>0$. By the method of undetermined coefficients the following obtains:

$$
\begin{aligned}
\alpha_{1}= & \frac{\hat{f}-\mu p^{f}}{\rho+\Omega_{f}}\left(2 \delta+\rho-\Omega_{f}\right), \quad \alpha_{2}=\frac{1}{4}\left(2 \delta+\rho-2 U_{f F}-\Omega_{f}\right), \\
\alpha_{3}= & \frac{\hat{n}-\mu p^{n}}{\rho+\Omega_{n}}\left(2 \delta+\rho-\Omega_{n}\right), \quad \alpha_{4}=\frac{1}{4}\left(2 \delta+\rho-2 U_{n N}-\Omega_{n}\right), \\
\alpha_{5}= & \frac{1}{2 \rho}\left[\hat{g}^{2}+\left(\hat{f}+\alpha_{1}\right)^{2}+\left(\hat{n}+\alpha_{3}\right)^{2}+\left(\left(p^{n}\right)^{2}+\left(p^{f}\right)^{2}+\left(p^{g}\right)^{2}\right) \mu^{2}\right] \\
& +\frac{\mu}{\rho}\left[M-p^{g} \hat{g}-p^{f}\left(\hat{f}+\alpha_{1}\right)-p^{n}\left(\hat{n}+\alpha_{3}\right)\right] .
\end{aligned}
$$

The coefficient $\mu$ represents the shadow value of the assets (i.e. the impact on the consumer's value function of a marginal increase in assets), which depends on prices, among other factors. It is determined by replacing the focs into $\dot{N}, \dot{F}, \dot{A}$ and solving the corresponding system of linear differential equations. Defining $\Psi_{f}=\delta\left(\rho+2 \delta-\Omega_{f}\right)-2 U_{f F}(\rho+2 \delta)$ and $\Psi_{n}=\delta\left(\rho+2 \delta-\Omega_{n}\right)-$ $2 U_{n N}(\rho+2 \delta)$, yields

$$
\mu=\varepsilon_{1} / \varepsilon_{2}
$$


where

$$
\begin{aligned}
\varepsilon_{1}= & \left(\rho A_{0}+M-p^{g} \hat{g}\right)\left(\rho+\Omega_{f}\right)\left(\rho+\Omega_{n}\right) \\
& +2\left[\hat{f} p^{f}\left(\rho+\Omega_{n}\right)-\hat{n} p^{n}\left(\rho+\Omega_{f}\right)\right](\rho+\delta) \\
& +2 p^{f} \Psi_{f} \frac{\rho+\Omega_{n}}{\left(\rho+\Omega_{f}\right)^{2}}\left[\rho\left(\rho+\Omega_{f}\right) F_{0}+2 \hat{f}(\rho+\delta)\right] \\
& +2 p^{n} \Psi_{n} \frac{\rho+\Omega_{f}}{\left(\rho+\Omega_{n}\right)^{2}}\left[\rho\left(\rho+\Omega_{n}\right) N_{0}+2 \hat{n}(\rho+\delta)\right], \\
\varepsilon_{2}= & -\left(p^{g}\right)^{2}\left(\rho+\Omega_{f}\right)\left(\rho+\Omega_{n}\right)-2\left[\left(p^{n}\right)^{2}\left(\rho+\Omega_{f}\right)+\left(p^{f}\right)^{2}\left(\rho+\Omega_{n}\right)\right](\rho+\delta) \\
& +\frac{4\left(p^{f}\right)^{2}\left(\rho+\Omega_{n}\right)(\rho+\delta)}{\left(\rho+\Omega_{f}\right)^{2}} \Psi_{f}+\frac{4\left(p^{n}\right)^{2}\left(\rho+\Omega_{f}\right)(\rho+\delta)}{\left(\rho+\Omega_{n}\right)^{2}} \Psi_{n} .
\end{aligned}
$$

Replacing the values of $\alpha_{1}, \alpha_{2}, \alpha_{3}, \alpha_{4}, \alpha_{5}$ and $\mu$ in (9) and (10) and rearranging yields the policy functions (18) and (19):

$$
\begin{aligned}
& n^{*}=\frac{2(\rho+\delta)}{\rho+\Omega_{n}}\left(\hat{n}-\mu p_{t}^{n}\right)+\frac{1}{2}\left(\rho+2 \delta-\Omega_{n}\right) N_{t}, \\
& f^{*}=\frac{2(\rho+\delta)}{\rho+\Omega_{n}}\left(\hat{f}-\mu p_{t}^{f}\right)+\frac{1}{2}\left(\rho+2 \delta-\Omega_{f}\right) F_{t},
\end{aligned}
$$

Note that the requirement $\mu>0$, which we imposed to ensure that the marginal utility of the composite good $g$ is positive, ensures that the law of demand holds for food consumption choices, for any given stock of consumption experience. The sign of the coefficients of $N_{t}$ and $F_{t}$ depends on the sign of $U_{n N}$ and $U_{f F}$, respectively.

Replacing the policy functions in the differential equations $\dot{F}_{t}, \dot{N}_{t}$ and $\dot{A}_{t}$ and solving yields the time path of food consumption experiences:

$$
\begin{aligned}
N_{t} & =\left(N_{0}-N_{s s}\right) e^{\lambda_{n} t}+N_{s s} \\
F_{t} & =\left(F_{0}-F_{S S}\right) e^{\lambda_{f} t}+F_{S S}
\end{aligned}
$$

where $\lambda_{n}:=\rho-\Omega_{n}$ and $\lambda_{f}:=\rho-\Omega_{f}$ are the two eigenvalues that are assumed to be negative to ensure saddle point stability. This requirement is equivalent to assume $\delta(\delta+\rho)-(2 \delta+\rho) \mathcal{U}_{n N}>$ 0 and $\delta(\delta+\rho)-(2 \delta+\rho) \mathcal{U}_{f F}>0$.

To obtain the optimal path of food consumption choices in West Germany as a function of time replace (20) and (21) in (18) and (19), which yields:

$$
\begin{aligned}
& n_{t}^{W}=\left(\delta+\lambda_{n}\right)\left(N_{0}-N_{s s}\right) e^{\lambda_{n} t}+\delta N_{s s}, \\
& f_{t}^{W}=\left(\delta+\lambda_{f}\right)\left(F_{0}-F_{s s}\right) e^{\lambda_{f} t}+\delta F_{s s} .
\end{aligned}
$$

In the long run equilibrium, consumption of Novel and Familiar Food will be, respectively,

$$
\begin{aligned}
& n_{s s}=\delta N_{s s}=\delta \frac{(\delta+\rho)\left(\hat{n}-p^{n} \mu\right)}{\delta(\delta+\rho)-(2 \delta+\rho) \mathcal{U}_{n N}}, \\
& f_{s S}=\delta F_{s s}=\delta \frac{(\delta+\rho)\left(\hat{f}-p^{f} \mu\right)}{\delta(\delta+\rho)-(2 \delta+\rho) \mathcal{U}_{f F}} .
\end{aligned}
$$

Let $\hat{n}-p^{n} \mu>0$ and $\hat{f}-p^{f} \mu>0$ to ensure that the steady state levels of consumption are positive, and assume that the steady state consumption of Novel Food respects the law of demand $\left(\partial N^{s s} / \partial p^{n}<0\right)$, which requires $\alpha_{5}+p^{n} \partial \mu / \partial p^{n}>0$. 
In East Germany, based on the empirical evidence discussed in the previous section and reported in Table B1, consumption of Novel Food was negligible before the reunification. If Novel Food respects the law of demand, this empirical evidence can be rationalized saying that the price of Novel Food was excessively high. In contrast, consumption of Familiar Food $f^{E}$ was positive. Let $N_{0}^{E}=0$ and $F_{0}^{E}>0$ denote the consumption experience of Novel and Familiar Food in East Germany at the reunification time. A common assumption in the empirical literature on the German reunification is that East and West Germans would not behave differently in the long run if the Wall had not been erected. In our dynamic model this assumption implies that, after the reunification, the long run equilibrium level of consumption (either of Novel Food or Familiar Food) will be the same in East and West Germany.

Hence in East Germany the optimal path of food consumption choices after the reunification is given by the following

$$
\begin{aligned}
n_{t}^{E} & =\left[\delta-\left(\delta+\lambda_{n}\right) e^{\lambda_{n} t}\right] N_{S S} \\
f_{t}^{E} & =\left(\delta+\lambda_{f}\right)\left(F_{0}^{E}-F_{s S}\right) e^{\lambda_{f} t}+\delta F_{S S}
\end{aligned}
$$

Two comments are in place. First, the sign of $\delta+\lambda_{n}$ and $\delta+\lambda_{f}$ can either be positive or negative. More specifically $\delta+\lambda_{n}>0\left(\delta+\lambda_{f}>0\right)$ if and only if Novel Food (familiar food) features learning, i.e. $\mathcal{U}_{n N}>0\left(\mathcal{U}_{f F}>0\right)$ and it is negative if it features habit formation, i.e. $\mathcal{U}_{n N}<0$ $\left(\mathcal{U}_{f F}<0\right)$. Second, the long run equilibrium for Familiar Food $F_{s s}$ can be either higher or lower than the initial consumption experience with familiar food in East Germany $F_{0}^{E}$.

At the reunification time, the response of Novel and Familiar Food is as follows:

$$
\begin{aligned}
& \frac{\partial n_{0}^{E}}{\partial p^{n}}=-\lambda_{n} \frac{\partial N^{s s}}{\partial p^{n}}=\frac{\lambda_{n}}{\delta(\delta+\rho)-(2 \delta+\rho) \mathcal{U}_{n N}}\left(\mu+p^{n} \frac{\partial \mu}{\partial p^{n}}\right)<0, \\
& \frac{\partial f_{0}^{E}}{\partial p^{n}}=-\lambda_{f} \frac{\partial F^{s s}}{\partial p^{n}}=\frac{\lambda_{f} p^{f}(\delta+\rho)}{\delta(\delta+\rho)-(2 \delta+\rho) \mathcal{U}_{f F}} \frac{\partial \mu}{\partial p^{n}},
\end{aligned}
$$

The reunification implies a sudden and significant decrease in the price of Novel Food which produces an instantaneous increase in the consumption of Novel Food because the new steady state level of consumption $\left(N_{s s}\right)$ is higher than the previous one (which was zero). For familiar food, instead, the response is ambiguous as it depends on $\partial \mu / \partial p^{n}{ }^{14}$

In the empirical exercise, we compare the consumption levels in East and West Germany. Analytically this difference in consumption at a given point in time is represented by the following expressions:

$$
\begin{aligned}
\Delta n_{t} & =n_{t}^{E}-n_{t}^{W}=-\left(\delta+\lambda_{n}\right) N_{0}^{W} e^{\lambda_{n} t} \\
\Delta f_{t} & =f_{t}^{E}-f_{t}^{W}=\left(\delta+\lambda_{f}\right)\left(F_{0}^{E}-F_{0}^{W}\right) e^{\lambda_{f} t} .
\end{aligned}
$$

When considering Novel Food, this difference is positive (negative) if $\delta+\lambda_{n}<0\left(\delta+\lambda_{n}>0\right)$ which holds if and only if $\mathcal{U}_{n N}<0\left(\mathcal{U}_{n N}>0\right)$. Hence at each point in time after the reunification $\Delta n_{t}$ will be positive if and only if Novel good is habit forming $\left(\mathcal{U}_{n N}<0\right)$ and negative if it features learning in consumption $\left(\mathcal{U}_{n N}>0\right)$, as stated in Proposition 1 .

When considering familiar food, the difference is positive if $\left(\delta+\lambda_{f}\right)\left(F_{0}^{E}-F_{0}^{W}\right)>0$. The first term is positive (negative) if and only if $\mathcal{U}_{f F}<0\left(\mathcal{U}_{f F}>0\right)$. The second term is positive (negative) depending on whether $F_{0}^{E}-F_{0}^{W}$ is positive (negative). If before the reunification the consumption of Familiar Food was close to its steady state level, then $\operatorname{sign}\left(F_{0}^{E}-F_{0}^{W}\right)=\operatorname{sign}\left(f_{0}^{E}-f_{0}^{W}\right)$. Hence

\footnotetext{
${ }^{14}$ The same conclusion would be obtained considering the policy functions (18) and (19), as $\frac{\partial \eta^{*}}{\partial p^{n}}=$ $-\frac{2(\rho+\delta)}{\rho+\Omega_{n}}\left(\mu+p^{n} \frac{\partial \mu}{\partial p^{n}}\right), \frac{\partial f^{*}}{\partial p^{n}}=-\frac{2 p^{f}(\rho+\delta)}{\rho+\Omega_{f}} \frac{\partial \mu}{\partial p^{n}}$ and $\frac{\partial q^{*}}{\partial p^{n}}=-p^{g} \frac{\partial \mu}{\partial p^{n}}$.
} 
the following holds:

$$
\operatorname{sign}\left(\Delta f_{t}\right)=\operatorname{sign}\left(\mathcal{U}_{f F}\right) \operatorname{sign}\left(\Delta f_{0}\right) .
$$

Empirically we have information on both consumption of Familiar Food at the reunification time $\Delta f_{0}$ and of consumption in a subsequent period $\Delta f_{t}$, which allows to infer the properties of reinforcement/satiation of past consumption experience with Familiar Food on current preferences.

Finally, to assess whether the individual is better off after a reduction in the price of Novel Food, take the derivative of the value function with respect to $p^{n}$ for given value of $N_{0}, F_{0}$ and $A_{0}$ :

$$
\begin{aligned}
\frac{\partial \mathcal{V}}{\partial p^{n}}= & {\left[\rho A_{0}+M-p^{g}\left(\hat{g}-p^{g} \mu\right)\right] \frac{\partial \mu}{\partial p^{n}} } \\
& -\left[\left(2 \delta+\rho-\Omega_{n}\right) N_{0}+\frac{4(\rho+\delta)^{2}\left(\hat{n}-\mu p^{n}\right)}{\rho\left(\rho+\Omega_{n}\right)}\right] \frac{\mu+p^{n} \frac{\partial \mu}{\partial p^{n}}}{\rho+\Omega_{n}} \\
& -\frac{2 \delta+\rho-\Omega_{f}}{\rho+\Omega_{f}} p^{f} \frac{\partial \mu}{\partial p^{n}} F_{0}-\frac{4 p^{f}(\rho+\delta)^{2}\left(\hat{f}-\mu p^{n}\right)}{\rho\left(\rho+\Omega_{f}\right)^{2}} \frac{\partial \mu}{\partial p^{n}} .
\end{aligned}
$$

In general, the sign of the above expression is ambiguous because it depends on $\frac{\partial \mu}{\partial p^{n}}$ and on the sign of the terms $2 \delta+\rho-\Omega_{n}$ and $2 \delta+\rho-\Omega_{f}$ (which in turn depend on $U_{n N}$ and $U_{f F}$ ). If $N_{0}=0$ and $\frac{\partial \mu}{\partial p^{n}}=0$, however, a decrease in the price of Novel goods unambiguously increases the optimal discounted intertemporal utility of the agent. 


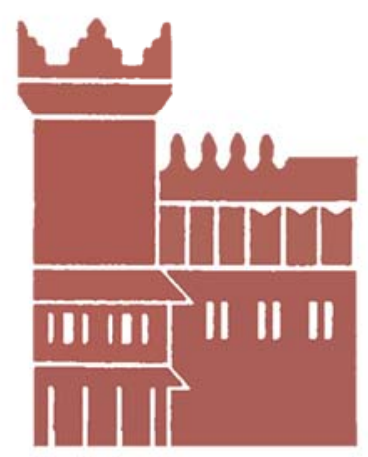

Alma Mater Studiorum - Università di Bologna DEPARTMENT OF ECONOMICS

Strada Maggiore 45

40125 Bologna - Italy

Tel. +39051 2092604

Fax +390512092664

http://www.dse.unibo.it 